\title{
Furnace Injection of Alkaline Sorbents for Sulfuric Acid Removal
}

\author{
Final Report
}

Cooperative Agreement No.: DE-FC26-99FT40718

Prepared for:

William W. Aljoe

U.S. Department of Energy

National Energy Technology Laboratory

626 Cochrans Mill Road

Pittsburgh, Pennsylvania 15236

Prepared by:

Gary M. Blythe

URS Corporation

9400 Amberglen Boulevard

Austin, Texas 78729

January 2004 


\section{DISCLAIMER OF WARRANTIES AND LIMITATION OF LIABILITIES}

This report was prepared as an account of work sponsored by an agency of the United States Government. Neither the United States Government nor any agency thereof, nor any of their employees, makes any warranty, express or implied, or assumes any legal liability or responsibility for the accuracy, completeness, or usefulness of any information, apparatus, product, or process disclosed, or represents that its use would not infringe privately owned rights. Reference herein to any specific commercial product, process, or service by trade name, trademark, manufacturer, or otherwise does not necessarily constitute or imply its endorsement, recommendation, or favoring by the United States Government or any agency thereof. The views and opinions of authors expressed herein do not necessarily state or reflect those of the United States Government or any agency thereof. 


\section{ABSTRACT}

The objective of this project has been to demonstrate the use of alkaline reagents injected into the furnace of coal-fired boilers as a means of controlling sulfuric acid emissions. The project was co-funded by the U.S. DOE National Energy Technology Laboratory under Cooperative Agreement DE-FC26-99FT40718, along with EPRI, the American Electric Power Company (AEP), FirstEnergy Corporation, the Tennessee Valley Authority, and Carmeuse North America.

Sulfuric acid controls are becoming of increased interest for coal-fired power generating units for a number of reasons. In particular, sulfuric acid can cause plant operation problems such as air heater plugging and fouling, back-end corrosion, and plume opacity. These issues will likely be exacerbated with the retrofit of selective catalytic reduction (SCR) for $\mathrm{NO}_{\mathrm{X}}$ control, as $\mathrm{SCR}$ catalysts are known to further oxidize a portion of the flue gas $\mathrm{SO}_{2}$ to $\mathrm{SO}_{3}$.

The project tested the effectiveness of furnace injection of four different magnesium-based or dolomitic alkaline sorbents on full-scale utility boilers. These reagents were tested during one- to two-week tests conducted on two FirstEnergy Bruce Mansfield Plant (BMP) units. One of the sorbents tested was a magnesium hydroxide slurry byproduct from a modified Thiosorbic ${ }^{\circledR}$ Lime wet flue gas desulfurization process. The other three sorbents are available commercially and include dolomite, pressure-hydrated dolomitic lime, and commercially available magnesium hydroxide. The dolomite reagent was injected as a dry powder through out-of-service burners. The other three reagents were injected as slurries through air-atomizing nozzles inserted through the front wall of the upper furnace.

After completing the four one- to two-week tests, the most promising sorbents were selected for longer-term (approximately 25-day) full-scale tests on two different units. The longer-term tests were conducted to confirm sorbent effectiveness over extended operation on two different boilers, and to determine balance-of-plant impacts. The first long-term test was conducted on FirstEnergy's BMP Unit 3, and the second was conducted on AEP's Gavin Plant, Unit 1. The Gavin Plant test provided an opportunity to evaluate the effects of sorbent injected into the furnace on $\mathrm{SO}_{3}$ formed across an operating $\mathrm{SCR}$ reactor.

A final task in the project was to compare projected costs for furnace injection of magnesium hydroxide slurries to estimated costs for other potential sulfuric acid control technologies. Estimates were developed for reagent and utility costs, and capital costs, for furnace injection of magnesium hydroxide slurries and seven other sulfuric acid control technologies. The estimates were based on retrofit application to a model coal-fired plant. 


\section{EXECUTIVE SUMMARY}

The objective of this project has been to demonstrate the use of alkaline reagents injected into the furnace of coal-fired boilers as a means of controlling sulfuric acid emissions. The project was co-funded by the U.S. DOE National Energy Technology Laboratory under Cooperative Agreement DE-FC26-99FT40718, along with EPRI, the American Electric Power Company (AEP), FirstEnergy Corporation, the Tennessee Valley Authority, and Carmeuse North America. URS Group was the prime contractor.

Sulfuric acid controls are becoming of increased interest to power generators operating coal-fired units, for a number of reasons. Sulfuric acid is a Toxic Release Inventory species, a precursor to acid aerosol/condensable emissions, and can cause plant operation problems such as air heater plugging and fouling, back-end corrosion, and plume opacity. These issues will likely be exacerbated with the widespread retrofitting of selective catalytic reduction (SCR) for $\mathrm{NO}_{\mathrm{X}}$ control on coal-fired plants, as SCR catalysts are known to further oxidize a portion of the flue gas $\mathrm{SO}_{2}$ to $\mathrm{SO}_{3}$.

The project tested the effectiveness of furnace injection of four different magnesium-based or dolomitic alkaline sorbents on full-scale utility boilers. These reagents were tested during four one- to two-week tests conducted on two FirstEnergy Bruce Mansfield Plant (BMP) units. One of the sorbents tested was a magnesium hydroxide slurry byproduct from a modified Thiosorbic ${ }^{\circledR}$ Lime wet flue gas desulfurization process. The other three sorbents are available commercially and include dolomite, pressure-hydrated dolomitic lime, and commercially available magnesium hydroxide. The dolomite reagent was injected as a dry powder through out-of-service burners. The other three reagents were injected as slurries through air-atomizing nozzles inserted through the front wall of the upper furnace, either across from the nose of the furnace or across from the pendant superheater tubes.

After completing the four one- to two-week tests, the most promising sorbents were selected for longer-term (approximately 25-day) full-scale tests on two different units. The longer-term tests were conducted to confirm sorbent effectiveness over extended operation on two different boilers, and to determine balance-of-plant impacts. The first long-term test was conducted on FirstEnergy's BMP Unit 3, and the second test was conducted on AEP's Gavin Plant, Unit 1. The Gavin Plant test provided an opportunity to evaluate the effects of sorbent injected into the furnace on $\mathrm{SO}_{3}$ formed across an operating $\mathrm{SCR}$ reactor.

The long-term tests determined the effectiveness of injecting commercially available magnesium hydroxide slurry (Gavin Plant) and byproduct magnesium hydroxide slurry (both Gavin Plant and $\mathrm{BMP}$ ) for $\mathrm{SO}_{3} /$ sulfuric acid control. The results show that injecting either slurry could achieve up to 70 to $75 \%$ overall sulfuric acid removal. At BMP, which did not have an SCR at the time of this testing, the overall removal was limited by the need to leave sufficient concentrations of $\mathrm{SO}_{3} /$ sulfuric acid in the flue gas to maintain acceptable electrostatic 
precipitator (ESP) particulate control performance. At higher removal efficiencies, ESP performance appeared to be limited by high electrical resistivity of the fly ash/magnesium salt mixture. At Gavin Plant, the furnace-injected sorbent was found to be effective at removing furnace-formed $\mathrm{SO}_{3}$ but relatively ineffective at removing $\mathrm{SO}_{3}$ formed downstream, across the SCR system. Thus, the overall sulfuric acid removal was limited to that which could be removed within the furnace.

The long-term tests also determined balance-of-plant impacts from furnace injection of magnesium hydroxide slurry, including impacts on boiler back-end temperatures and pressure drops, SCR catalyst properties, ESP performance, removal of other flue gas species, and flue gas opacity. For the most part, the balance-of-plant impacts were neutral to positive, although as mentioned above adverse effects on ESP performance became an issue during the BMP test when operating at high sulfuric acid removal percentages.

A final task in the project was to compare projected costs for furnace injection of magnesium hydroxide slurries to estimated costs for seven other potential sulfuric acid control technologies. Other potential controls considered included switching to low-sulfur coal, several post-furnace sorbent injection technologies, and wet ESP technology. The example plant was assumed to require sulfuric acid controls because of an SCR retrofit; the SCR and sulfuric acid controls were assumed to operate during the five-month annual "ozone season." Two levels of sulfuric acid control were considered.

These estimates showed that the relative costs of sulfuric acid controls can be very site specific, depending on a range of issues such as what air emissions controls are currently installed, plant location relative to sorbent suppliers, and how coal combustion byproducts are disposed of or reused. For the case of restoring the stack sulfuric acid concentration to pre-SCR levels, furnace injection of either the byproduct or commercial magnesium hydroxide slurry was estimated to be cost competitive with fuel switching or several of the post-furnace sorbent injection technologies. The differences in annual costs for these technologies typically was within the assumed accuracy for these estimates, such that it would take a more detailed analysis to select the least-cost control option for the example plant. At the assumed conditions of the example plant (retrofit to an existing plant and control process operation only during the five-month ozone season) the wet ESP case was estimated to be the most costly control option because of its relatively high capital cost.

The second control level case was for the stack to be controlled to 3 ppmv of sulfuric acid or less, corresponding with a "clear stack" (little or no visible sulfuric acid plume). Furnace injection of either the byproduct or commercial magnesium hydroxide slurry was not estimated to be able to achieve this level of control unless additional downstream controls were added. For this case, several post-furnace sorbent injection technologies appeared to be more cost effective. 


\section{CONTENTS}

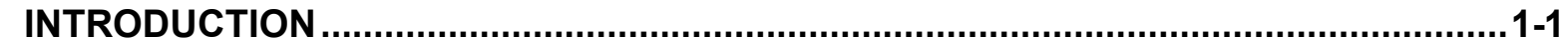

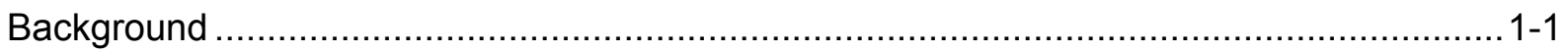

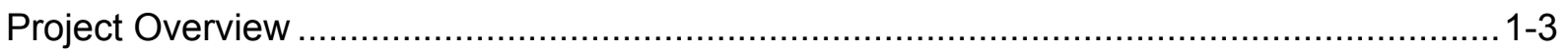

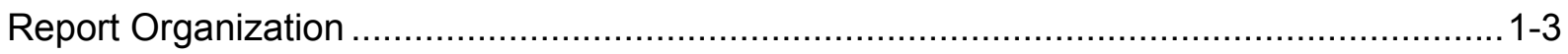

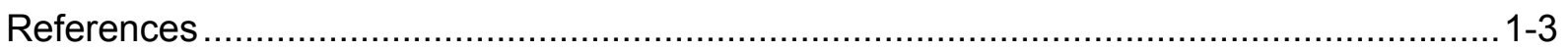

2 SHORT-TERM TEST RESULTS.......................................................................... 2-1

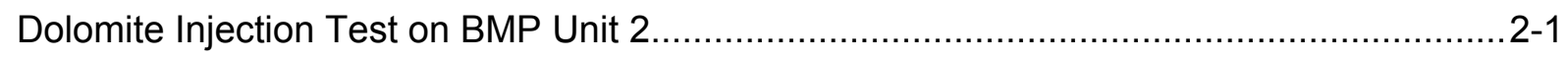

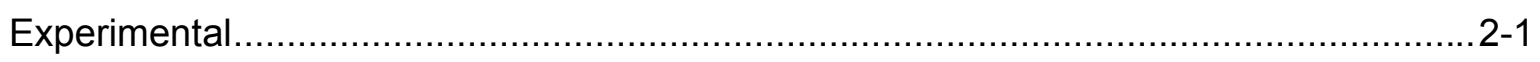

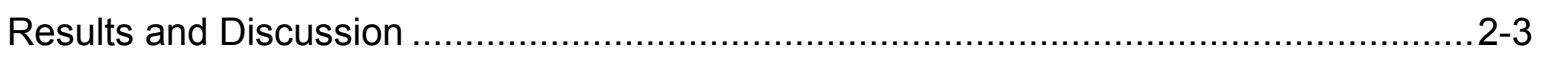

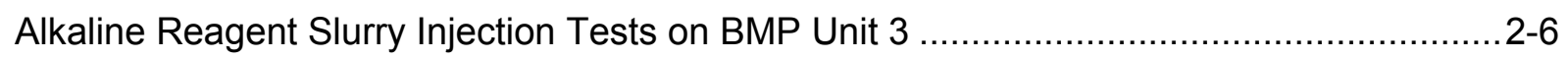

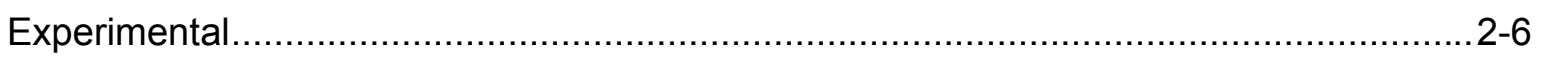

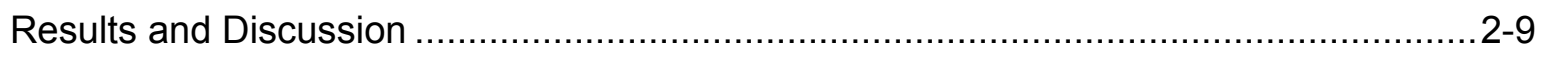

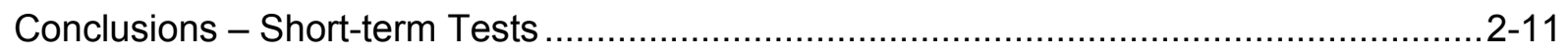

LONG-TERM MG INJECTION TEST RESULTS ..................................................... 3-1

Byproduct Mg Slurry Injection Test on BMP Unit 3 …..................................................

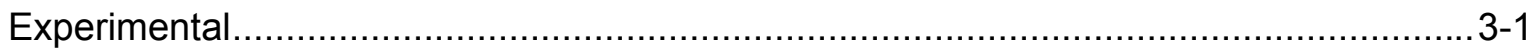

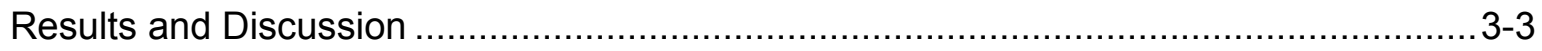

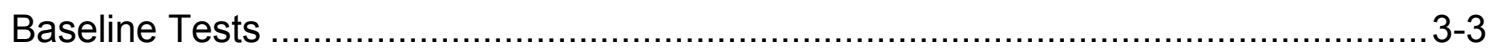

Long-term Test $\mathrm{SO}_{3}$ Removal Results ..........................................................

Long-term Test Balance-of-plant Effects ........................................................ 3-7

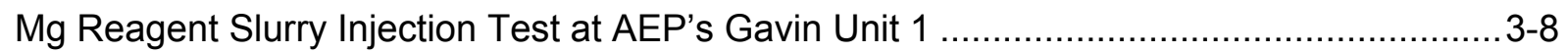

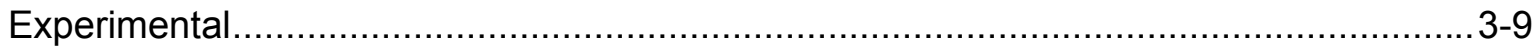

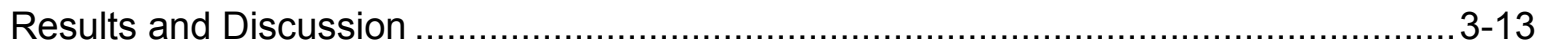


Unit 1 Operating Conditions...........................................................................

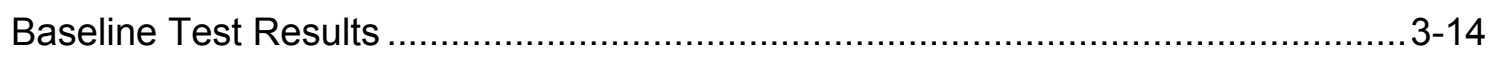

Long-term Test $\mathrm{SO}_{3}$ Removal Results ......................................................... 3-15

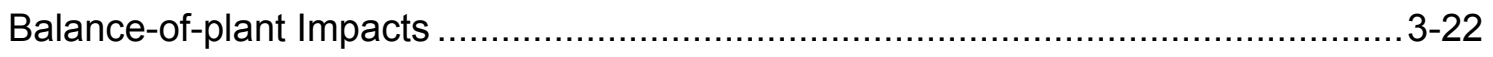

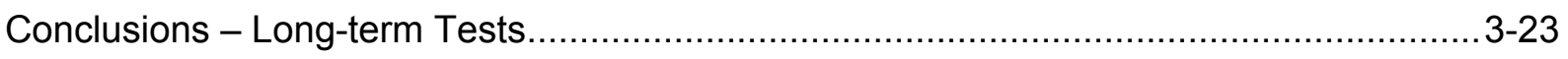

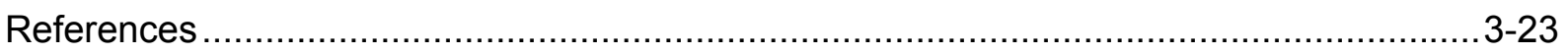

4 ECONOMIC COMPARISON OF FLUE GAS SULFURIC ACID REMOVAL

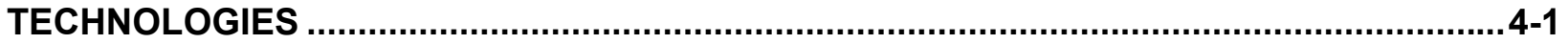

Introduction - Sulfuric Acid Control Alternatives ...................................................... 4-1

Fuel Blending/Switching ……....................................................................... $4-1$

Furnace Injection of Magnesium-based or Dolomitic Alkalis ........................................ 4-2

Alkali Injection into the Economizer Outlet or SCR Outlet Duct .................................... 4-3

Alkali Injection into the Air Heater Outlet Duct......................................................... 4-5

Flue Gas Humidification, With or Without Alkali Injection ............................................. 4-6

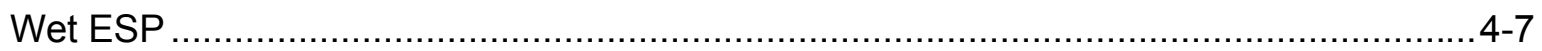

Experimental - Sulfuric Acid Control Technology Cost Estimates .......................................4-8

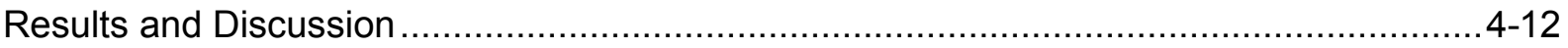

Heat and Material Balance Estimate Results ………….................................... 4-12

Capital Cost Estimates …….......................................................................... 4-17

Summary of Operating and Capital Cost Estimates for Control Technologies ................4-26

Discussion of First-year Cost Estimate Results.......................................................4-32

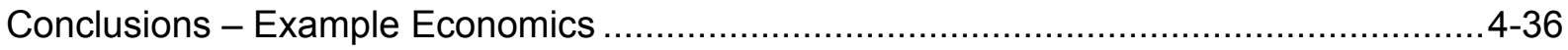

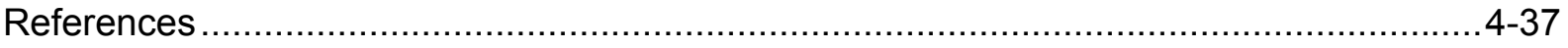

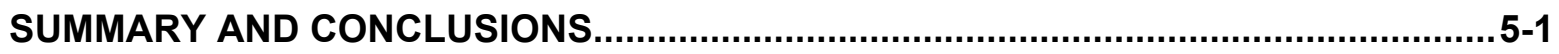

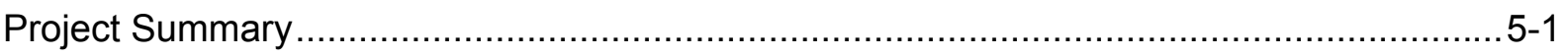

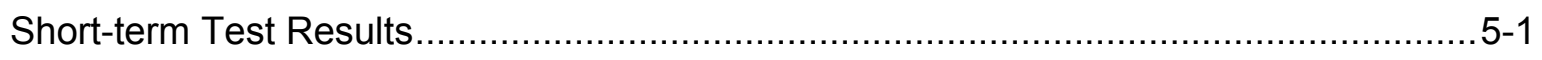

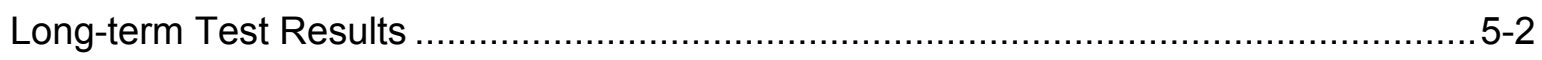

Sulfuric Acid Control Process Economics ……………........................................ 5-3

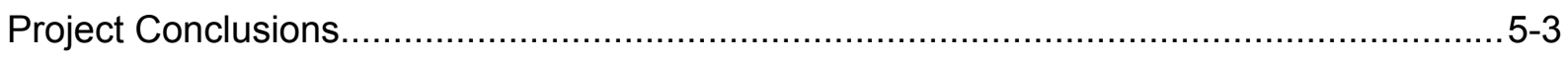




\section{LIST OF FIGURES}

Figure 2-1 Illustration of Flue Gas Path for BMP Unit 2

Figure 2-2 Illustration of Flue Gas Path for BMP Unit 3 during Normal Full-load Operation

Figure 2-3 Illustration of Slurry Injection Levels for BMP Unit 3....................................... 2-8

Figure 2-4 Illustration of Slurry Injection Locations for BMP Unit 3 - Plan View......................2-8

Figure 3-1. Plan View Illustration of Slurry Injection Locations (nos. 5 and 8 were not used) .

Figure 3-2. Summary of Baseline CCS Measurements at BMP Unit 3 (all values in ppmv [dry basis] $\mathrm{SO}_{3}$ or sulfuric acid at actual flue gas $\mathrm{O}_{2}$ concentration)

Figure 3-3. BMP Unit 3 Gross Unit Load and Byproduct Mg Injection Rate during Longterm Test

Figure 3-4. Results from the BMP Unit 3 Long-term Byproduct Mg Test (ESP B outlet location).....

Figure 3-5. Illustration of Flue Gas Path for Gavin Unit 1

Figure 3-6. Illustration of Slurry Injection Levels for Gavin Unit 1

Figure 3-7. Plan View Illustration of Slurry Injection Nozzle Locations at the $17^{\text {th }}$ Floor of Gavin Unit 1

Figure 3-8. Plan View Illustration of Slurry Injection Nozzle Locations at the $13^{\text {th }}$ Floor of Gavin Unit 1

Figure 3-9. Gavin Unit 1 Operating Conditions during Long-term Sorbent Injection Testing

Figure 3-10. Results from the Gavin Unit 1 Byproduct Mg Injection Test Period $\left(\mathrm{SO}_{3}\right.$ removals based on economizer outlet concentrations).

Figure 3-11. Comparison of Byproduct $\mathrm{Mg}$ and Commercial Mg Sorbent Performance for Gavin Unit 1 ( $\mathrm{SO}_{3}$ removals based on economizer outlet concentrations)

Figure 3-12. Results from the Gavin Unit 1 Commercial Mg Injection Test Period Compared to Byproduct Mg Injection Results $\left(\mathrm{SO}_{3}\right.$ removals based on ESP outlet concentrations).

Figure 3-13. $\mathrm{SO}_{3}$ Concentration Changes across the Gavin Unit 1 SCR Reactors (byproduct Mg injection)

Figure 3-14. $\mathrm{SO}_{3}$ Concentration Changes across the Gavin Unit 1 Air Heaters and ESPs (byproduct $\mathrm{Mg}$ injection)...

Figure 4-1 Illustration of Potential $\mathrm{SO}_{3} /$ Sulfuric Acid Control Options

Figure 4-2 Baseline and Post-SCR SO $3 /$ Sulfuric Acid Concentrations for Hypothetical Plant.

Figure 4-3 Summary of First-year Capital Recovery and Non-labor Operating Costs by $\mathrm{SO}_{3} /$ Sulfuric Acid Control Technology for Achieving the Lower Removal Percentage Target. 
Figure 4-4 Summary of First-year Capital Recovery and Non-labor Operating Costs by $\mathrm{SO}_{3} /$ Sulfuric Acid Control Technology for Achieving the Higher Removal

Percentage Target 


\section{LIST OF TABLES}

Table 2-1 Comparison of Furnace Injected Alkaline Sorbents for Sulfuric Acid Control (based on short-term test results)

Table 4-1 Summary of $\mathrm{SO}_{3}$ Control Technology Performance Data Sources, and Reagents and Utilities Required....

Table 4-2 Assumptions Made for Heat and Material Balances for Model Plant.

Table 4-3 Summary of $\mathrm{SO}_{3}$ Control Performance Estimates for Lower Percentage Control Target (return to pre-SCR stack sulfuric acid concentrations)

Table 4-4 Summary of Bases for Consumables Quantity Estimates for Candidate $\mathrm{SO}_{3} /$ Sulfuric Acid Control Technologies

Table 4-5 Summary of $\mathrm{SO}_{3}$ Control Technology Heat and Material Balances for Lower Control Percentage Target (return to pre-SCR stack sulfuric acid concentration, operating 5 months /year)

Table 4-6 Summary of $\mathrm{SO}_{3}$ Control Performance Estimates for Higher Percentage Control Target (3 ppmv at stack with SCR in Service).

Table 4-7 Summary of $\mathrm{SO}_{3}$ Control Technology Heat and Material Balances for Higher Percentage Control Target (3 ppmv at stack with SCR in service, operating 5 months /year).

Table 4-8 Summary of $\mathrm{SO}_{3}$ Control Technology Capital Cost Estimates for the Lower Sulfuric Acid Removal Percentage Target - All Values in \$1000.

Table 4-9 Summary of $\mathrm{SO}_{3}$ Control Technology Capital Cost Estimates for the Higher Sulfuric Acid Removal Percentage Target - All Values in \$1000.

Table 4-10 Summary of $\mathrm{SO}_{3}$ Control Technology First-year Reagent and Utility Cost Estimates for the Lower Target Sulfuric Acid Removal Percentage (return to preSCR stack concentrations, operation 5 months per year) - All Values in $\$ 1000$.

Table 4-11 Summary of $\mathrm{SO}_{3}$ Control Technology First-year Reagent and Utility Cost Estimates for the Higher Target Sulfuric Acid Removal Percentage (3 ppmv at stack with SCR in service, operation 5 months per year) - All Values in $\$ 1000$

Table 4-12 Factors Used to Generate Annual Reagent and Utility Costs 


\section{INTRODUCTION}

This document is the final report for the project "Furnace Injection of Alkaline Sorbents for Sulfuric Acid Control." The objective of this project has been to demonstrate the use of alkaline reagents injected into the furnace of coal-fired boilers as a means of controlling sulfuric acid emissions. The coincident removal of hydrochloric acid $(\mathrm{HCl})$ and hydrofluoric acid (HF) was also determined, as was the removal of arsenic, a known poison for $\mathrm{NO}_{\mathrm{X}}$ selective catalytic reduction (SCR) catalysts. The project was co-funded by the U.S. DOE National Energy Technology Laboratory under Cooperative Agreement DE-FC26-99FT40718, along with EPRI, the American Electric Power Company (AEP), FirstEnergy Corporation (FirstEnergy), the Tennessee Valley Authority, and Carmeuse North America. URS Group was the prime contractor.

\section{Background}

Sulfuric acid is present in most flue gases from coal combustion because a small percentage of the $\mathrm{SO}_{2}$ produced from the sulfur in the coal (approximately 0.5 to $1.5 \%$ ) is further oxidized to form $\mathrm{SO}_{3}$. The $\mathrm{SO}_{3}$ combines with flue gas moisture to form vapor-phase or condensed sulfuric acid at temperatures below about $500^{\circ} \mathrm{F}\left(260^{\circ} \mathrm{C}\right)$. In this report, the terms "sulfuric acid" and " $\mathrm{SO}_{3}$ " sometimes appear to be used interchangeably. However, in the furnace and in the flue gas path up to the air heater, the predominant form of sulfur in this oxidation state is vapor-phase $\mathrm{SO}_{3}$, while downstream of the air heater the predominant form is vapor-phase or condensed sulfuric acid $\left(\mathrm{H}_{2} \mathrm{SO}_{4}\right)$. In general, the text of the report refers to the species assumed to be present at the location in the flue gas path being discussed.

Besides being a Toxic Release Inventory substance and a potential precursor to acid aerosol/condensable emissions from coal-fired boilers, $\mathrm{SO}_{3} /$ sulfuric acid in the flue gas can lead to power plant operating problems. These problems can include boiler air heater plugging and fouling, corrosion in the air heater and downstream, and reduced power plant efficiency if air heater outlet flue gas temperatures are raised to avoid such problems. Also, the formation of a visible plume can be an issue, particularly for plants with wet flue gas desulfurization (FGD) systems. These issues will likely be exacerbated with the retrofit of SCR for $\mathrm{NO}_{\mathrm{X}}$ control, as $\mathrm{SCR}$ catalysts are known to further oxidize a portion of the flue gas $\mathrm{SO}_{2}$ to $\mathrm{SO}_{3}$. Furthermore, on units that cycle in load, the $\mathrm{SO}_{3}$ content in the furnace exit gas can limit SCR operation at lower unit load, due to the potential for forming ammonium sulfate salts that foul active catalyst sites at the correspondingly reduced economizer outlet flue gas temperatures.

The objective of the current project was to evaluate the effectiveness of alkaline sorbents injected into the furnace for removing $\mathrm{SO}_{3} /$ sulfuric acid formed in the furnace and across SCR catalysts. 
The injected alkali and captured $\mathrm{SO}_{3} /$ sulfuric acid are removed as sulfate salts in the downstream particulate control device.

Furnace injection was seen as a potentially attractive option for removing flue gas $\mathrm{SO}_{3} / \mathrm{sulfuric}$ acid for several reasons. One is that injecting alkaline materials in the furnace would maximize the residence time over which the alkali could react with $\mathrm{SO}_{3}$ formed in the furnace or across SCR catalysts. Also, alkali injection in the furnace may remove vapor-phase arsenic from the flue gas going to the SCR catalysts; vapor-phase arsenic is a known SCR catalyst poison. Finally, $\mathrm{SO}_{3}$ removal upstream of the SCR system could reduce low-load limits on SCR operation as described in the previous paragraph.

The project focused on calcium-based and/or magnesium-based alkalis. Sodium- or potassiumbased alkalis are generally low melting, and would be expected to cause slagging or fouling if injected into the furnace in significant quantities. They are also strong SCR catalyst poisons. Therefore, they were not considered for furnace injection in this project. Calcium-based alkalis have been used in Europe to remove vapor-phase arsenic from flue gases upstream of SCR reactors, with some coincident $\mathrm{SO}_{3}$ removal. Calcium alkalis and calcium sulfates are known to have high bulk particle electrical resistivity properties, though, so there were concerns that injection of high-calcium alkalis to remove $\mathrm{SO}_{3}$ at high efficiency could lead to ESP operating problems.

There was particular interest in testing magnesium-based alkalis. Magnesium-based alkalis have long been used to control $\mathrm{SO}_{3}$-related problems on oil-fired units, and to a lesser extent on coalfired units. One reason magnesium-based alkalis are effective on oil-fired units is that the magnesium ties up vanadium deposits that would otherwise catalyze the oxidation of $\mathrm{SO}_{2}$ to $\mathrm{SO}_{3}$ in the furnace gas. Ashes from oil firing typically have high vanadium content while coal ashes typically do not; therefore, vanadium deposits are not thought to have a significant role in the oxidation of $\mathrm{SO}_{2}$ to $\mathrm{SO}_{3}$ in coal-fired units. Consequently, there was some concern that magnesium-based sorbents would be less effective on coal-fired units than on oil-fired units. Although magnesium alkali injection has been tested and used commercially for $\mathrm{SO}_{3}$ control on some coal-fired units, this previous experience has not been at the high $\mathrm{SO}_{3}$ concentrations and high control efficiencies that would be required with an SCR in service.

There were other considerations that favored the use of magnesium-based sorbents. Magnesium sulfates are more water-soluble than calcium sulfates, so it was expected that injection of magnesium alkalis would be less likely to form hard downstream scale or deposits than would calcium-based alkalis. Also, magnesium-based alkalis are known to modify coal ash fusion temperatures and slag properties, such that the injection of magnesium-based alkalis in the furnace might reduce slagging in the furnace and/or make slag deposits more friable.

The main disadvantage perceived for magnesium-based alkalis was their higher cost than calcium-based materials. However, one potential reagent identified was a magnesium hydroxide slurry that can be a byproduct from a Thiosorbic ${ }^{\circledR}$ Lime FGD process, presumably at lower cost than commercial reagents. Also, dolomitic reagents (equimolar in calcium and magnesium alkalis) were anticipated to offer some of the advantages of magnesium-based reagents at costs per ton close to those of calcium-based alkalis. 
These alkaline materials could be injected into the furnace as dry powders or as slurries. For this test program, most of the testing was conducted with slurry injection, primarily because slurry injection was easier to implement. Tanks, pumps and nozzles are easier to retrofit for relatively short-term tests than are solids storage silos and pneumatic solids handling equipment. The mode of sorbent injection was not anticipated to markedly impact the measured results.

\section{Project Overview}

The project first tested the effectiveness of furnace injection of four different magnesium-based or dolomitic alkaline sorbents on full-scale utility boilers. These reagents were tested during four one- to two-week tests conducted on two FirstEnergy Bruce Mansfield Plant (BMP) units. One of the sorbents tested was a byproduct magnesium hydroxide slurry (byproduct $\mathrm{Mg}$ ) produced from a wet FGD system that employs a modified Thiosorbic ${ }^{\circledR}$ Lime scrubbing process. The other three sorbents are available commercially and include dolomite, pressure-hydrated dolomitic lime, and commercial magnesium hydroxide (commercial Mg). The dolomite was injected as a powder into the furnace of BMP Unit 2, while the other three reagents were injected as slurries into the upper furnace of BMP Unit 3.

After completing the four one- to two-week tests, the most promising sorbents were selected for longer-term (approximately 25-day) full-scale tests. The longer-term tests were conducted to confirm the effectiveness of the sorbents tested over extended operation and to determine balance-of-plant impacts. Two longer-term tests were conducted, one on FirstEnergy's BMP Unit 3 and the second on AEP's Gavin Plant Unit 1. Testing on two different units provided an opportunity to see how well results from one boiler would transfer to another boiler, built by another manufacturer and firing a different bituminous coal. The Gavin Plant testing also offered the opportunity to determine the impacts of sorbent injected into the furnace on $\mathrm{SO}_{3}$ formed across an operating SCR reactor.

\section{Report Organization}

This report provides a summary of technical results from the project. Detailed results from the short-term and long-term tests were presented and discussed in previous topical reports. ${ }^{1,2}$ Section 2 provides description of the short-term test results, and Section 3 presents results from the long-term byproduct and commercial Mg injection tests. Section 4 presents results of cost estimates for applying furnace injection of Mg sorbents compared to estimates for other potential $\mathrm{SO}_{3} /$ sulfuric acid control technologies. Section 5 provides a summary and conclusions from the project.

\section{References}

1. Sulfuric Acid Removal Process Evaluation: Short-Term Results, EPRI, Palo Alto, CA, and the U.S. Department of Energy, National Energy Technology Laboratory, Pittsburgh, PA: 2001. EPRI 1003980. 
2. Sulfuric Acid Removal Process Evaluation: Long-Term Results, EPRI, Palo Alto, CA, the U.S. Department of Energy, National Energy Technology Laboratory, Pittsburgh, PA, TVA, Chattanooga, TN, American Electric Power, Columbus, OH, and FirstEnergy, Shippingport, PA: 2002. EPRI 1004165 


\section{SHORT-TERM TEST RESULTS}

Four short-term tests were conducted to evaluate the effectiveness for $\mathrm{SO}_{3}$ control of magnesium-based or dolomitic alkalis into the furnaces of two BMP units. The first short-term test evaluated dolomite injected into the furnace of BMP Unit 2 through out-of-service burners, while the second, third and fourth tests evaluated magnesium-based or dolomitic alkaline slurries injected through air-atomizing nozzles into the upper furnace of BMP Unit 3. This section describes the four tests and summarizes the test results.

\section{Dolomite Injection Test on BMP Unit 2}

\section{Experimental}

The first short-term sorbent injection test was conducted the week of April 18, 2000, and investigated the effects of injecting dolomite $\left(\mathrm{CaCO}_{3} \bullet \mathrm{MgCO}_{3}\right)$, a mineral similar to limestone, as a dry powder into the furnace of BMP Unit 2. During the test program, various analytical techniques were used to assess the effects of sorbent injection. These primarily included sampling with the Controlled Condensation System (CCS) to determine flue gas $\mathrm{SO}_{3}$ content and with an acid dew-point meter to determine the sulfuric acid dew point (and, indirectly, the sulfuric acid concentration) of the flue gas.

Several other measurements were made as part of these tests. EPA Reference Method 26a was used to determine hydrochloric acid and hydrofluoric acid, as well as chlorine $\left(\mathrm{Cl}_{2}\right)$ and fluorine $\left(\mathrm{F}_{2}\right)$ concentrations in the flue gas. Unburned carbon in fly ash was determined by loss on ignition (LOI). Coal and FGD slurry samples were also collected and analyzed for a variety of parameters. Finally, visual observations were made of boiler furnace and superheater surfaces prior to and during sorbent injection, to determine impacts on slagging and fouling.

Unit 2 is one of three coal-fired units at BMP; it is rated at 780 net MW. Unit 2 has an opposedwall fired, supercritical boiler rated at approximately $6,415,000$ pounds of steam per hour $(2,916,000 \mathrm{~kg} / \mathrm{hr})$ at $3785 \mathrm{psig}(26,100 \mathrm{kPa})$ and $1005 / 1005^{\circ} \mathrm{F}\left(541 / 541^{\circ} \mathrm{C}\right)$ superheat and reheat temperatures. The boiler has 16 burners each on the front and back walls of the furnace. It has been retrofitted with low $\mathrm{NO}_{\mathrm{X}}$ burners and over-fire air. The burners are arranged in four horizontal rows on each wall, with four burners per row. One ball mill provides the pulverized fuel for each row. Depending on fuel quality and mill condition, full load can generally be achieved with six of the eight mills in operation (and thus six of eight rows of burners in service). 
All three units at BMP typically burn 2.0 to $4.5 \%$ sulfur bituminous coal. The facility also has permission to burn up to $20 \%$ of the fuel as petroleum coke. During the period of this short-term test on Unit 2, a standard coal blend was used (i.e., no petroleum coke co-firing).

Unit 2 was brought into service in the mid-1970s. The 780-net-MW unit operates as a swing unit to meet the load demands of the grid. The boiler is equipped with two air heaters following the economizer section. The average flue gas temperature at the outlet of the air heaters is controlled to about $320^{\circ} \mathrm{F}\left(160^{\circ} \mathrm{C}\right)$ due to acid dew point considerations.

Figure 2-1 illustrates the flue gas path for Unit 2, and notes the gas sampling locations used during this test. Flue gas from the two air heaters passes enters a plenum, then exits through six circular ducts to six venturi scrubbers that remove particulate material and $\mathrm{SO}_{2}$. The six scrubber inlet ducts are labeled A, B, C, D, E, and F from east to west. The scrubbers use a magnesiumenhanced, Thiosorbic ${ }^{\circledR}$ lime slurry reagent and produce a calcium sulfite hemihydrate $\left(\mathrm{CaSO}_{3} \bullet 1 / 2 \mathrm{H}_{2} \mathrm{O}\right)$ byproduct. The flue gas then passes through induced draft fans, one per scrubber module. The six scrubbed flue gas streams are combined in two ducts that each lead to separate flues in the stack. The gas from scrubber ducts A, B, and C combine to go to flue A, and ducts D, $\mathrm{E}$, and $\mathrm{F}$ go to flue $\mathrm{B}$.

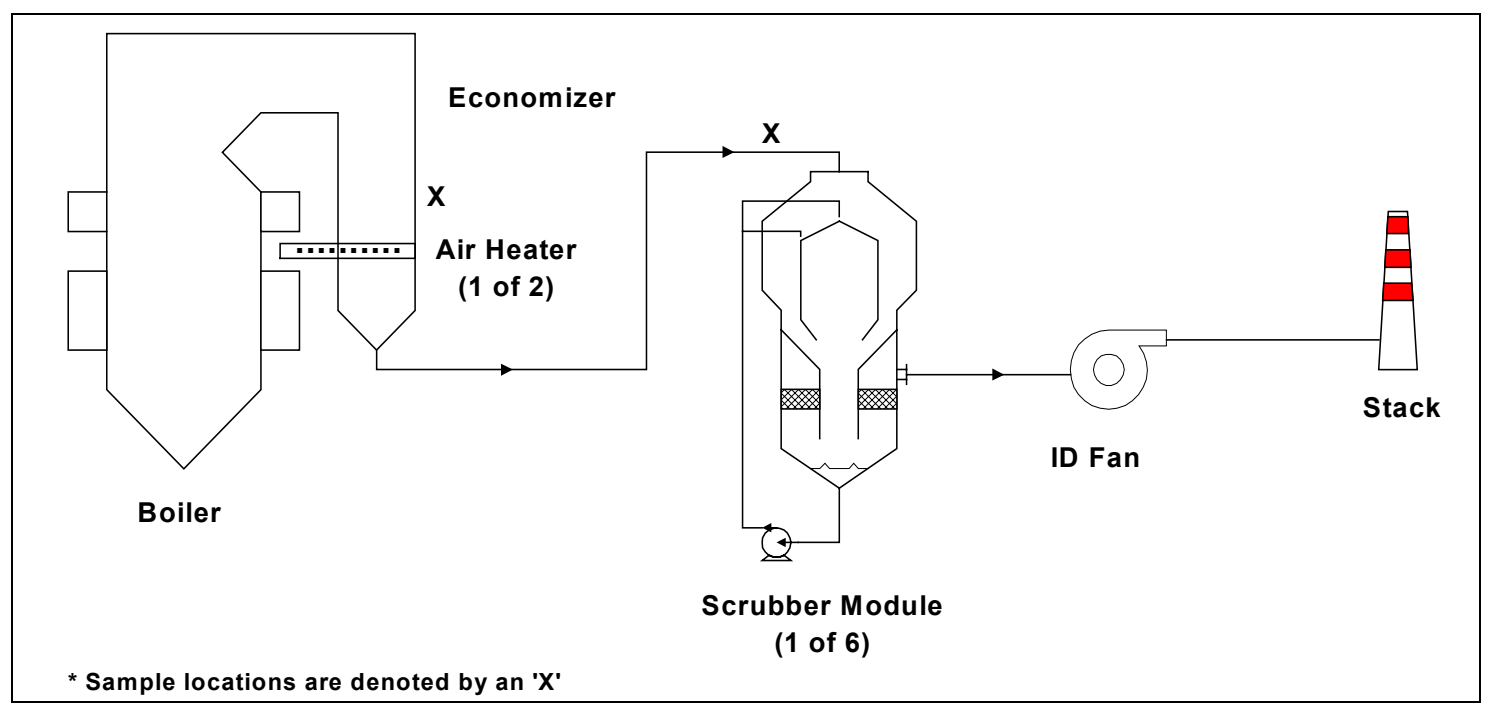

Figure 2-1

Illustration of Flue Gas Path for BMP Unit 2

The concrete stack contains four 19-ft $(5.8-\mathrm{m})$ diameter steel flues. Two of the flues are from Unit 1 and two of the flues are from Unit 2. Since the flue gas from two units is combined in one stack, it was difficult to determine if sulfuric acid control measures tested on one unit had an effect on plume opacity. The flue gas in the stack is saturated at a temperature of about $130^{\circ} \mathrm{F}$ $\left(54^{\circ} \mathrm{C}\right)$. No reheat is used on the stack gas.

During these tests, the top rows of burners on the front and rear walls of the unit were generally out of service. Injection of dolomite was through the top row of burners on the front wall. This was accomplished by charging the bunkers that feed these burners with dolomite. The dolomite 
was delivered to the coal feeders, fed to the ball mill, pulverized and blown through the burners into the furnace.

The flue gas configuration on Unit 2 (or Unit 1) was seen as being potentially advantageous over that of Unit 3 for dolomite injection. On Units 1 and 2, venturi wet scrubbers are used for combined particulate and $\mathrm{SO}_{2}$ control while Unit 3 has a more conventional configuration with an electrostatic precipitator (ESP) for particulate control followed by a wet scrubber for $\mathrm{SO}_{2}$ control. The Unit 2 configuration was seen as being potentially advantageous for two reasons. First, there were concerns that injecting significant quantities of dolomite into the furnace would adversely affect the performance of an ESP particulate collection device because of the high bulk resistivity of the calcium oxides and salts that would be formed. This is not an issue for a wet scrubbing particulate control device. Second, it was expected that excess calcium oxide and magnesium oxide formed in the furnace from the injected dolomite would be removed by the wet scrubbers and used as a source of alkalinity in the scrubbers, offsetting a portion of the FGD lime slurry reagent makeup. Thus, with the Unit 2 flue gas configuration, not only could an ESP performance issue be avoided, but a portion of the FGD lime slurry reagent could be replaced with less expensive dolomite.

\section{Results and Discussion}

The unit typically operated close to full load at about $750 \mathrm{MW}$ (gross) during the day, with lower loads overnight. Dolomite was injected almost continuously over a period of 93 hours. There was one interruption of almost 2 hours early in the injection period.

The dolomite was injected in place of coal through the top row of burners on the front wall of the boiler. The injection rate was approximately 8 to $9 \%$ of the coal feed rate to the unit. The coal fired had an average sulfur content of $4.1 \mathrm{wt} \%$. The resulting flue gas prior to dolomite injection had an $\mathrm{SO}_{3}$ concentration that averaged $52 \mathrm{ppmv}$ as measured by the Controlled Condensation method at the east economizer outlet location. This corresponds with approximately 1.6 to $1.7 \%$ of the $\mathrm{SO}_{2}$ in the flue gas being oxidized to $\mathrm{SO}_{3}$. The molar ratio of alkalinity in the dolomite (calcium plus magnesium) to sulfur in the coal fired averaged 0.6:1 to $0.7: 1$. The molar ratio of alkalinity in the dolomite injected to $\mathrm{SO}_{3}$ in the baseline flue gas was about 40:1.

The dolomite greatly reduced flue gas $\mathrm{SO}_{3}$ concentrations. Over the last two days of the test, the $\mathrm{SO}_{3}$ concentrations at the economizer outlet showed an average of $7 \mathrm{ppmv}$, or an $86 \%$ reduction from the baseline concentration average of $52 \mathrm{ppmv}$. As mentioned above, this was at an average molar ratio of total alkalinity in the dolomite (calcium plus magnesium) to sulfur in the coal of $0.6: 1$ to $0.7: 1$.

During the test, the dolomite injection rate was varied in an attempt to determine $\mathrm{SO}_{3}$ removal as a function of dolomite rate. In general, the injection rate changes proved to be too rapid to ensure that steady-state $\mathrm{SO}_{3}$ removal performance was measured at each rate. However, during two periods where the injection rate was held at a value long enough to approach steady-state performance, $\mathrm{SO}_{3}$ removal was quite sensitive to dolomite injection rate. At a molar ratio of dolomite alkalinity (calcium plus magnesium) to coal sulfur of $0.57: 1$, the apparent $\mathrm{SO}_{3}$ removal 
averaged $74 \%$; individual measurements indicated 69 to $82 \%$ removal. At a molar ratio of $0.68: 1$, the apparent removal improved to $95 \%$.

Dolomite injection had little effect on the concentrations of other acid gases in the flue gas. No removal of hydrochloric acid or hydrofluoric acid from the flue gas was measured. Some removal of chlorine and fluorine from the flue gas was observed, but the uncontrolled concentrations of these gases were already quite low (less than $1 \mathrm{ppmv}$ ).

LOI measurements of economizer ash "grab" samples collected from the economizer outlet hoppers indicated that LOI values increased from less than $1 \%$ under baseline operation to as high as $8 \%$ during dolomite injection. LOI measurements were conducted to provide an indication of unburned carbon in the fly ash, which is a measure of the boiler combustion efficiency. It would be expected that significant increases in fly ash LOI would correspond with higher boiler flue gas CO concentrations; however, this was not the case. Although the LOI results suggest an adverse effect of dolomite injection on unburned carbon concentrations, there is some question as to how representative of current operating conditions the economizer ash hopper grab samples might have been. No firm conclusions can be made about the effects of dolomite injection on coal combustion efficiency as determined by LOI content in the fly ash.

Another concern about dolomite injection in the furnace was the potential for increased slagging in the upper furnace. Prior to injection of dolomite, the upper furnace side walls, partial division walls and pendants had very little slag accumulations, with $1 / 2$ to 1 inch $(1.2$ to $2.5 \mathrm{~cm})$ of slag build-up. After nearly four consecutive days of injecting dolomite, the slag accumulations on the side wall varied from 0 to 2 inches $(0$ to $5.1 \mathrm{~cm})$ in thickness. Accumulations on the partial division walls were between 1 and 2 inches $(2.5$ and $5.1 \mathrm{~cm})$ and the pendant superheaters had between 2 and 4 inches $(5.1$ and $10.2 \mathrm{~cm}$ ) of slag accumulation. There did not appear to be any bridging of flue gas flow passages. It is not certain whether the slag accumulations observed represent normal day-to-day variations, or represent a tendency for increased slagging during dolomite injection. A longer test duration would be required to establish such an effect. Dolomite injection did appear to have an adverse effect on unit heat rate, as the average air heater exit temperature at a load of 760 gross $\mathrm{MW}$ was observed to increase by $8^{\circ} \mathrm{F}\left(4^{\circ} \mathrm{C}\right)$ over the duration of the test.

Because Unit 2 does not have an ESP for particulate control, the entrained, partially utilized dolomite was removed from the flue gas as particulate matter in the wet-lime FGD scrubbers. Chemical analyses of the scrubber solids indicate that virtually all of the calcium content of the dolomite and about half of the magnesium content was used to react with $\mathrm{SO}_{2}$ removed in the scrubbers. Between the two components, nearly half of the normal FGD system lime slurry makeup appeared to have been offset (replaced) by the injected dolomite. The contribution from the magnesium content was due to alkalinity provided by excess magnesium oxide dissolving into the liquid phase of the scrubber slurry. With continuous dolomite injection over periods of weeks and months, FGD liquor magnesium concentrations in the thickener return would tend to increase due to cycling up of magnesium dissolving from the dolomite. Over time, solubility limits may reduce the amount of magnesium in the dolomite that can be dissolved and utilized in the scrubber. 
There were concerns about two potential adverse effects of injected dolomite on the FGD system. One is that magnesium oxide not utilized in the scrubber would continue to hydrate and dissolve in the thickener, to the point where magnesium sulfite might precipitate in the thickener. Although the $\mathrm{pH}$ of the thickener underflow and overflow did increase above the scrubber $\mathrm{pH}$ set points, indicating further magnesium oxide hydration there, no magnesium sulfite precipitation was observed. This might become an issue if the liquor magnesium concentration were allowed to cycle up during longer-term injection, though.

The other concern was about the potential for gypsum scaling in the scrubbers. Analyses of the recycle liquor did not indicate an increase in gypsum scaling potential during dolomite injection. However, it remains possible for scaling at localized areas of the scrubber, such as around the wet/dry interface.

Overall, dolomite injection into the furnace appears to be an effective approach for lowering flue gas sulfuric acid concentrations by $90 \%$ or greater, particularly on Unit 2 where the dolomite injected offsets the consumption of more expensive lime reagent in the FGD system. Although this injection technology shows promise as a sulfuric acid control technology for Unit 2, dolomite was not selected as a reagent for longer-term testing as part of this project. This is largely because this reagent, injected through out-of-service burners, appears to be most advantageous for boilers that use wet scrubbers for combined particulate and $\mathrm{SO}_{2}$ control, which represent a relatively small percentage of the total population. The large amounts of dolomite which appear to be required to achieve high $\mathrm{SO}_{3}$ removal efficiencies would likely overwhelm ESPs in the larger number of plants that use ESPs as the primary particulate control device.

Because dolomite injection through out-of-service burners was not selected for further evaluation as part of this project, a longer-term test consisting of several weeks of dolomite injection would be required to adequately evaluate this technology. The objectives of a longer-term test would be to:

- Measure $\mathrm{SO}_{3}$ removal as a function of dolomite injection rate, with longer periods of operation at each rate (one to two days each rate) so as to ensure steady-state $\mathrm{SO}_{3}$ removal performance at that rate.

- Provide more information about the effects of dolomite injection on combustion efficiency and fly ash LOI.

- Observe the effects of dolomite injection on slagging and fouling in the furnace and back pass of the boiler, and on air heater performance, over an extended period, to determine whether the buildup seen in this 93 -hour test represents a steady-state condition or would continue to grow with time.

- For plants that use a venturi-type scrubber for combined particulate and $\mathrm{SO}_{2}$ control, it would allow longer-term effects of dolomite injection on the FGD system to be evaluated, such as determining steady-state magnesium ion concentrations in the FGD liquor, determining whether magnesium sulfite precipitation in the thickener will become a problem, and determining effects of gypsum scale formation in the scrubbers. For the latter, one or more scrubber modules should be inspected immediately before and after the dolomite test to quantify scale buildup. 
- For plants that use ESPs for particulate control, it would allow evaluation of dolomite injection on ESP performance. Based on other results from this project, it is expected that the greatly increased flue gas particulate content would adversely affect ESP performance, particularly in combination with the lowered $\mathrm{SO}_{3} /$ sulfuric acid concentration.

Also, the dolomite injection rate should be varied with boiler load and coal sulfur changes, to determine if high sulfuric acid removal percentages can be maintained if the dolomite injection rate is reduced in proportion with overnight load reductions and/or at lower coal sulfur content.

\section{Alkaline Reagent Slurry Injection Tests on BMP Unit 3}

\section{Experimental}

During the second through fourth short-term tests, alkaline slurry sorbents were injected into one half of the BMP Unit 3 boiler for up to two weeks each to assess their effectiveness for flue gas $\mathrm{SO}_{3}$ control. Various analytical techniques were used to assess the effects of sorbent injection, similar to those used during the dolomite injection test conducted on Unit 2 as described above.

Unit 3 is rated at 800 net MW. It has an opposed-wall fired, supercritical boiler rated at approximately $6,415,000$ pounds of steam per hour $(2,916,00 \mathrm{~kg} / \mathrm{hr})$ at $3785 \mathrm{psig}(26,100 \mathrm{kPa})$ and $1005 / 1005^{\circ} \mathrm{F}\left(541 / 541^{\circ} \mathrm{C}\right)$ superheat and reheat temperatures. Like Unit 2, the boiler has 16 burners each on the front and back walls of the furnace. The burners are arranged in four horizontal rows on each wall, with four burners per row. One ball mill provides the pulverized fuel for each row. Depending on fuel quality and mill condition, full load can generally be achieved with six of the eight mills in operation (and thus six of eight rows of burners in service).

Unit 3 typically burns a coal blend, predominantly blends of a McElroy coal, similar to that described for Unit 2. The actual coal sulfur can vary over a range from 2.0 to $4.5 \%$. The facility also has permission to burn up to $20 \%$ of the fuel as petroleum coke. During the test periods on Unit 3, a standard coal blend averaging about $4 \%$ sulfur was typically fired, although during the byproduct magnesium hydroxide test a small amount of petroleum coke was reportedly blended with a lower sulfur coal for a portion of that test.

Unit 3 was brought into service in 1980 . The 800 -net-MW unit operates as a swing unit to meet the load demands of the grid. During most of the short-term tests, Unit 3 operated at 750 to 850 MW gross load during daylight hours and 550 to $650 \mathrm{MW}$ overnight. The boiler is equipped with two air heaters following the economizer section. The average flue gas temperature at the outlet of the air heaters is controlled to about $320^{\circ} \mathrm{F}\left(160^{\circ} \mathrm{C}\right)$ due to acid dew point considerations.

Figure 2-2 illustrates the flue gas path for Unit 3, and notes the gas sampling locations used during this test. Flue gas from each of the two air heaters splits into two duct runs, each of which goes to an ESP followed by an induced draft (ID) fan. There are no ties between the four ducts (two per air heater) so when an ID fan is out of service, there is no gas flow through the associated air heater outlet duct and ESP. Correspondingly, the gas flow through the air heater on 
that side of the boiler is also reduced, although the plant tries to bias the ID fans to equalize the gas flow as much as possible. Downstream of the ID fans, the flue gas flows to a common plenum, then the gas flow splits to up to five horizontal-gas-flow, FGD system absorber modules (four normally operate at full load). The scrubbers use a magnesium-enhanced, Thiosorbic ${ }^{\circledR}$ lime slurry reagent. The flue gas in the stack is saturated at a temperature of about $130^{\circ} \mathrm{F}\left(54^{\circ} \mathrm{C}\right)$; no reheat is employed.

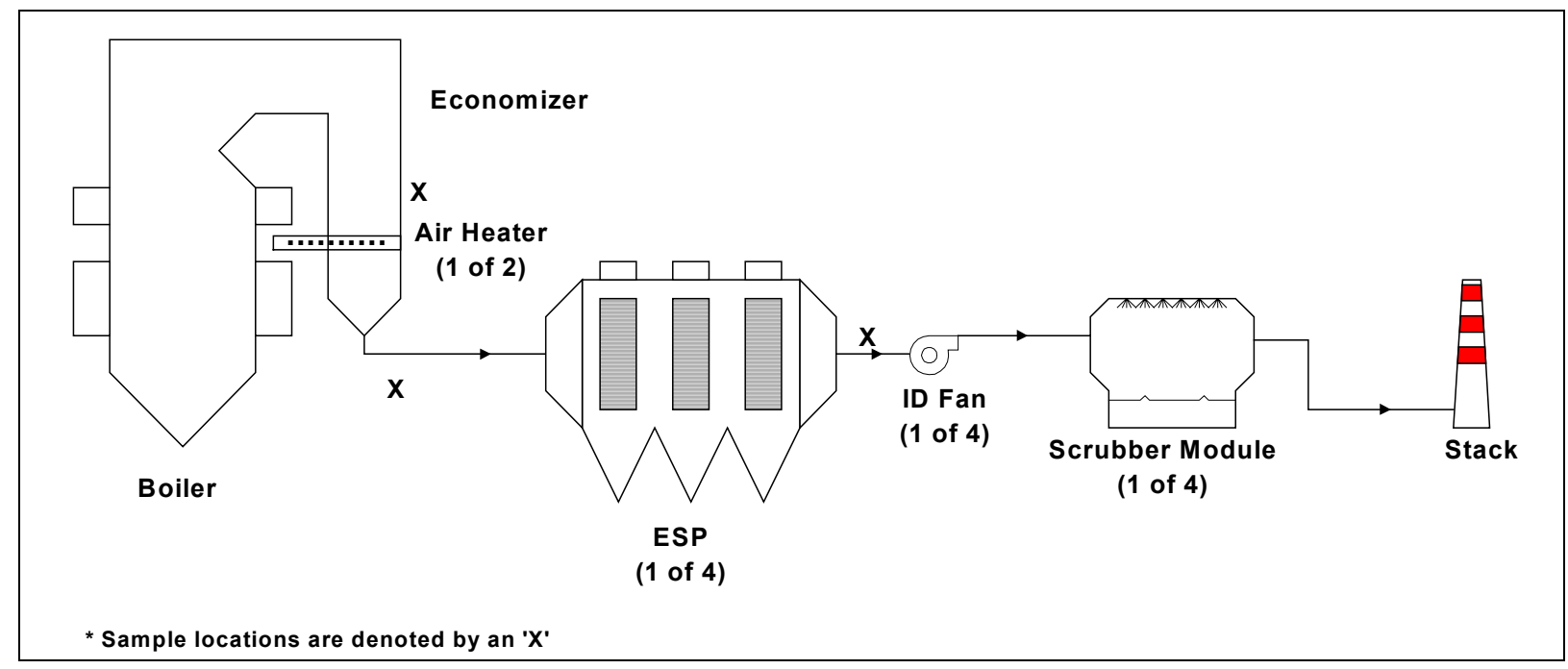

Figure 2-2

Illustration of Flue Gas Path for BMP Unit 3 during Normal Full-load Operation

The three sorbent slurries tested included a pressure-hydrated dolomitic lime (PHDL) $\left[\mathrm{Ca}(\mathrm{OH})_{2} \bullet \mathrm{Mg}(\mathrm{OH})_{2}\right]$, a technical-grade magnesium hydroxide slurry from Martin Marietta (commercial $\mathrm{Mg}$ ), and a byproduct magnesium hydroxide produced at Allegheny Energy's Pleasants Station (byproduct Mg). During these tests, injection of the sorbent slurries was accomplished through up to six air-atomizing nozzles inserted through inspection port openings on the front wall of half of the boiler. During the PHDL and commercial Mg test, the slurry was fed through ports located at the $11^{\text {th }}$ floor of the boiler structure, approximately across from the "nose" of the boiler. Midway through the third slurry injection test, the byproduct Mg test, the injection location was elevated to the $14^{\text {th }}$ floor of the boiler structure, across from the pendant secondary superheater tubes. The injection levels are illustrated in Figure 2-3.

At either level, the slurry injection lances were inserted through up to six upper furnace inspection ports on the east half of the boiler. At both the $11^{\text {th }}$ and $14^{\text {th }}$ floor, there are twelve observation ports across the face of the boiler. There is a port adjacent to each corner of the boiler along the front wall, then the remaining ports are situated on either side of five partial division walls that are equally spaced across the upper furnace cavity. Figure 2-4 illustrates the six lance locations on the east half of the boiler. Note that on the $14^{\text {th }}$ floor, lance location No. 5 was blocked by a camera installed at that inspection port. When injecting at the $14^{\text {th }}$ floor, the slurry flow that would normally have been split among six nozzles was instead fed to only five. 


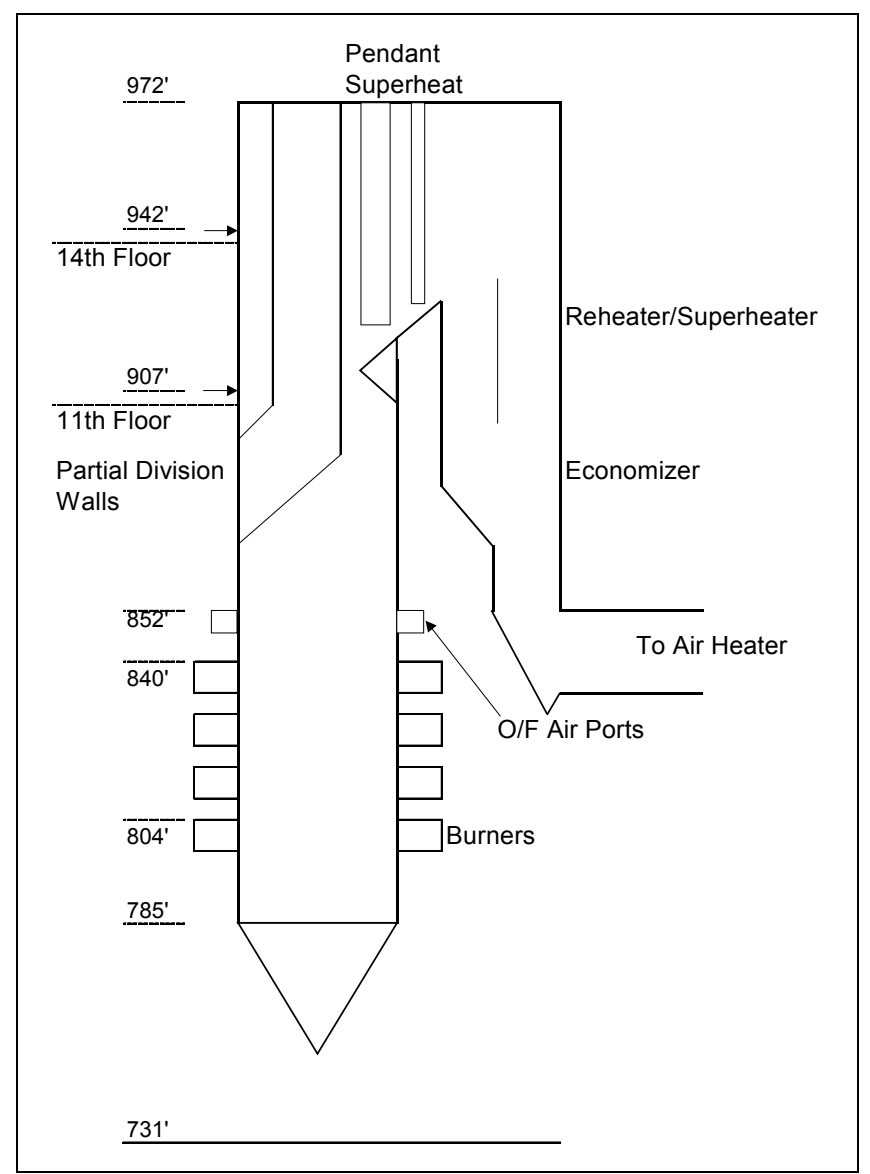

Figure 2-3

Illustration of Slurry Injection Levels for BMP Unit 3

Note: $1 \mathrm{ft}=0.305 \mathrm{~m}$.

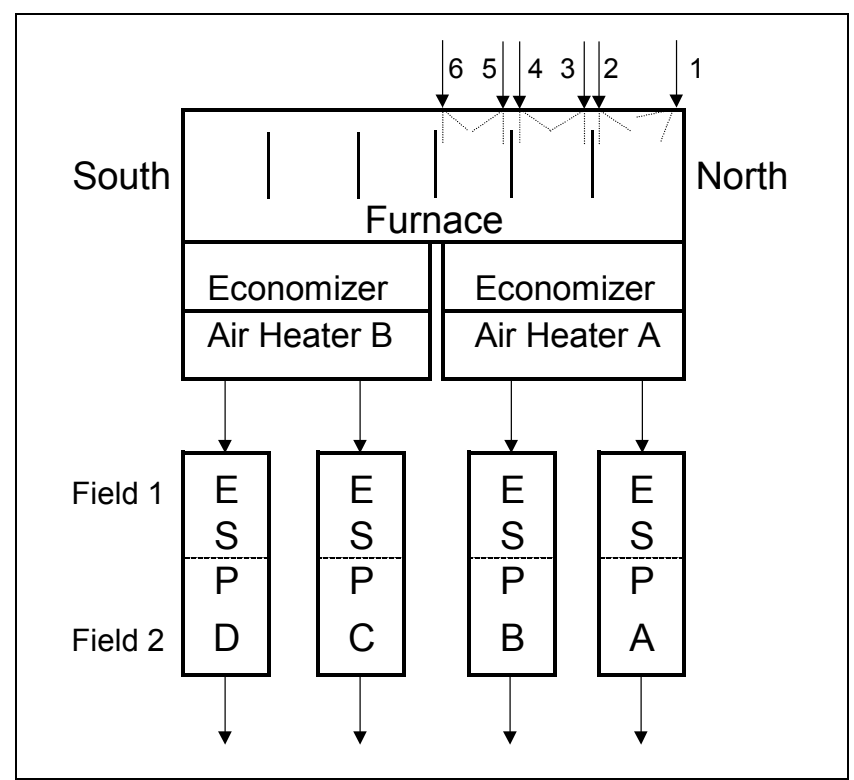

Figure 2-4

Illustration of Slurry Injection Locations for BMP Unit 3 - Plan View 
The air-atomizing nozzles were designed by Ashworth Engineering specifically for this application. The proprietary design employs an internal mix configuration, and was designed for relatively low airflow requirements and to achieve a relatively large minimum passage diameter. The air pressure to the nozzles was typically $80 \mathrm{psig}(550 \mathrm{kPa})$, although in some testing the pressure was varied to quantify its effect on $\mathrm{SO}_{3}$ control performance.

The sorbents injected into the furnace were delivered to the site in truckload quantities, as slurries containing 15 to $60 \mathrm{wt} \%$ solids, depending on the reagent. Two 11,000 -gallon $\left(41-\mathrm{m}^{3}\right)$ slurry storage tanks were situated in the basement of Unit 3 . The tanker trucks unloaded into one or both of these tanks. Between the two tanks, approximately four to five truckloads could be stored on site. From the storage tanks, one of two air-driven diaphragm pumps was used to transfer slurry up to a 1000-gallon $\left(3.8-\mathrm{m}^{3}\right)$ "day" tank located on the $9^{\text {th }}$ floor of the boiler house. The day tank level was controlled by a signal from an ultrasonic level indicator on the day tank. Relays controlled by this signal energized (opened) a solenoid valve on the air supply to the transfer pump on low day tank level, and closed the solenoid valve on high level.

From the day tank, one or two Moyno progressing cavity pumps were used to feed slurry to the injection nozzles. The Moyno pumps were equipped with magnetic flow meters at their discharge, and pump speed was modulated to maintain slurry flow rate at a set point. The slurry flow rate set point was manually adjusted according to the density and purity of the reagent, the Unit 3 load, the expected Unit 3 coal sulfur content, and the desired reagent-to- $\mathrm{SO}_{3}$ molar ratio. Slurry from the Moyno pumps was fed to a manifold, which in turn distributed slurry to the five or six operating injection nozzles. Plant compressed air was connected to each lance individually, through flexible hoses, to provide atomizing air.

Also illustrated in Figure 2-4 is the arrangement of the four ESPs relative to the two air heaters. Note that, because of the direction of rotation of the regenerative-type air heaters, the flue gas going to the outboard ESPs (labeled "A" and "D" in Figure 2-4) tends to be cooler and have a lower $\mathrm{SO}_{3}$ content than the flue gas going to the inboard ESPs (labeled "B" and "C"). However, no attempt was made to bias the sorbent slurry flow to the nozzles on the inboard side of the east air heater to account for this observed stratification. It was felt that the stratification was caused by the drop in gas temperature across the air heater, and was not reflective of stratification in flue gas $\mathrm{SO}_{3}$ content in the furnace, where the sorbent was injected.

\section{Results and Discussion}

A baseline test and three short-term (two-week) slurry injection tests were conducted on half of Unit 3 at BMP, to determine the effectiveness of sorbents injected into the furnace at controlling flue gas sulfuric acid concentrations as measured downstream of the ESP.

The baseline testing on Unit 3 determined that about $1 \%$ of the coal sulfur is oxidized to $\mathrm{SO}_{3}$ rather than $\mathrm{SO}_{2}$ in the furnace and back pass of the boiler. The equivalent value for Unit 2 during baseline testing for the dolomite powder injection test was higher, 1.6 to $1.7 \%$. The $1 \%$ conversion for Unit 3 was used along with the coal sulfur content and one-half the measured Unit 3 coal feed rates to estimate the molar rate of $\mathrm{SO}_{3}$ formation in Unit 3. This, in turn, was used to 
determine what slurry injection rate was required to achieve a desired sorbent-to- $\mathrm{SO}_{3}$ mole ratio, or to calculate this mole ratio while injecting sorbent slurry at a given rate.

The first sorbent tested was PHDL. The PHDL was injected at molar ratios of calcium plus magnesium hydroxides to $\mathrm{SO}_{3}$ in the furnace exit gas as high as 12:1. Even at the highest injection rate, the observed $\mathrm{SO}_{3}$ removal was limited to approximately $60 \%$ or less.

Previous literature data suggest that magnesium hydroxide injected into the furnace is much more reactive with flue gas $\mathrm{SO}_{3}$ than calcium hydroxide. If only the magnesium hydroxide content of the PHDL is considered, the highest $\mathrm{Mg}: \mathrm{SO}_{3}$ ratio tested was 6:1. However, considering just the weight of solids injected, the highest PHDL injection rate was equivalent to injecting pure magnesium hydroxide at a $\mathrm{Mg}: \mathrm{SO}_{3}$ ratio of almost 14:1.

The PHDL injection was not observed to have a significant effect on ESP operation. This appears to be because high levels of $\mathrm{SO}_{3}$ removal were not achieved, and ample $\mathrm{SO}_{3}$ remained in the flue gas to condition the fly ash/sorbent mixture.

The second sorbent injected, commercial $\mathrm{Mg}$, was able to achieve the target $\mathrm{SO}_{3}$ removal of $90 \%$ or greater. An injection rate equivalent to a $\mathrm{Mg}: \mathrm{SO}_{3}$ ratio in the range of 12:1 to 14:1 was able to lower the ESP B outlet $\mathrm{SO}_{3}$ concentrations from about 30 ppmv to approximately 2 to 3 ppmv. There was evidence that commercial $\mathrm{Mg}$ injected on the east side of the boiler was crossing over to the west flue gas path, which was not having sorbent injected, potentially diluting the sorbent effectiveness measured on the east side. Therefore, when injecting sorbent into the entire furnace, lower $\mathrm{Mg}: \mathrm{SO}_{3}$ values may be effective at achieving the high $\mathrm{SO}_{3}$ removal percentages as described above.

Injecting at this rate, and lowering the ESP outlet $\mathrm{SO}_{3}$ concentrations to such a low value was observed to have an adverse effect on ESP operation. During the time period of high $\mathrm{SO}_{3}$ removal, the operating currents in the affected ESP were greatly reduced, and particulate emissions from that ESP were observed to increase by a factor of approximately four. This result suggests that it would not be possible to remove $\mathrm{SO}_{3}$ down to the 2 ppmv level, as measured at the ESP outlet, and maintain acceptable ESP performance at BMP. It appears that an ESP outlet concentration of approximately 5 to 8 ppmv would be required to maintain ESP performance.

The third short-term slurry injection test evaluated a byproduct $\mathrm{Mg}$ sorbent produced from a modified Thiosorbic ${ }^{\circledR}$ lime FGD process at Allegheny Energy's Pleasants Station. The solids in this slurry average about 4 to 5 microns for a mass mean particle diameter, and have a specific surface area of about 49 to $63 \mathrm{~m}^{2} / \mathrm{g}$. The gypsum solids in this slurry most likely have a low specific surface area (less than $5 \mathrm{~m}^{2} / \mathrm{g}$ ) and contribute very little to the average, so the specific surface area of the magnesium hydroxide in this slurry is probably in the range of 70 to 100 $\mathrm{m}^{2} / \mathrm{g}$.

This material was also capable of lowering the ESP outlet $\mathrm{SO}_{3}$ concentrations on the side injected to $2 \mathrm{ppmv}$, but at a lower $\mathrm{Mg}: \mathrm{SO}_{3}$ ratio of about 7:1. Because the byproduct $\mathrm{Mg}$ is not pure magnesium hydroxide (it is about $62 \%$ magnesium hydroxide, with most of the balance being gypsum fines) the amount of solids injected at this molar ratio is about the same as when 
injecting the commercial $\mathrm{Mg}$ at a molar ratio of 11:1 to 12:1. However, for a plant like BMP Unit 3 , this material may be advantageous because it could be produced on site by lime addition to recover liquid-phase magnesium in FGD blow down liquor.

Although the byproduct $\mathrm{Mg}$ appeared to be more effective at $\mathrm{SO}_{3}$ removal, this was observed when it was injected higher in the furnace than where the PHDL and commercial Mg were injected. The results mentioned in the previous paragraph are for injection at the higher, $14^{\text {th }}$ floor level of the boiler structure. The effect is most likely due to the furnace gas temperatures being lower adjacent to the $14^{\text {th }}$ floor location, and less likely to cause dead burning of the calcined reagent $(\mathrm{MgO})$. When the byproduct $\mathrm{Mg}$ was injected at the $11^{\text {th }}$ floor location, it was much less effective.

This observation raised the issue of whether the first two sorbent slurries would be more effective if they were injected at the higher location. However, the project budget did not allow repeat testing of the first two sorbents at the new injection level. Also, as mentioned above, the fact that the byproduct $\mathrm{Mg}$ could be produced on site made it the favored reagent for BMP.

As during the commercial Mg test, ESP operation was adversely affected when the outlet $\mathrm{SO}_{3}$ concentrations were controlled down to 2 ppmv. Comparing data when injecting at high sorbent rates on the $11^{\text {th }}$ floor, where the $\mathrm{SO}_{3}$ removal percentages were lower, to data when injecting at a $7: 1 \mathrm{Mg}: \mathrm{SO}_{3}$ ratio at the $14^{\text {th }}$ floor, the effect appears to be from lowered $\mathrm{SO}_{3}$ concentrations and not from the mass of sorbent injected per se. That is, when injecting similar quantities on the $11^{\text {th }}$ floor, and the ESP outlet $\mathrm{SO}_{3}$ concentrations remained well above 2 ppmv, no adverse effect on ESP performance was noted. To maintain acceptable ESP operation, it appeared that ESP outlet sulfuric acid concentrations would have to be maintained at approximately 5 ppmv or greater. This apparent requirement may limit the applicability of this injection process when very low stack sulfuric acid concentrations are desired.

Based on these short-term test results, the byproduct $\mathrm{Mg}$ was recommended for further testing on the whole boiler over a longer test duration of 25 to 30 days. These results are described in Section 3.

\section{Conclusions - Short-term Tests}

Results from these short-term tests were reviewed to develop estimates of the quantities of each alkaline sorbent required to achieve two levels of $\mathrm{SO}_{3}$ removal performance. These estimates are compared in Table 2-1. The quantities are expressed in terms of moles of alkaline sorbent per mole of $\mathrm{SO}_{3}$ in the economizer outlet flue gas under baseline (no sorbent injection) conditions. For the dolomite and PHDL reagents, the ratios are based on calcium- plus magnesium-based alkalinity, whereas for the commercial and byproduct $\mathrm{Mg}$, the ratios are based only on magnesium hydroxide content in the sorbent slurry.

Note that the molar ratios shown in Table 2-1 should be considered approximate, because of variations from test to test and because some values had to be interpolated from test results at other removal levels. Test to test variations, in particular, could appreciably confound these 
Table 2-1

Comparison of Furnace Injected Alkaline Sorbents for Sulfuric Acid Control (based on short-term test results)

\begin{tabular}{|c|c|c|c|c|}
\hline Sorbent & Injection Mode & Injection Location & $\begin{array}{l}\text { Estimated Molar } \\
\text { Ratio to Achieve } \\
60 \% \text { Sulfuric Acid } \\
\text { Removal }\end{array}$ & $\begin{array}{l}\text { Estimated Molar } \\
\text { Ratio to Achieve } \\
90 \% \text { Sulfuric Acid } \\
\text { Removal }\end{array}$ \\
\hline Dolomite & Dry Power & $\begin{array}{l}\text { Top Front Row of } \\
\text { Burners, Unit } 2\end{array}$ & $30: 1^{*}$ & $40: 1^{*}$ \\
\hline $\begin{array}{l}\text { Pressure- } \\
\text { Hydrated } \\
\text { Dolomitic Lime }\end{array}$ & Atomized Slurry & $\begin{array}{l}\text { Across from Boiler } \\
\text { Nose }\left(11^{\text {th }} \text { Floor }\right) \text {, } \\
\text { Unit } 3\end{array}$ & $12: 1^{*}$ & Not Achieved \\
\hline $\begin{array}{l}\text { Commercial } \\
\text { Magnesium } \\
\text { Hydroxide }\end{array}$ & Atomized Slurry & $\begin{array}{l}\text { Across from Boiler } \\
\text { Nose }\left(11^{\text {th }} \text { Floor }\right) \text {, } \\
\text { Unit } 3\end{array}$ & $4: 1-5: 1^{* *}$ & $12: 1^{* *}$ \\
\hline $\begin{array}{l}\text { Byproduct } \\
\text { Magnesium } \\
\text { Hydroxide }\end{array}$ & Atomized Slurry & $\begin{array}{l}\text { Across from } \\
\text { Pendant Superheat } \\
\text { Tubes (14 }{ }^{\text {th }} \text { Floor), } \\
\text { Unit } 3\end{array}$ & $4: 1^{* *}$ & $7: 1^{* *}$ \\
\hline
\end{tabular}

*Molar ratio of calcium plus magnesium in reagent injected to $\mathrm{SO}_{3}$ at the economizer outlet under baseline conditions

**Molar ratio of magnesium in reagent injected to $\mathrm{SO}_{3}$ at the economizer outlet under baseline conditions

estimates. For example, the dolomite test results are for Unit 2, which showed higher $\mathrm{SO}_{3}$ concentration levels than in Unit 3, and are based on $\mathrm{SO}_{3}$ removal as measured at the economizer outlet. The removals for the slurry injection tests conducted on Unit 3 are based on ESP outlet conditions, and reflect $\mathrm{SO}_{3}$ removal across the air heater and ESP. For the slurry injection test results, the PHDL and commercial $\mathrm{Mg}$ test results are based on slurry injection at the $11^{\text {th }}$ floor level on Unit 3, while the byproduct $\mathrm{Mg}$ test results are based on injection at the $14^{\text {th }}$ floor, which was more favorable (at least for that reagent).

These comparisons show that the byproduct magnesium hydroxide would require the lowest molar ratios to achieve either the moderate $(60 \%)$ or the high $(90 \%)$ sulfuric acid removal level. However, as mentioned above, the injection location higher in the furnace during the test of this reagent may confound this comparison. Also, because the byproduct magnesium hydroxide is not pure, the amount of solids actually required to be injected would be similar to or greater than that required for the nearly pure commercial product. Finally, recall that ESP performance may be adversely affected when achieving $90 \%$ sulfuric acid removal with any of these reagents.

The relative costs of these reagents and balance-of-plant impacts should also figure into this comparison. Raw dolomite stone can be delivered to most locations for approximately $\$ 10$ per ton ( $\$ 11$ per metric ton), but this material requires grinding to fine particle sizes before injection into the boiler as a powder. The commercial $\mathrm{Mg}$ delivered cost would likely be in the range of approximately $\$ 200$ to $\$ 300$ per dry ton (\$220 to $\$ 330$ per dry metric ton). The costs associated with preparing the byproduct $\mathrm{Mg}$ is not well documented at this time, but it is estimated that the 
material could be produced at BMP for $\$ 100$ per dry ton of pure magnesium hydroxide ( $\$ 110$ per dry metric ton) or less.

Balance-of-plant issues could not be fully evaluated in these tests, but can include impacts on the FGD system (Unit 2) or ESP (Unit 3), fly ash sales or other reuse, boiler slagging and fouling, etc. Heat rate penalties (evaporation of water from the slurries, air heater fouling) or benefits (ability to lower air heater exit flue gas temperature if $\mathrm{SO}_{3}$ is removed upstream) can also impact the relative cost effectiveness of these sorbents. The long-term test results discussed in Section 3 provide some information about balance-of-plant effects for two of the four reagents, and potential cost impacts are discussed in Section 4.

Based on the results summarized above, the two magnesium hydroxide slurry reagents were selected for further, long-term testing. Dolomite injection was not selected because the high injection rates required to achieve high $\mathrm{SO}_{3}$ removal efficiency appear to eliminate this process from consideration for plants that have ESP particulate collectors, which are most common in bituminous coal fired units. The PHDL slurry reagent was not further tested because of the limited $\mathrm{SO}_{3}$ /sulfuric acid control measured during the short-term test with that reagent. Although the commercial Mg appears to be more costly than the byproduct $\mathrm{Mg}$, it was tested at one of the two long-term test sites because of the limited availability of the byproduct material. 


\section{LONG-TERM MG INJECTION TEST RESULTS}

Results from a 23-day byproduct Mg injection test on Unit 3 at BMP and a 23-day test of byproduct $\mathrm{Mg}$ and commercial Mg injection at AEP's Gavin Plant are presented and discussed in this section. The objectives of the long-term tests were to evaluate the ability to control sulfuric acid emissions, as measured at the ESP outlet, over an extended period of time, and to evaluate balance-of-plant effects from sorbent injection.

\section{Byproduct Mg Slurry Injection Test on BMP Unit 3}

\section{Experimental}

During the long-term test, byproduct Mg slurry was injected into the entire Unit 3 boiler continuously for 23 days, to assess its effectiveness for flue gas $\mathrm{SO}_{3}$ control. BMP Unit 3 was previously described in Section 2.

Various analytical techniques were used to assess the effects of sorbent injection. These primarily included sampling with the Controlled Condensation System (CCS) method for determining flue gas $\mathrm{SO}_{3}$ content and, to a lesser extent, an acid dew-point meter for determining the sulfuric acid dew point (and, indirectly, the concentration of sulfuric acid) of the flue gas. This final report primarily addresses the $\mathrm{SO}_{3}$ removal results from the long-term tests.

A number of other measurements were made as part of the long-term test at BMP Unit 3. EPA Reference Method 26a was used for determining $\mathrm{HCl}, \mathrm{HF}$, chlorine $\left(\mathrm{Cl}_{2}\right)$, and fluorine $\left(\mathrm{F}_{2}\right)$ concentrations in the ESP outlet flue gas. A modified version of EPA Method 108 was used to determine flue gas vapor-phase and particulate arsenic concentrations at the economizer outlet. Impacts on ESP operation were quantified by taking voltage and current data on operating electrical sections of Unit 3's ESPs. A modified version of EPA Reference Method 17 was used to quantify ESP outlet particulate readings under baseline operation and during sorbent injection. Sorbent and ESP hopper samples were analyzed for magnesium content by acid dissolution followed by atomic absorption analysis. Some sorbent samples were also analyzed for calcium and sulfate content. Coal samples were collected and analyzed for a variety of parameters according to ASTM protocols. SCR catalyst coupons were inserted into the economizer outlet flue gas stream at the beginning of sorbent injection, and individual coupons were removed periodically as the test progressed. These coupons were analyzed off site for the impacts of byproduct $\mathrm{Mg}$ on catalyst activity. Finally, visual observations were made of boiler furnace and pendant superheater tube surfaces prior to and during sorbent injection, to observe any trends related to slag formation. The results of all of these additional measurements are described at a 
summary level in this report. The reader is referred to the Topical Report covering the long-term tests for details of the results of these measurements. ${ }^{1}$

During this long-term test, injection of sorbent slurries was accomplished through air-atomizing nozzles inserted through inspection port openings on the front wall of the boiler. The injection location was at the $14^{\text {th }}$ floor of the boiler structure, across from the pendant superheat tubes. The injection levels on Unit 3 were illustrated in Figure 2-3.

At the $14^{\text {th }}$ floor, there are twelve ports across the face of the boiler. There is a port adjacent to each corner of the furnace along the front wall, and the remaining ports are situated on either side of five partial division walls that are equally spaced across the upper furnace cavity. Figure 3-1 illustrates the twelve potential port/lance locations. However, on the $14^{\text {th }}$ floor potential lance location numbers 5 and 8 were blocked by cameras installed in those inspection ports. Consequently, only ten of the twelve potential slurry injection locations could be used.

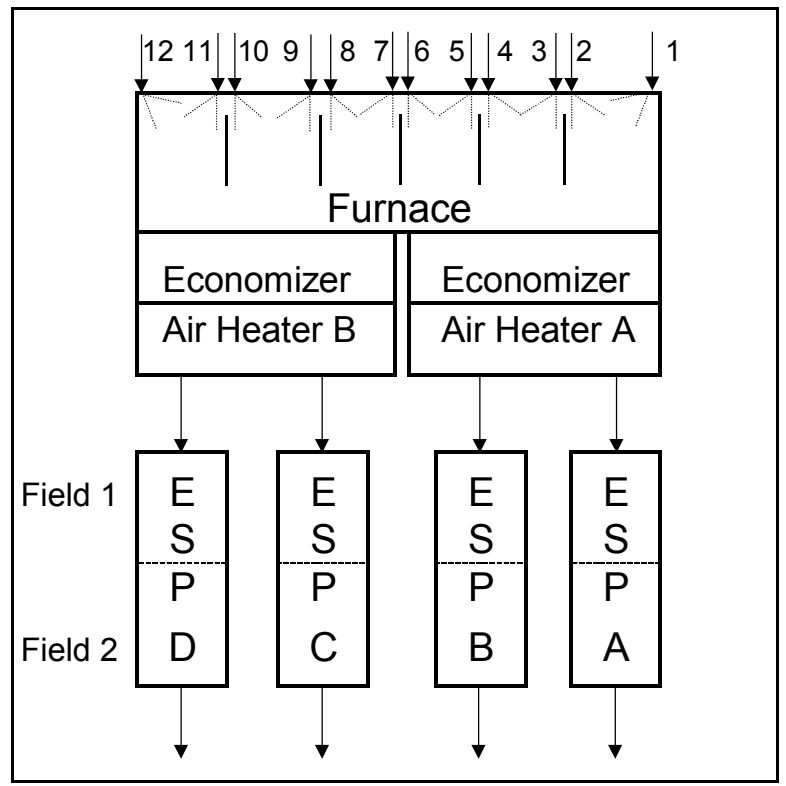

Figure 3-1. Plan View Illustration of Slurry Injection Locations (nos. 5 and 8 were not used)

The air-atomizing nozzles were designed by Ashworth Engineering specifically for this application. The proprietary design employs an internal mix configuration, and was designed for relatively low airflow requirements and to achieve a relatively large minimum passage diameter. The air pressure to the nozzles was nominally $80 \mathrm{psig}(550 \mathrm{kPa})$.

The byproduct Mg long-term test was conducted over the time period May 11 through June 3, 2001. Baseline (no sorbent injection) measurements were conducted several days prior to the beginning of sorbent injection, from May 7 through 10. During most flue gas testing, the steam generator operated close to full load (over 800 gross MW) with one to two pulverizers and burner rows out of service. The Unit 3 load during time periods when byproduct $\mathrm{Mg}$ was being injected but no flue gas measurements were made was generally in the range of 750 to 860 gross 
MW during daylight hours on weekdays, and varied over the range of 500 to 750 gross MW overnight and on weekends. One weekend in the middle of the test the unit load was dropped into the range of 350 to 450 gross MW so the two steam condensers could be cleaned.

\section{Results and Discussion}

\section{Baseline Tests}

Baseline data were collected over several days immediately prior to the beginning of byproduct $\mathrm{Mg}$ injection on May 11, to determine baseline (no sorbent injection) $\mathrm{SO}_{3} /$ sulfuric acid concentrations at a variety of measurement locations. Figure 3-2 summarizes the results of CCS measurements made at various locations throughout the flue gas path on Unit 3 by location, showing the average of all measurements made at a particular location. Each value shown in the figure represents an average of three to nine individual measurements.

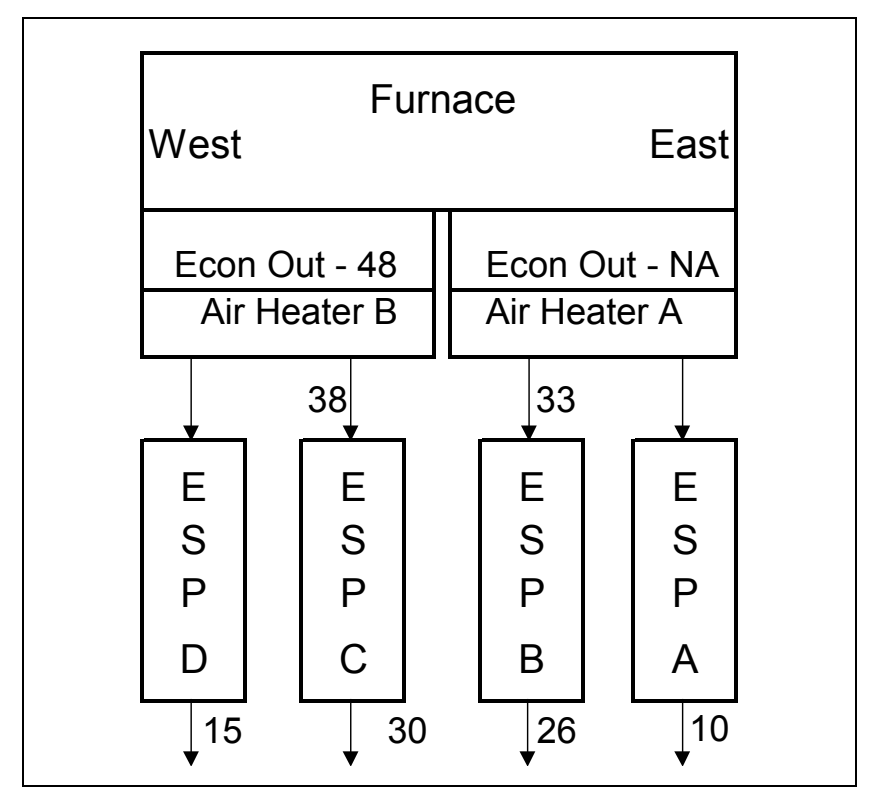

Figure 3-2. Summary of Baseline CCS Measurements at BMP Unit 3 (all values in ppmv [dry basis] $\mathrm{SO}_{3}$ or sulfuric acid at actual flue gas $\mathrm{O}_{2}$ concentration)

The averages in Figure 3-2 show some side-to-side variation in $\mathrm{SO}_{3}$ conversion in the furnace and back pass of the boiler, as measured at the "hot" sides of the two air heater outlets, with higher concentrations on the west side of the boiler. Only one economizer outlet was measured for $\mathrm{SO}_{3}$ concentration, and it showed a substantially higher concentration than was measured at this location during previous baseline testing in October 2000 (48 ppmv vs. 28 ppmv previously). The 48-ppmv value represents the average of nine runs conducted over a three-day period (standard deviation of $5.2 \mathrm{ppmv}$ ), so it should be a representative and repeatable value for conditions in early May 2001. 
The air heater outlet concentrations measured downstream of this economizer outlet indicate about $20 \% \mathrm{SO}_{3}$ removal across the "B" air heater on its hot side. Another $21 \%$ reduction in $\mathrm{SO}_{3} /$ sulfuric acid concentration is seen across both ESPs $\mathrm{B}$ and $\mathrm{C}$. The sampling ports for the outlet of the cold side of the air heaters and inlets to ESPs A and D are difficult to access on Unit 3 , therefore no CCS measurements were made at those locations. However, comparing the west economizer outlet value to the concentrations measured at the outlet of ESP D, a total of $67 \%$ reduction in $\mathrm{SO}_{3}$ concentration is seen. Most of the reduction in $\mathrm{SO}_{3}$ /sulfuric acid concentration seen at the ESP A and D outlets is presumed to occur across the air heaters, either by sulfuric acid condensation on the cooler air heater baskets or adsorption on the cooler fly ash particles on the cold side.

Throughout this section, $\mathrm{SO}_{3}$ /sulfuric acid removal during sorbent injection is reported as the percent reduction in vapor-phase sulfuric acid concentrations measured at the ESP B outlet for injection versus baseline conditions. The average baseline values were shown in Figure 3-2.

The economizer outlet $\mathrm{SO}_{3}$ concentration data shown in Figure 3-2 were used to calculate an average $\mathrm{SO}_{2}$ to $\mathrm{SO}_{3}$ conversion percentage for Unit 3, to serve as a basis for calculating sorbentto- $\mathrm{SO}_{3}$ molar ratios. Seven Unit 3 coal feed samples were collected and analyzed for the baseline tests. The ultimate analyses of these coal samples showed sulfur contents of 3.5 to $4.5 \mathrm{wt} \%$, or 5.9 to $7.0 \mathrm{lb} \mathrm{SO}_{2} / \mathrm{MM}$ Btu heat input. These results were used in combustion calculations to determine the total amount of $\mathrm{SO}_{2}$ that would be produced from the combustion of these coals, then that value was compared to the measured economizer outlet $\mathrm{SO}_{3}$ concentrations.

For the October 2000 baseline measurements reported in Section 2, the calculated conversion percentage compared to coal samples from that time period was $0.9 \%$. That percentage is near the middle of the expected range for bituminous coals in pulverized-coal-fired boilers (approximately $0.5 \%$ to $1.5 \%$ ). The May 2001 data for the " $\mathrm{B}$ " economizer outlet correspond with a significantly higher $1.6 \%$ conversion of the coal sulfur to $\mathrm{SO}_{3}$, based on the average of $3.83 \mathrm{wt} \%$ sulfur in the seven coal samples. This conversion percentage can be affected by many variables, including excess air levels in the furnace, slag accumulations on heat transfer surfaces, etc. It is not certain why this conversion was higher in May 2001 than had been measured previously in October 2000, but it could be related to differing amounts of slagging and fouling of boiler heat transfer amounts during the two test periods. The May test immediately preceded a planned boiler outage, and the boiler heat transfer surfaces had not been cleaned for some time.

Downstream measurements suggested that the $\mathrm{SO}_{3}$ production was lower on the east side of the furnace (corresponding with the " $\mathrm{A}$ " economizer outlet) than on the west side. Although the outlet $\mathrm{SO}_{3}$ concentrations from the east economizer were not measured, it is expected that the conversion of $\mathrm{SO}_{2}$ to $\mathrm{SO}_{3}$ would have been lower for that side. To account for this apparent side to side difference, the overall conversion of $\mathrm{SO}_{2}$ to $\mathrm{SO}_{3}$ in the Unit 3 boiler was assumed to be slightly lower than the $1.6 \%$ conversion measured on the west side, or $1.5 \%$, for calculating sorbent-to- $\mathrm{SO}_{3}$ mole ratios for the long-term test. It is recognized that the actual percentage at any given time could vary because of the influences of excess air levels and other factors. 


\section{Long-term Test $\mathrm{SO}_{3}$ Removal Results}

The long-term slurry injection test at BMP Unit 3 was conducted over the time period May 11 through June 3, 2001, using byproduct magnesium hydroxide produced at Allegheny Energy's Pleasants Power Station. The byproduct slurry was trucked from the Pleasants Station and unloaded into the 11,000-gallon $\left(41-\mathrm{m}^{3}\right)$ storage tanks at BMP Unit 3. Eight to nine truckloads per day were typically required at the slurry injection rates tested. Figure 3-3 illustrates the Unit 3 gross load, and the byproduct $\mathrm{Mg}$ injection molar ratios over the test duration. Two to three days worth of day from early in the test are missing in the figure because of an outage of the plant's data historian system.

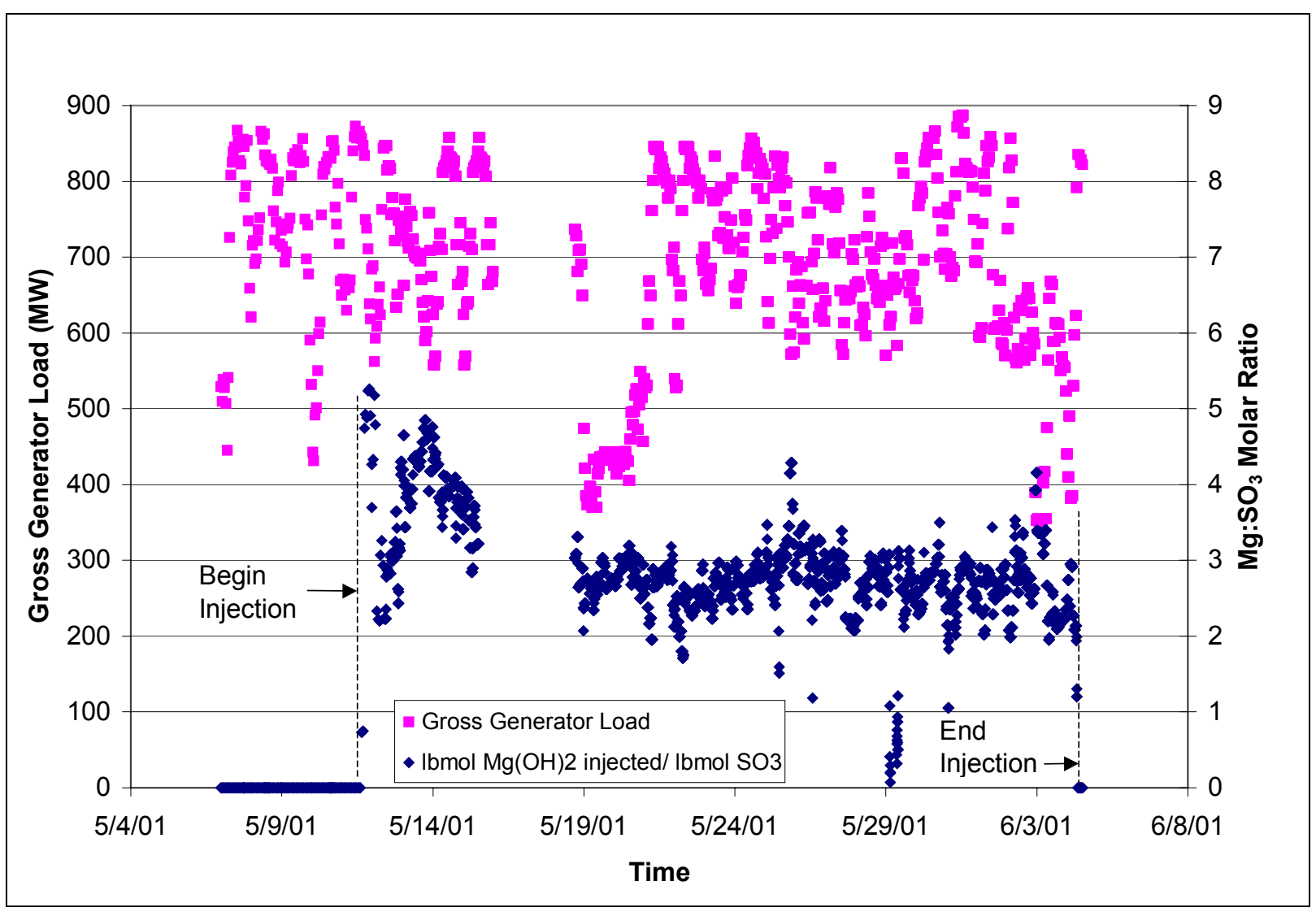

Figure 3-3. BMP Unit 3 Gross Unit Load and Byproduct Mg Injection Rate during Long-term Test

The sulfuric acid removal performance was measured by CCS method sampling only at the beginning (May 12-14) and the end of the long-term test period (May 30-June 3). The sulfuric acid removal results from these two byproduct $\mathrm{Mg}$ long-term test periods are plotted in Figure 34. The Mg: $\mathrm{SO}_{3}$ molar ratios in Figures 3-3 and 3-4 are based on the amount of $\mathrm{Mg}(\mathrm{OH})_{2}$ in the byproduct slurry injected, the Unit 3 coal feed rate, ultimate analyses of coal samples for this time period, and an assumed $1.5 \%$ conversion of coal sulfur to $\mathrm{SO}_{3}$, which was derived from the baseline data as described above. 


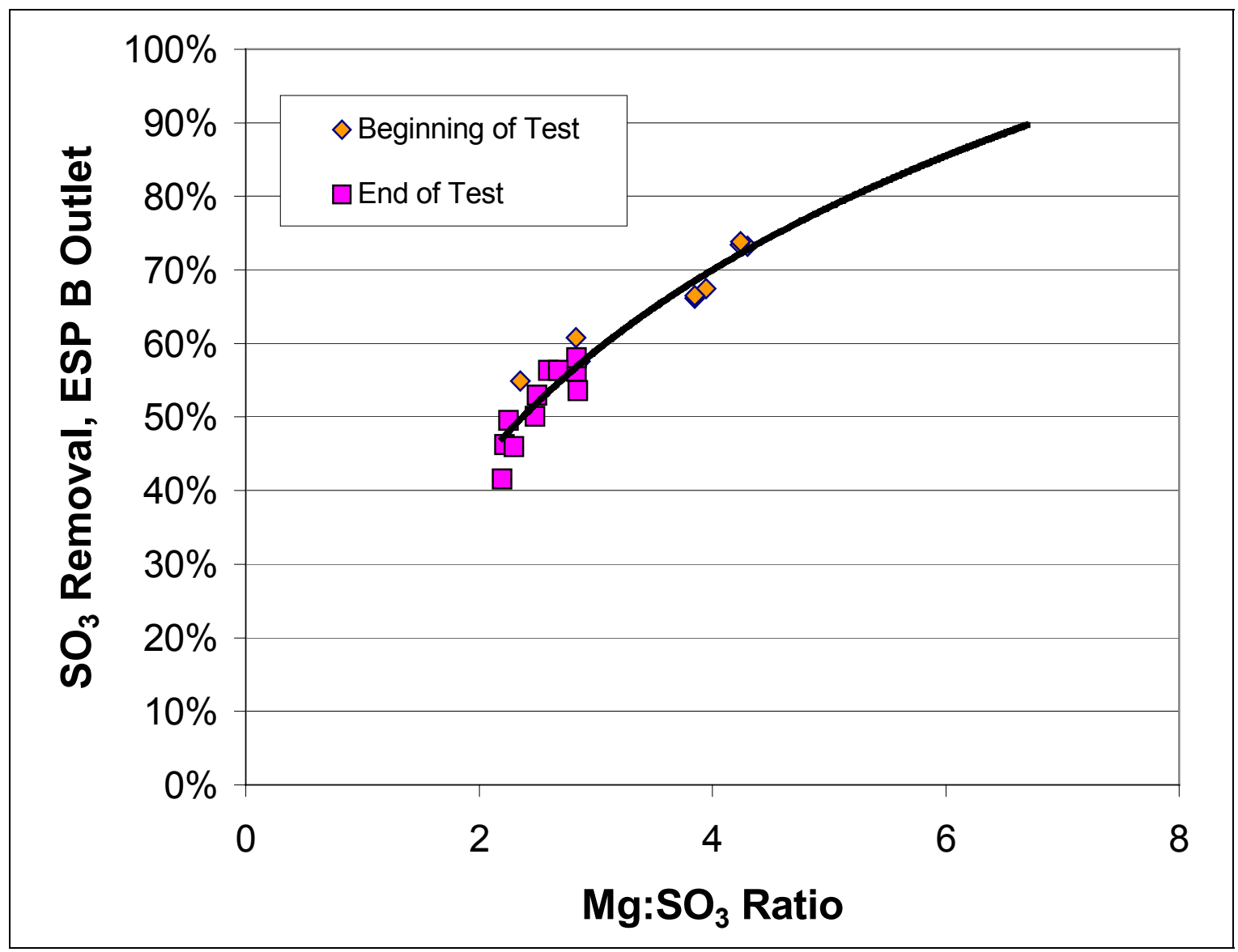

Figure 3-4. Results from the BMP Unit 3 Long-term Byproduct Mg Test (ESP B outlet location)

The results plotted in Figure 3-4 are for sulfuric acid removal as measured at the ESP B outlet. The ESP A and ESP D data were not used because, as described previously, the outlet sulfuric acid concentrations from these ESPs are typically much lower than from ESPs B and C. This is most likely because ESPs A and D take flue gas from the cool side of the air heaters, and thus experience greater sulfuric acid removal across the air heaters.

In the short-term tests previously conducted at BMP Unit 3, where the sorbent injection was just on the east half of the furnace, the ESP B data were always used as a measure of sorbent performance. With injection across the entire furnace, it was expected that both the ESP B and ESP C data could be used to measure sorbent effectiveness. However, the ESP C data from the latter portions of the test appear to be anomalous. The end-of-test ESP C outlet sulfuric acid concentrations were measured to be about half or less of those at the ESP B outlet, both during sorbent injection on May 31 through June 3 and after sorbent injection ceased on June 4. This disparity was not seen when comparing the ESP B and ESP C outlet data from the first half of the test. There were no obvious measurement errors that appeared to contribute to the disparity seen in these results.

The results plotted in Figure 3-4 show the performance measured at the beginning of the test compared to that measured at the end of the test. At the beginning of the test, the $\mathrm{Mg}: \mathrm{SO}_{3}$ molar ratios were varied from about 2.4 to 4.3 moles magnesium hydroxide injected per mole of $\mathrm{SO}_{3}$ 
under baseline conditions, while at the end of the test, the ratios were in a lower range of 2.2 to 2.9:1. At the end of the test, sorbent injection rates and overall sulfuric acid removal percentages were controlled to lower values to avoid adverse effects on ESP performance. This effect is discussed below.

Apparent sulfuric acid removal efficiencies ranged from about 55 to $75 \%$ at the beginning of the test, and from about 40 to $60 \%$ at the lower $\mathrm{Mg}: \mathrm{SO}_{3}$ ratios at the end of the test. The removal percentages for the beginning of the test are based on the baseline values for ESP B outlet from May 7-10, while the end-of-test values are based on baseline ESP B outlet values from June 4, approximately 24 hours after injection ceased.

The data from the beginning and end of the test overlap well for measurements at the same $\mathrm{Mg}: \mathrm{SO}_{3}$ ratios. The figure also shows a logarithmic least squares fit of the data for both time periods. One relationship appears to fit the two data sets quite well, with an $\mathrm{R}^{2}$ value greater than 0.92. The logarithmic relationship shows a reduced slope at higher injection rates and higher overall $\mathrm{SO}_{3}$ removal percentages.

The test data were extrapolated based on the logarithmic correlation of the data to determine what molar ratio would be projected to achieve 90\% sulfuric acid removal at the ESP B outlet, also illustrated in Figure 3-4. The extrapolation predicts that a $\mathrm{Mg}: \mathrm{SO}_{3}$ molar ratio of 6.7:1 would be required to achieve $90 \%$ sulfuric acid removal. This is nearly equal to the value of approximately 7:1 seen in the short-term test results with byproduct $\mathrm{Mg}$ injection.

This is seen as very good agreement between the two data sets, particularly considering there was reason to believe the short-term test results would over-predict the $\mathrm{Mg}: \mathrm{SO}_{3}$ requirement for the long-term test. The short-term tests were conducted on only half of the furnace, and there was evidence that some of the injected sorbent migrated to the other side of the furnace and did not contribute to sulfuric acid removal as measured at the ESP B outlet. The molar ratio requirements measured in the short-term tests may have been slightly overstated for this reason.

\section{Long-term Test Balance-of-plant Effects}

Balance-of-plant effects measured were primarily focused on the impacts of sorbent injection and $\mathrm{SO}_{3}$ /sulfuric acid removal on ESP performance during the long-term slurry injection tests. However, measurements were also made of halogen species and arsenic concentrations in the Unit 3 flue gas, both during baseline and sorbent injection conditions, and SCR catalyst coupons were exposed to the Unit 3 flue gas during sorbent injection and later analyzed for a number of parameters. The following is a summary of these results.

The amounts of sorbent injected and sulfuric acid removed were limited by ESP performance during the course of the long-term test. In general, at high sulfuric acid removal percentages the power to the ESP electrical fields decreased and ESP outlet opacity (as measured by in-duct transmissometers) increased, presumably due to increased fly ash resistivity resulting from the upstream sulfuric acid removal. However, the ESPs on Unit 3 are relatively small (with a design specific collection area [SCA] of $247 \mathrm{ft}^{2} / \mathrm{kacfm}$ ), which may have impacted their ability to maintain high particulate control efficiency during sorbent injection. Also, prior to the beginning 
of the test, electrical conditions in two of the four ESPs showed poor electrical conditions (reduced secondary current and voltage values). These conditions were apparently an adverse effect of dolomite injection testing conducted on Unit 3 just a week before the long-term byproduct Mg test (perhaps due to dolomite solids buildup on plates and wires). Otherwise, higher injection rates and higher sulfuric acid removal levels might have been possible.

No significant effect of sorbent injection was noted on Unit 3 air heater pressure drop or outlet flue gas temperatures, or on economizer outlet gas temperatures. No significant effect was noted on boiler slagging tendencies during the test period, either.

Flue gas particulate loading measurements by EPA Method 17 at the end of the test, when the overall sulfuric acid removal percentage was controlled at $70 \%$ or less, did not show a significant impact on ESP outlet mass loading. Similarly, measurements by applicable EPA reference methods did not detect any measurable removal of gas-phase $\mathrm{HCl}$ or $\mathrm{HF}$ from the ESP outlet flue gas. Removal of gas-phase arsenic from the economizer outlet gas also was not measured to increase during sorbent injection. However, the gas-phase arsenic measurement results appear to be contradicted by the SCR catalyst coupon results, as mentioned in the next paragraph.

Effects on SCR catalyst coupons were minimal, mostly ranging from neutral to slightly positive in nature. The most notable positive effect was a decrease in arsenic accumulation in the coupons from the long-term test compared to arsenic accumulation in baseline (no Mg injection) coupons. Arsenic is a known SCR catalyst poison, so reduced arsenic accumulation could be an indicator of positive effects of Mg injection on SCR catalyst life. This result suggests that vapor-phase arsenic was removed from the economizer outlet flue gas, although this removal was not detected by manual flue gas measurements as mentioned above.

One objective of sorbent injection to remove sulfuric acid is to reduce the opacity of the stack flue gas. Sulfuric acid in the flue gas condenses as a sub-micron-diameter acid mist at the inlet to wet scrubbers, and the acid mist is very efficient in scattering light, which causes elevated stack gas opacity. The stack gas opacity was not measured directly, as there was no one certified for EPA Method 9 (visual opacity) at the plant. However, qualitatively the stack gas opacity was greatly reduced throughout the long-term test period compared to baseline opacity.

In summary, the long-term test showed that byproduct Mg injection at the $14^{\text {th }}$ floor of the boiler could achieve 60 to $70 \%$ sulfuric acid removal, with reduced plume opacity and only minor impacts on ESP performance. Higher sulfuric acid removal levels might have been possible if two of the four ESPs had been in better electrical condition at the start of the test. No other significant balance-of-plant impacts were noted.

\section{Mg Reagent Slurry Injection Test at AEP's Gavin Unit 1}

A second long-term (23-day) test was conducted as part of this project, on the entire boiler at AEP's Gavin Plant Unit 1 (1300 MW), to assess the effectiveness of furnace injection of magnesium-based sorbents for flue gas $\mathrm{SO}_{3}$ control. The long-term test at Gavin Plant provided the opportunity to measure the effectiveness of sorbent injection at removing $\mathrm{SO}_{3}$ formed across 
an SCR catalyst as well as that formed in the furnace. Two different sorbents, byproduct $\mathrm{Mg}$ slurry and commercially available magnesium hydroxide (commercial $\mathrm{Mg}$ ) slurry were tested.

\section{Experimental}

The effects of sorbent injection were primarily evaluated by sampling with a modified CCS method to determine flue gas $\mathrm{SO}_{3}$ and sulfuric acid content during baseline and then injection conditions. These results are presented in this section.

Other impacts of sorbent injection were measured by a variety of techniques. EPA Reference Method 26a was used for determining $\mathrm{HCl}, \mathrm{HF}$, chlorine and fluorine concentrations in the ESP outlet flue gas. A modified version of EPA Method 108 was used to determine flue gas vaporphase and particulate arsenic concentrations at the economizer outlet. Impacts on ESP operation were quantified by taking voltage and current data on operating electrical sections of the Unit 1 ESP's, and by measuring ESP outlet flue gas particulate loading by a modified EPA Method 17. Sorbent and ESP hopper samples were analyzed for magnesium content. Some sorbent samples were also analyzed for calcium and sulfate content. Coal samples were collected and analyzed for a variety of parameters according to ASTM protocols. Finally, visual observations were made of boiler furnace and pendant superheater tube surfaces prior to and during sorbent injection, to observe any trends related to slag formation, and a few slag samples were collected and analyzed. These results are discussed only as an overview in this final report. Details of these results are included in a previous Topical Report for this project ${ }^{1}$.

Gavin Station Unit 1 is rated at 1300 net MW. It has an opposed-wall-fired boiler that typically burns 3.5 to $4 \%$ sulfur coal. The unit generally operates as a base-loaded unit, operating at reduced load only during overnight hours in response to reduced load demands from the grid. During most of the long-term test, Unit 1 operated at 1320 to $1390 \mathrm{MW}$ gross load from 8:00 a.m. until midnight, but at reduced loads of 1000 to 1200 gross MW overnight.

Figure 3-5 illustrates the flue gas path for Unit 1, and notes the gas sampling locations used during this test. Flue gas from the economizer splits into three gas paths. Each gas path goes to an SCR reactor. Ammonia is fed to each of the three SCR reactors from an Ammonia-OnDemand system to achieve $90 \% \mathrm{NO}_{\mathrm{X}}$ reduction. Also, about $1 \%$ of the flue gas $\mathrm{SO}_{2}$ is further oxidized to $\mathrm{SO}_{3}$ across the catalyst layers in each reactor. From the SCR reactors, the flue gas flows to three air heaters. The average flue gas temperature at the outlet of the air heaters is controlled to about 350 to $360^{\circ} \mathrm{F}\left(177\right.$ to $\left.182^{\circ} \mathrm{C}\right)$ due to acid dew point considerations. The outlet gas from each of the three air heaters then goes to either an upper or lower ESP (one of six ESPs total) followed by ID fans. Downstream of the ID fans, the flue gas flows through up to six countercurrent FGD spray/tray absorber modules (five normally operate at full load). The FGD system uses a magnesium-enhanced, Thiosorbic ${ }^{\circledR}$ lime slurry reagent and operates in natural oxidation mode to produce a calcium sulfite hemihydrate byproduct. The flue gas then goes to a dedicated stack for Unit 1 . The flue gas in the stack is saturated at a temperature of about $130^{\circ} \mathrm{F}$ $\left(54^{\circ} \mathrm{C}\right)$; no reheat is employed. 


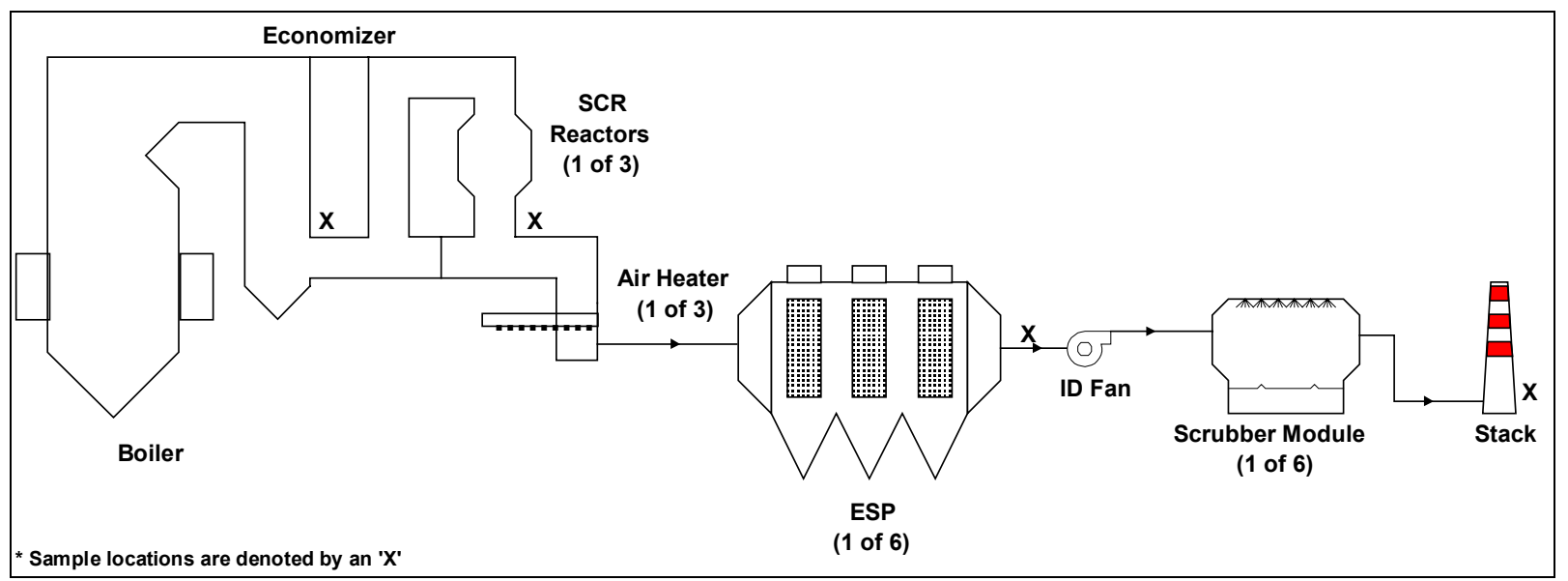

Figure 3-5. Illustration of Flue Gas Path for Gavin Unit 1

During these tests, injection of sorbent slurries was accomplished through air-atomizing nozzles inserted through inspection port openings and/or through ports installed in man doors on the front wall and front corners of the boiler. During most of the testing, the injection location was at the $17^{\text {th }}$ floor of the boiler structure, across from the top of the pendant superheat tubes. For a portion of the test, $40 \%$ of the total slurry flow was fed lower in the furnace, just above the nose of the boiler at the $13^{\text {th }}$ floor of the boiler structure. The remaining $60 \%$ was injected through the nozzles at the $17^{\text {th }}$ floor. The injection levels are illustrated in Figure 3-6.

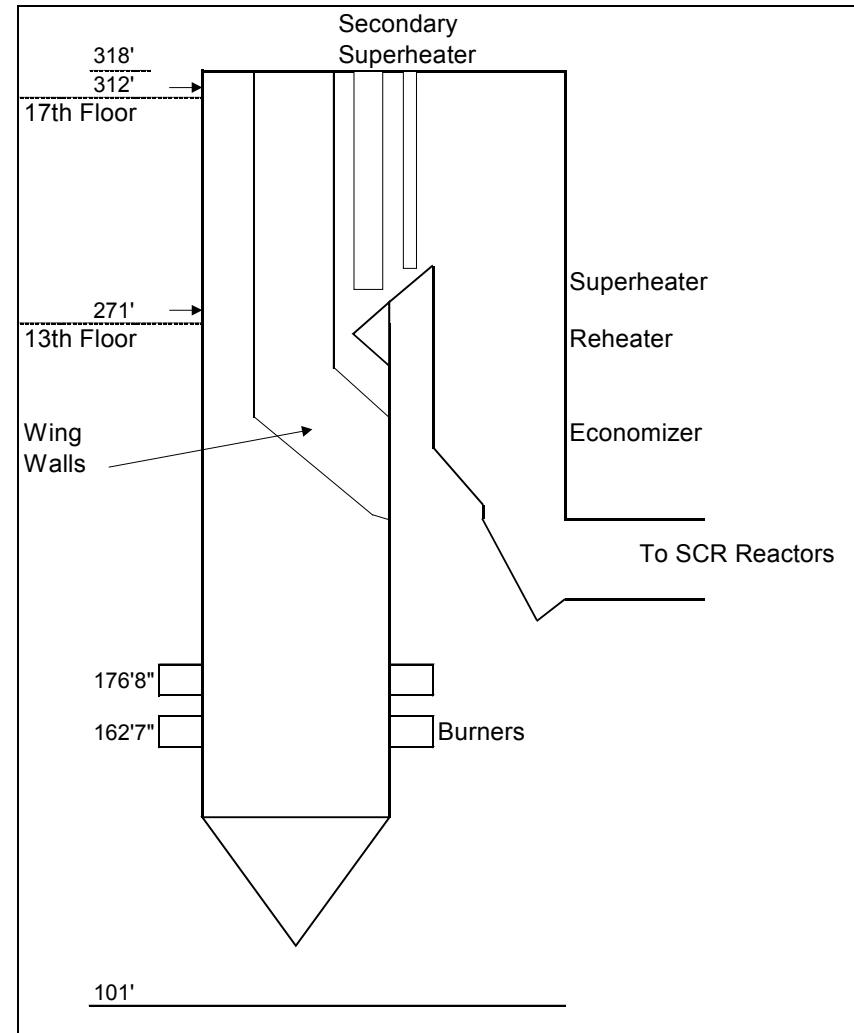

Figure 3-6. Illustration of Slurry Injection Levels for Gavin Unit 1 Note: $1 \mathrm{ft}=0.305 \mathrm{~m}$. 
At the $17^{\text {th }}$ floor, there are eight man doors spaced almost evenly across the front face of the boiler. There is also a man door on each side wall at this level, near the corners where the side walls intersect with the front wall. The plant installed 4-inch $(10-\mathrm{cm})$ pipe in each of these ten man doors, angled downward at 45 degrees, to serve as ports for slurry injection into the furnace. Figure 3-7 illustrates these ten lance locations.

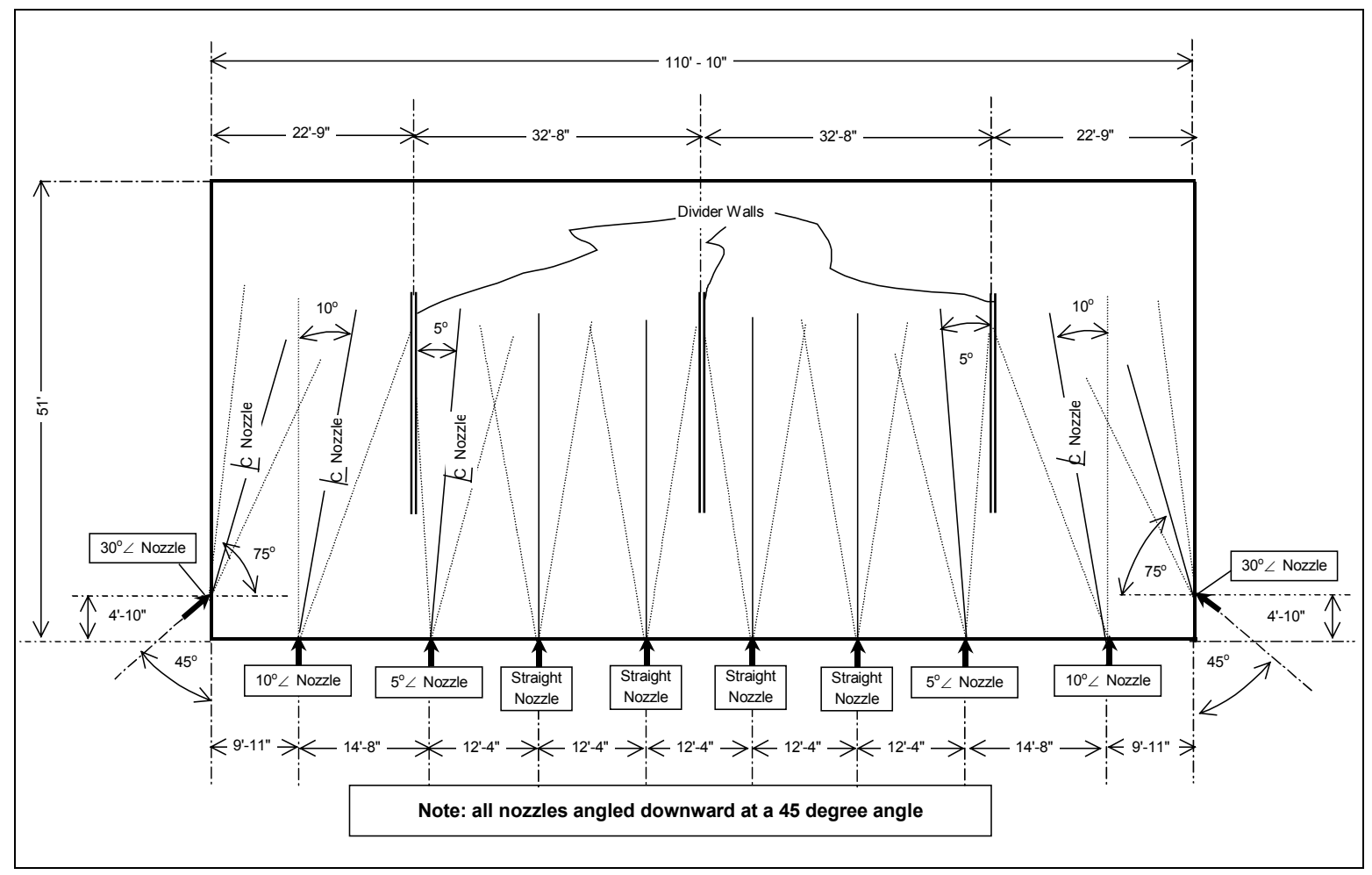

Figure 3-7. Plan View Illustration of Slurry Injection Nozzle Locations at the $17^{\text {th }}$ Floor of Gavin Unit 1

The plant was interested in testing slurry injection lower in the furnace, where the furnace gas temperatures might be high enough that ash slagging properties could be modified by magnesium addition. The boiler has a series of five inspection ports along the front wall at the $13^{\text {th }}$ floor, just above the nose of the boiler. There are also inspection ports on each of the side walls at the $13^{\text {th }}$ floor, very near the corners where the side walls intersect with the front wall. This provided locations for up to seven nozzle lances at the $13^{\text {th }}$ floor level. However, it was expected that the seven nozzle lance locations would not be adequate to inject the entire slurry flow (up to $165 \mathrm{gpm}$ [625 1/min]) using nozzles small enough to achieve fine atomization, and to provide good slurry coverage across the furnace cross section. The latter is exacerbated by the fact that the Unit 1 furnace is 110 feet wide and 51 feet deep $(33.5$ by $15.5 \mathrm{~m})$, and by the fact that the inspection ports on the front wall at the $13^{\text {th }}$ floor are not equally spaced. The ports range from 24 feet to 33.7 feet $(7.3 \mathrm{~m}$ to $10.3 \mathrm{~m}$ ) apart. For this reason, it was decided to test with only a portion of the slurry (40\%) added at the lower level. Figure 3-8 illustrates the nozzle lance locations at the $13^{\text {th }}$ floor level. 


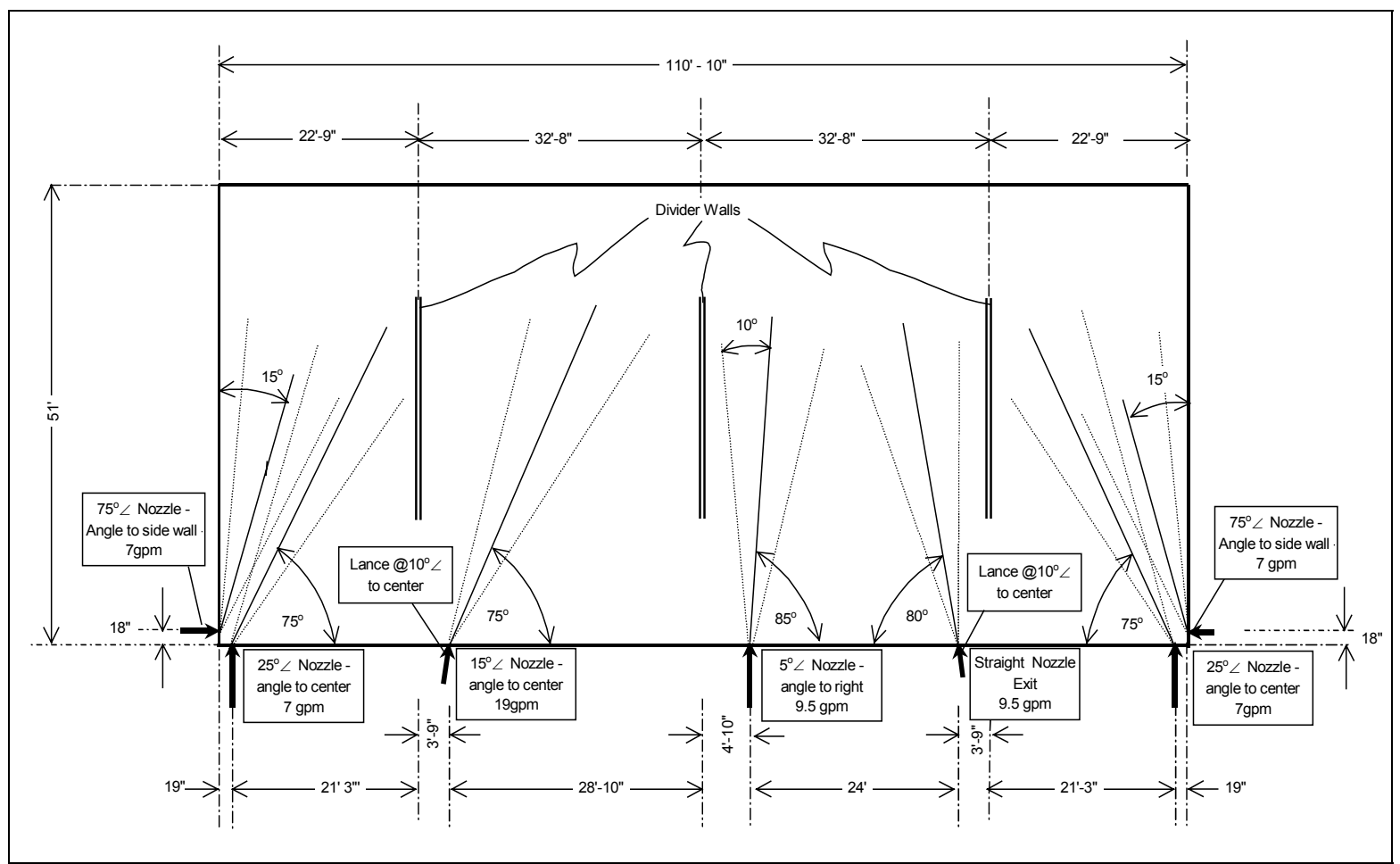

Figure 3-8. Plan View Illustration of Slurry Injection Nozzle Locations at the $13^{\text {th }}$ Floor of Gavin Unit 1

Note: $1 \mathrm{gpm}=3.8 \mathrm{l} / \mathrm{min}, 1 \mathrm{ft}=0.305 \mathrm{~m}$.

The air-atomizing nozzles were designed by Ashworth Engineering with nozzle angles selected specifically for this boiler geometry. The proprietary nozzle design employs an internal mix configuration, and was designed for relatively low airflow requirements and to achieve a relatively large minimum passage diameter. The air pressure to the nozzles was typically $80 \mathrm{psig}$ $(550 \mathrm{kPa})$, although under some conditions lower air pressures were encountered.

The slurry handling and injection system used for the long-term test at BMP was too small for the testing at Gavin, because of the larger unit size (1300 vs. 800 net MW) and because the $\mathrm{SO}_{3}$ concentrations were higher at Gavin downstream of the SCR system. A temporary slurry injection system was set up at the plant and operated by MPW Industrial Services. The byproduct $\mathrm{Mg}$ sorbent was delivered to the site by truck as a slurry containing 15 to $20 \mathrm{wt} \%$ solids. A onemillion-gallon $\left(3800-\mathrm{m}^{3}\right)$ chemical cleaning storage tank at the station was used to store byproduct Mg slurry. A relatively large storage tank was required to allow building an inventory at the site, because the planned injection rates were greater than the rate byproduct slurry could be produced at Allegheny Energy's Pleasants Power Station. The large storage tank did not have agitators, but a centrifugal pump was used to provide a small amount of recirculation of the slurry in the tank.

From the storage tank, a gasoline-engine-powered centrifugal pump was used to intermittently fill two 21,000-gallon $\left(80-\mathrm{m}^{3}\right)$ "day" tanks located on the ground outside of the Unit 1 boiler house. The two tanks were hydraulically connected to serve as one 42,000 -gallon $\left(160-\mathrm{m}^{3}\right)$ tank. A temporary run of PVC pipe connected the engine-driven pump with the two day tanks. The 
day tanks also did not have agitators. Day tank level was controlled by MPW personnel, who manually started and stopped the engine-driven pump as needed to maintain level.

From the day tanks, one or both of two eight-inch $(20-\mathrm{cm})$, diesel-engine-driven Moyno progressing cavity pumps were used to feed slurry to the injection nozzles. A turbine flow meter was installed on the Moyno pumps' common discharge header, and the diesel engine speed was modulated to control slurry flow rate. The slurry flow rate was adjusted by the MPW operator to achieve a desired value calculated from the density and purity of the reagent, the Unit 1 load, the expected Unit 1 coal sulfur content, and the desired reagent-to- $\mathrm{SO}_{3}$ molar ratio. Slurry from the Moyno pumps was fed through 3-inch flexible hose up to the $17^{\text {th }}$ floor to a manifold, which in turn distributed slurry to the ten lances and injection nozzles. When also injecting at the $13^{\text {th }}$ floor, a portion of the flow was split off at the $13^{\text {th }}$ floor through a second turbine meter and manifold, to the seven lances and nozzles at that level.

For the commercial Mg testing, magnesium hydroxide slurry was delivered to the site by truck by the Dow Chemical Company as $58-$ to $60-\mathrm{wt} \%$ slurry. This slurry was stored at the site in three additional 21,000 -gallon $\left(80-\mathrm{m}^{3}\right)$ storage tanks. These tanks did not normally require agitation, because the 58 -wt $\%$ slurry settles very slowly. During the commercial $\mathrm{Mg}$ test period, the $58-\mathrm{wt} \%$ slurry was pumped from the storage tanks to one of the 21,000 -gallon $\left(80-\mathrm{m}^{3}\right)$ day tanks, where it was diluted with plant water to a lower solids content. From this tank, the diluted slurry was pumped to the lances and nozzles as described above. Also, as mentioned above, the 21,000 -gallon $\left(80-\mathrm{m}^{3}\right)$ day tanks did not have agitators. A recirculation pump was used in an effort to keep the solids in the diluted slurry suspended. However, the recirculation rate did not prove to be adequate to keep the solids in the diluted slurry suspended, so the commercial $\mathrm{Mg}$ tests were plagued with varying solids content in the injected slurry.

The plant compressed air system did not have sufficient capacity to provide atomizing air to all 17 nozzles. The plant installed four electric-motor-driven compressors to supply air for the duration of this test. These compressors fed air through flexible hoses to a receiver tank on the $16^{\text {th }}$ floor of the boiler. The receiver tank was connected to each lance individually with flexible plant air hoses to provide atomizing air.

\section{Results and Discussion}

\section{Unit 1 Operating Conditions}

The long-term test was conducted on Unit 1 over the time period August 16 through September 7, 2001. Baseline (no sorbent injection) measurements for sulfuric acid concentration were conducted using a modified CCS method several days prior to the beginning of sorbent injection, from August 14 through 16. During the sorbent injection period, modified CCS runs were made on a six-day-per-week basis to assess sulfuric acid removal performance with the byproduct $\mathrm{Mg}$ and commercial $\mathrm{Mg}$ reagents. Typically, no CCS measurements were made on Sundays, although sorbent injection continued 24-hours per day, seven days a week, with few interruptions. 
Additional measurements were made late in the injection period, including modified Method 17 for ESP outlet mass loading, Method 26a for halogen concentrations, and modified Method 108 for arsenic concentrations. Baseline measurements were also made using these methods on September 8, after sorbent injection ended.

Unit 1 load and sorbent injection rates during the long-term test period are summarized in Figure 3-9. During most flue gas testing, from about 9:00 a.m. through 6:00 p.m. Mondays through Saturdays, the steam generator was generally at close to full load, at 1320 to 1390 gross MW. Unit loads often dropped into the range of 1000 to 1200 gross MW between midnight and 8:00 a.m., but the unit was typically at full load for at least an hour before flue gas sampling began.

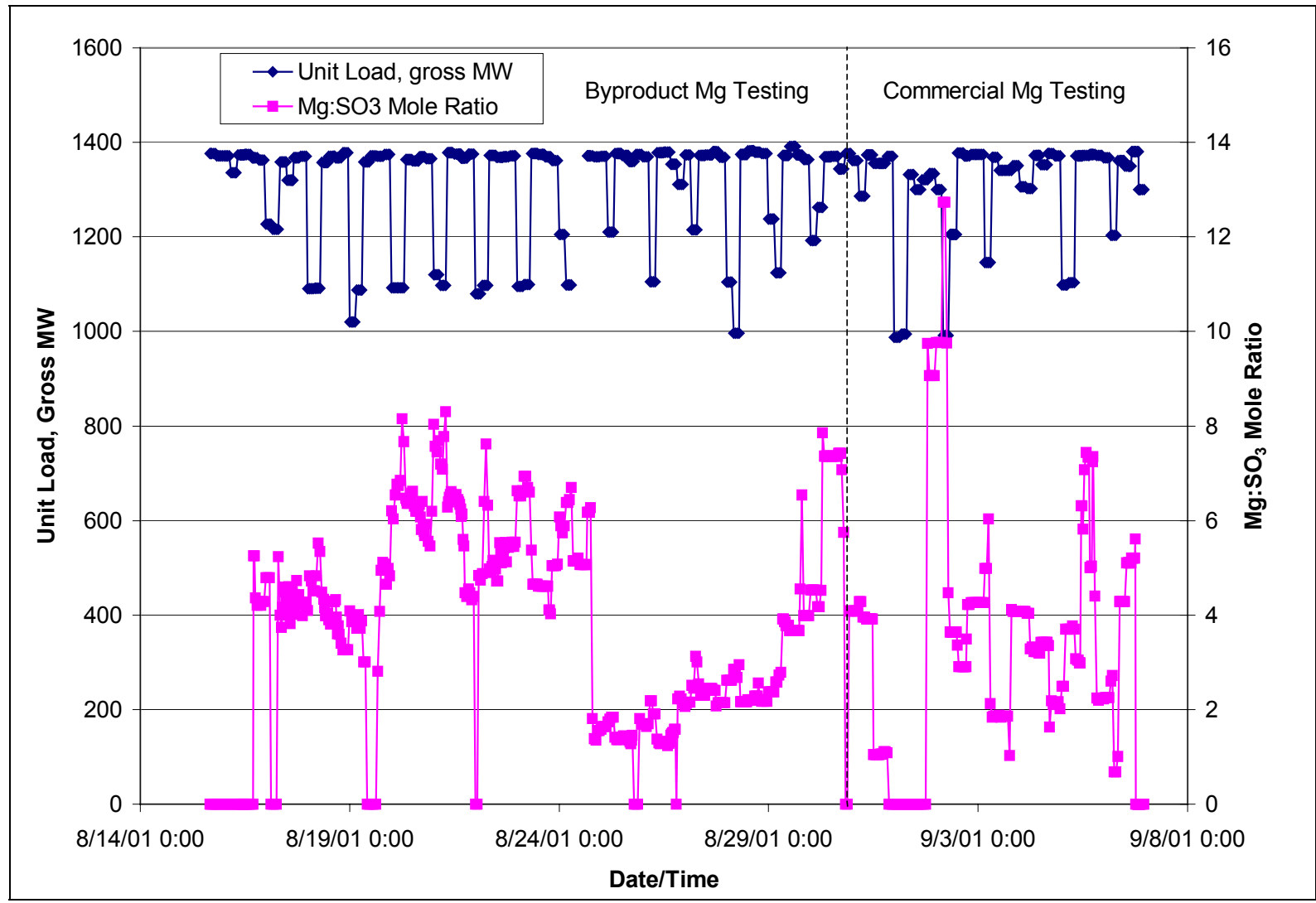

Figure 3-9. Gavin Unit 1 Operating Conditions during Long-term Sorbent Injection Testing

\section{Baseline Test Results}

The baseline $\mathrm{SO}_{3}$ /sulfuric acid concentration values from August 14 were about $10 \%$ to $30 \%$ lower than the values measured on August 15 and 16. This may be because the plant was switching from a lower sulfur coal being fired as an interim measure to control plume "touch downs" after the SCR retrofit, to the normal high-sulfur coal for the sorbent injection tests. The measurements on August 14 may have reflected a small percentage of the lower sulfur coal remaining in the fuel burned. For this reason, only the measurements from August 15 and 16 were used to calculate baseline (no sorbent injection) $\mathrm{SO}_{3}$ concentration averages. These average values show 37 ppmv of $\mathrm{SO}_{3}$ at the economizer outlet, $65 \mathrm{ppmv}$ at the SCR outlet (a 28-ppmv 
increase because of $\mathrm{SO}_{2}$ to $\mathrm{SO}_{3}$ oxidation across the SCR catalyst), $54 \mathrm{ppmv}$ at the ESP outlet, and 48 ppmv at the stack.

Throughout this section, $\mathrm{SO}_{3}$ removal during sorbent injection is reported as the percent reduction in $\mathrm{SO}_{3}$ concentration at a given location, for injection versus baseline conditions. The preceding values were used in those calculations.

The SCR outlet $\mathrm{SO}_{3}$ concentration data were used to calculate an average $\mathrm{SO}_{2}$ to $\mathrm{SO}_{3}$ conversion percentage for Unit 1, to serve as a basis for calculating and reporting sorbent-to- $\mathrm{SO}_{3}$ molar ratios. Daily coal proximate analysis results for the baseline test period were used in combustion calculations to calculate the total amount of $\mathrm{SO}_{2}$ that would be produced from the combustion of these coals, then that value was compared to the measured economizer/SCR outlet $\mathrm{SO}_{3}$ concentrations. The economizer outlet and SCR outlet concentrations correspond to approximately $1.3 \%$ conversion of $\mathrm{SO}_{2}$ to $\mathrm{SO}_{3}$ in the furnace, and an additional $1.0 \%$ conversion of $\mathrm{SO}_{2}$ to $\mathrm{SO}_{3}$ across the $\mathrm{SCR}$ catalyst.

Downstream measurements indicated that the sulfuric acid removal across the air heater and ESP was only about 17\% (11 ppmv removed) and the removal across the FGD system was about $11 \%$ ( 6 ppmv removed). Both of these apparent removal percentages are relatively low compared to what has been measured at other bituminous coal plants. ${ }^{2}$

The relatively low sulfuric acid removal percentage across the air heater and ESP is likely a result of two effects. One is the high air heater exit temperature (about $360^{\circ} \mathrm{F}\left[182^{\circ} \mathrm{C}\right]$ ), which was raised specifically to reduce the dropout of sulfuric acid on air heater baskets. The other is the high overall sulfuric acid concentration. Sulfuric acid is known to adsorb on fly ash particles and be collected in the ESP; this is the basis for sulfuric acid conditioning of fly ash resistivity. However, the quantity of sulfuric acid that can removed by this mechanism may be limited, and is thought to be primarily a function of the surface area of fly ash in the flue gas and the flue gas temperature. A high concentration of sulfuric acid in the flue gas and an elevated air heater exit temperature, which would tend to reduce fly ash adsorption capacity, would limit the percentage of the flue gas sulfuric acid that can be removed by this mechanism, as was observed.

The relatively low sulfuric acid removal percentage across the FGD system is thought to be a result of the high inlet concentration and the low liquid-to-gas ratio (21 gal/ACF $\left.\left[2.81 / \mathrm{m}^{3}\right]\right)$ in the magnesium-enhanced lime absorber.

\section{Long-term Test $\mathrm{SO}_{3}$ Removal Results}

The long-term slurry injection test at Gavin Unit 1 was conducted over the time period August 16 through September 7, 2001. Byproduct magnesium hydroxide produced at Allegheny Energy's Pleasants Power Station was tested through the evening of August 30, and a commercially available magnesium hydroxide produced by the Dow Chemical Company was tested from August 31 through September 7.

As described earlier, the Pleasants Power Station has a modified Dravo Thiosorbic ${ }^{\circledR}$ Lime FGD process that employs magnesium-enhanced scrubbing, with external forced oxidation to produce 
a gypsum byproduct. The liquor remaining after the gypsum is produced is further processed by lime addition to precipitate a mixture of magnesium hydroxide and gypsum particles. With the current equipment configuration at Pleasants Station, this byproduct slurry is produced at about 15 to $20 \mathrm{wt} \%$ total suspended solids.

The commercial $\mathrm{Mg}$ is produced by Dow at a plant in Leddington, Michigan, and shipped as a 58 $\mathrm{wt} \%$ slurry. Although the byproduct Mg was the reagent of choice for the long-term test at BMP, the commercial $\mathrm{Mg}$ was tested at Gavin Plant for two reasons. One was that the commercial Mg was never tested at the more favorable $14^{\text {th }}$ floor injection location at BMP, and it remained uncertain how the performance of the commercial $\mathrm{Mg}$ would compare to that of the byproduct $\mathrm{Mg}$ if it were similarly injected higher in the furnace. The second reason is that the Gavin Plant was looking for a near-term approach for lowering their stack gas sulfuric acid mist concentrations, and it was uncertain whether a sufficient quantity of byproduct $\mathrm{Mg}$ would be available to treat two units at Gavin (2600 MW of net generating capacity). The commercial Mg, if proven effective, could provide a second source of reagent for furnace injection.

The objectives of the long-term tests were to evaluate the ability to control sulfuric acid emissions, as measured at the ESP outlet, over an extended period of time, and to evaluate balance-of-plant effects from sorbent injection. The sulfuric acid removal performance was measured almost daily throughout the long-term test period, using a modified CCS sampling method.

The results from sorbent injection testing at Gavin Plant are more complicated to interpret than the previous BMP results because at Gavin, $\mathrm{SO}_{3}$ was produced both in the furnace and in the downstream SCR reactor. Also, because this was the first sorbent injection test conducted under operating SCR conditions, a range of $\mathrm{Mg}: \mathrm{SO}_{3}$ ratios had to be tested to evaluate each of the two sorbents. The plant's desire to test injection at the $17^{\text {th }}$ floor level versus injection split between the $13^{\text {th }}$ and $17^{\text {th }}$ floor added another variable to be evaluated. Consequently, the long-term test became a factorial evaluation of three variables $\left(\mathrm{Mg}: \mathrm{SO}_{3}\right.$ ratio, reagent, and injection level), although with continuous injection over 23 days to evaluate balance-of-plant effects.

The organization conducting the modified CCS measurements for $\mathrm{SO}_{3}$ /sulfuric acid concentration measurements, E.ON Engineering, had enough staff on site to allow simultaneous sampling of only three of the four locations of interest (economizer outlet, SCR outlet, ESP outlet, and stack). The plant was most interested in tracking the economizer outlet and SCR outlet locations, and wanted these two locations to be sampled during each measurement effort. Thus, the third of the simultaneous measurement locations was split about $50 \%$ each between the ESP outlet and stack locations. This represents a limitation on the usefulness of the CCS data. Because the furnace injected sorbent continues to react with flue gas $\mathrm{SO}_{3} /$ sulfuric acid downstream of the SCR outlet, the ESP outlet concentrations represent the best measure of sorbent effectiveness, but these concentrations are only available for half of the measurements. Although stack concentrations are available for the other half of the measurements, the concentration data from the two locations cannot be combined to evaluate variable effects, because of variability in the sulfuric acid removal observed across the FGD system. 
Throughout this discussion, the $\mathrm{Mg}: \mathrm{SO}_{3}$ molar ratios presented are based on the measured amount of magnesium hydroxide in the byproduct or commercial $\mathrm{Mg}$ slurry injected, the slurry feed rate, the Unit 1 coal feed rate, sulfur content analyses of coal samples for this time period, and a factor of $2.3 \%$ overall conversion of coal sulfur to $\mathrm{SO}_{3}$ at the SCR outlet location. This factor was derived from the baseline $\mathrm{SO}_{3}$ concentration data as described above, and is the sum of the observed conversion in the furnace $(1.3 \%)$ and SCR reactors $(1.0 \%)$. Note that this basis is different than in the previously reported BMP results, where the $\mathrm{Mg}: \mathrm{SO}_{3}$ molar ratios are based only on the $\mathrm{SO}_{3}$ conversion in the furnace.

The amount of magnesium hydroxide in the slurry feed was determined by analyzing samples of the injected slurry (typically two per day) for wt $\%$ solids content, density, magnesium content in the solids, and total alkalinity in the slurry. The coal sulfur data were based on daily composite sample analyses conducted by AEP's coal laboratory. The daily coal analyses showed that the sulfur content varied significantly over the course of the long-term test, with individual samples ranging from 2.1 to $4.4 \mathrm{wt} \%$ sulfur.

The reagent slurry feed rate was based on the MPW turbine meter installed at the Moyno pump outlet and logged on an hourly basis by MPW personnel. The flow meter readings were divided by a correction factor of 1.1 based on flow meter calibrations conducted at the beginning of the test period. Finally, coal feed rate data were recorded by Gavin Plant control room operators from plant instrumentation.

There are some limitations in the accuracy of these values. The biggest source of error is most likely the magnesium hydroxide content values for the commercial Mg slurries. As described earlier, the commercial $\mathrm{Mg}$ was diluted from $58 \mathrm{wt} \%$ in the day tanks, which did not have agitators. Unlike the 58 -wt $\%$ slurry, once diluted the commercial $\mathrm{Mg}$ slurry solids tended to settle rapidly in the tanks. The Moyno pump suction lines pulled from the bottom of the tank, where the solids in a freshly mixed tank rapidly settled. Thus, when starting on a fresh tank, the $\mathrm{wt} \%$ solids level tended to be higher than the target value, and as the inventory in the tank became depleted, the wt\% solids level tended to be lower than the target value. This variation was not adequately captured in just two slurry samples per day, as the tanks were filled and emptied several times a day. Thus, the $\mathrm{Mg}: \mathrm{SO}_{3}$ values for the commercial $\mathrm{Mg}$ tests are of questionable accuracy.

Another significant data quality issue is just how representative $\mathrm{SO}_{3}$ /sulfuric acid concentration data taken at a single measurement point with 2-meter or 3-meter-length probes are of the total flue gas flow in a plant of this size. For example, the stack internal diameter is 42 feet $(12.8 \mathrm{~m})$, so most of the stack cross-section could not be sampled.

Selected results are plotted in Figures 3-10 through 3-14. As mentioned earlier, it is more difficult to portray the sorbent injection results from Gavin Plant because of the $\mathrm{SO}_{2}$ to $\mathrm{SO}_{3}$ conversion that occurs across the SCR reactors. In these figures, $\mathrm{SO}_{3}$ removal percentages have been plotted as measured at two locations, the economizer outlet and the ESP outlet.

Figure 3-10 shows the economizer outlet data for the byproduct $\mathrm{Mg}$ test period. Data are plotted for injection at the $17^{\text {th }}$ floor location only, and for injection split between the $13^{\text {th }}$ and $17^{\text {th }}$ floor. 


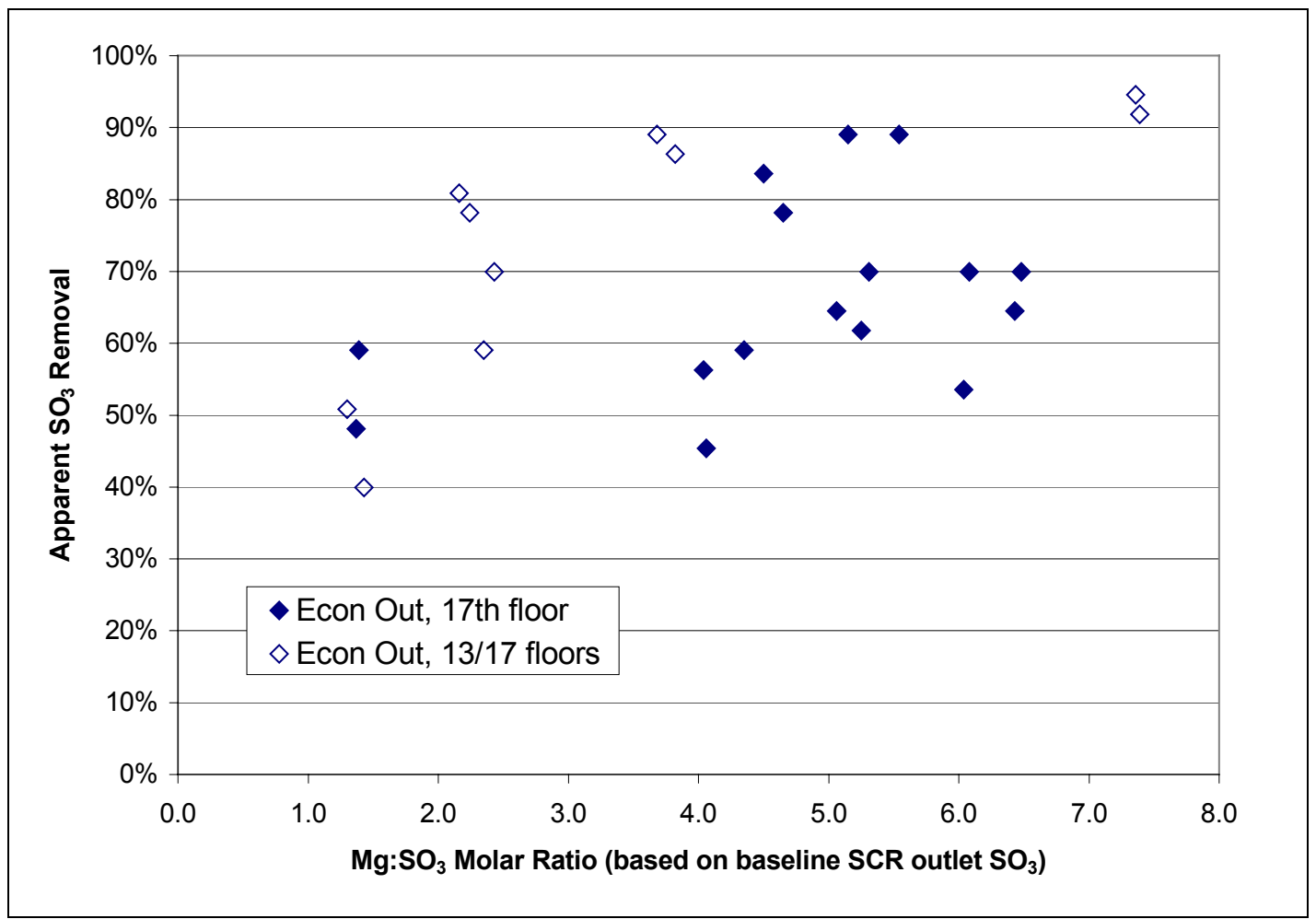

Figure 3-10. Results from the Gavin Unit 1 Byproduct Mg Injection Test Period $\left(\mathrm{SO}_{3}\right.$ removals based on economizer outlet concentrations)

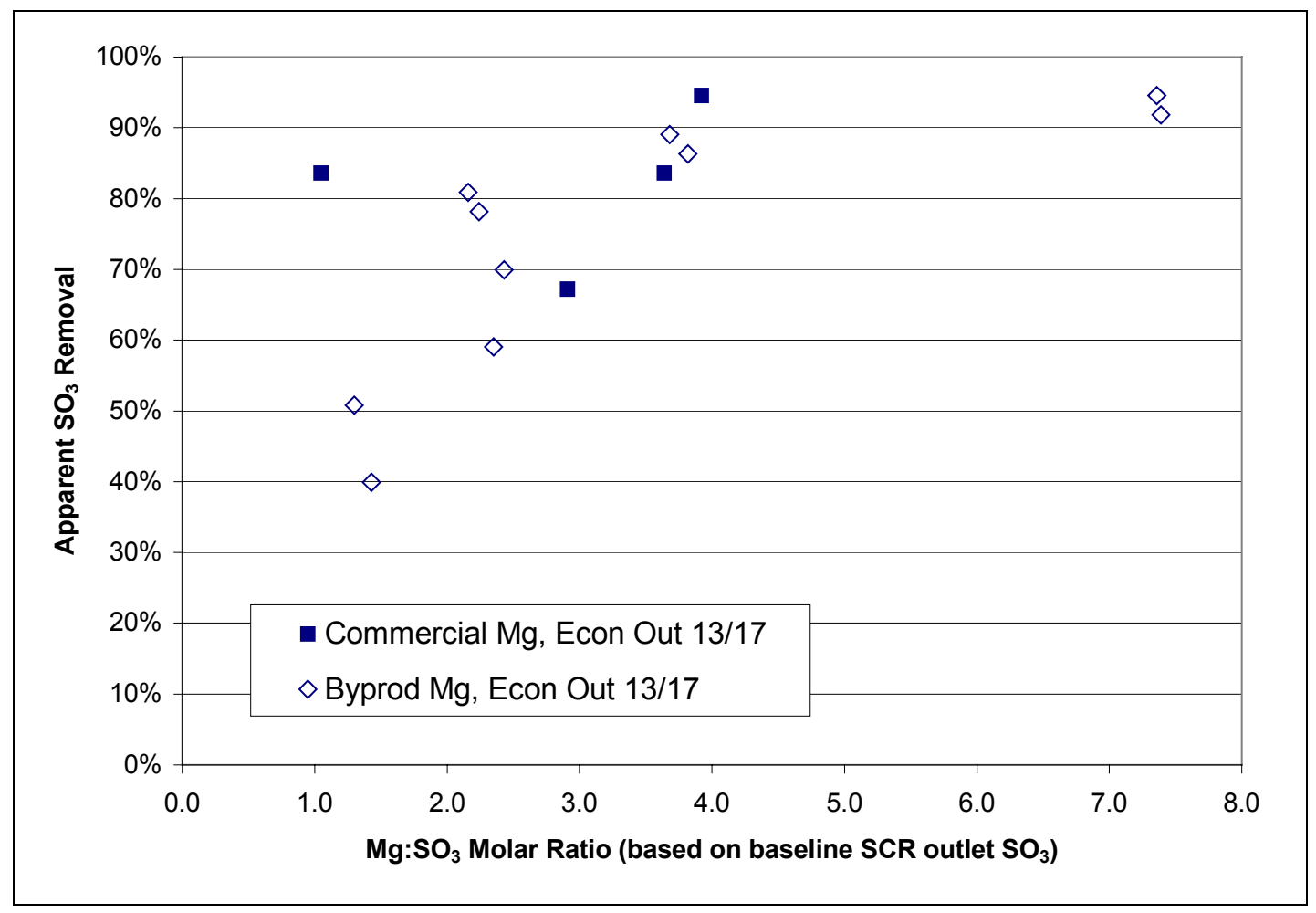

Figure 3-11. Comparison of Byproduct Mg and Commercial Mg Sorbent Performance for Gavin Unit 1 ( $\mathrm{SO}_{3}$ removals based on economizer outlet concentrations) 


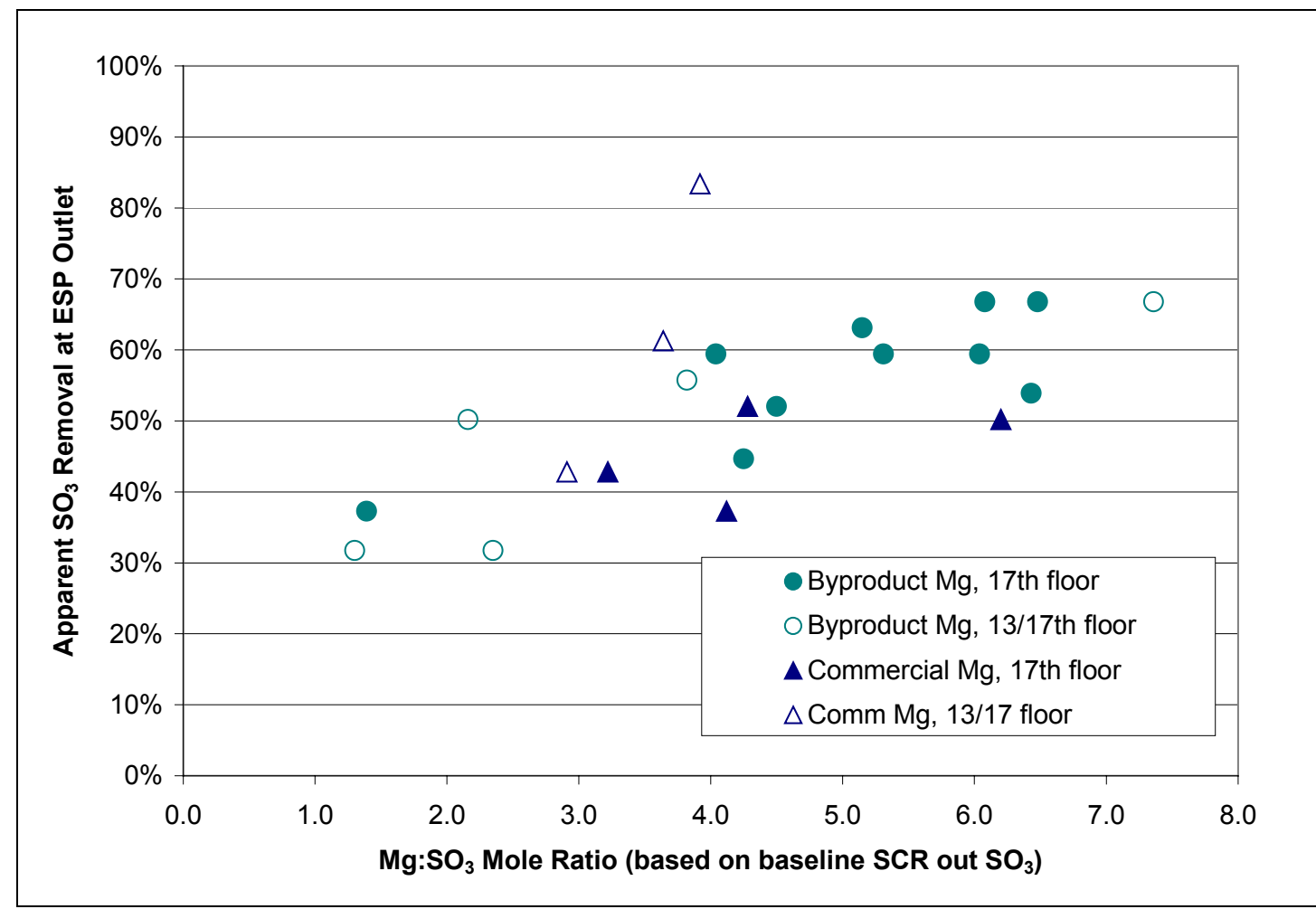

Figure 3-12. Results from the Gavin Unit 1 Commercial Mg Injection Test Period Compared to Byproduct Mg Injection Results ( $\mathrm{SO}_{3}$ removals based on ESP outlet concentrations)

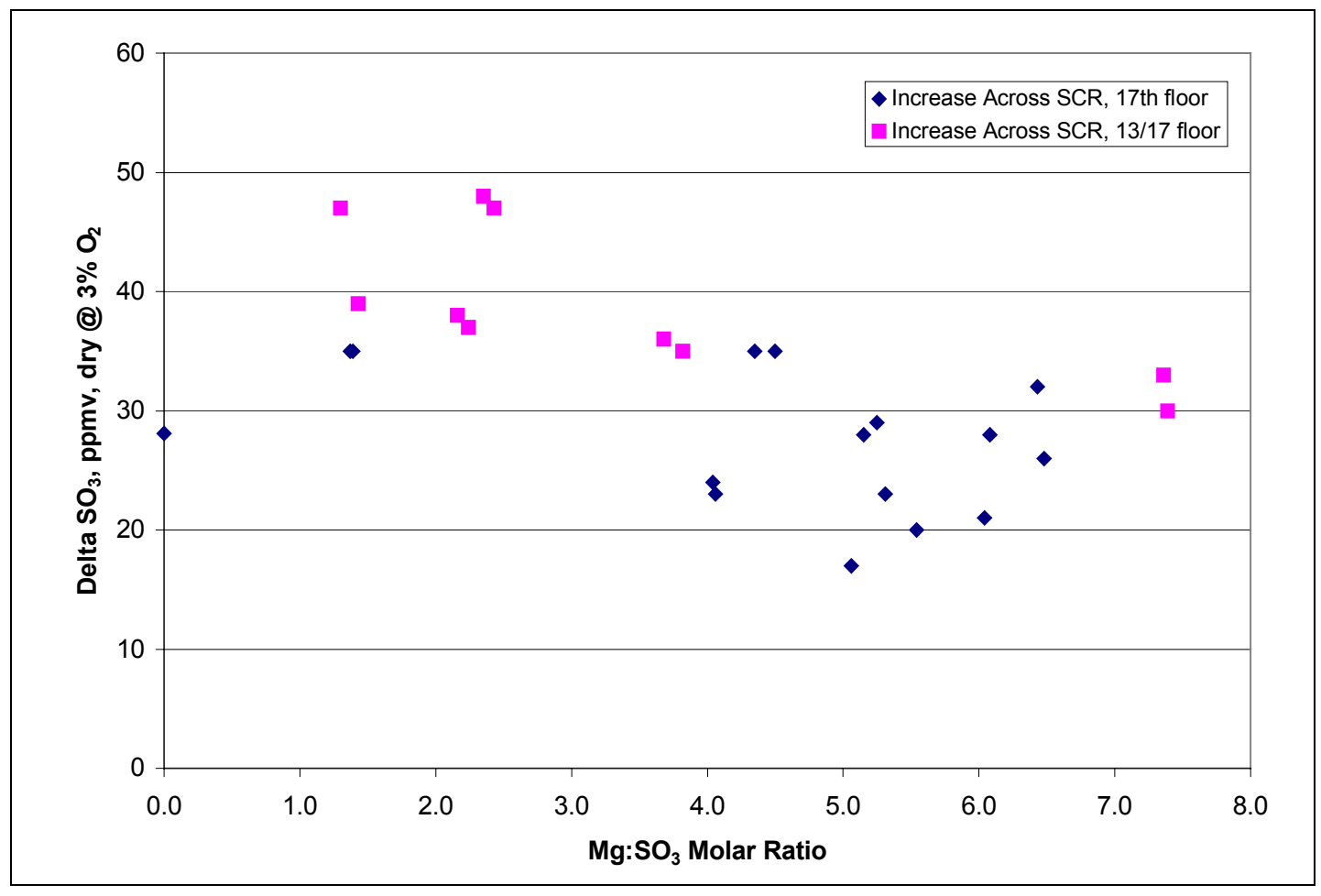

Figure 3-13. $\mathrm{SO}_{3}$ Concentration Changes across the Gavin Unit 1 SCR Reactors (byproduct Mg injection) 


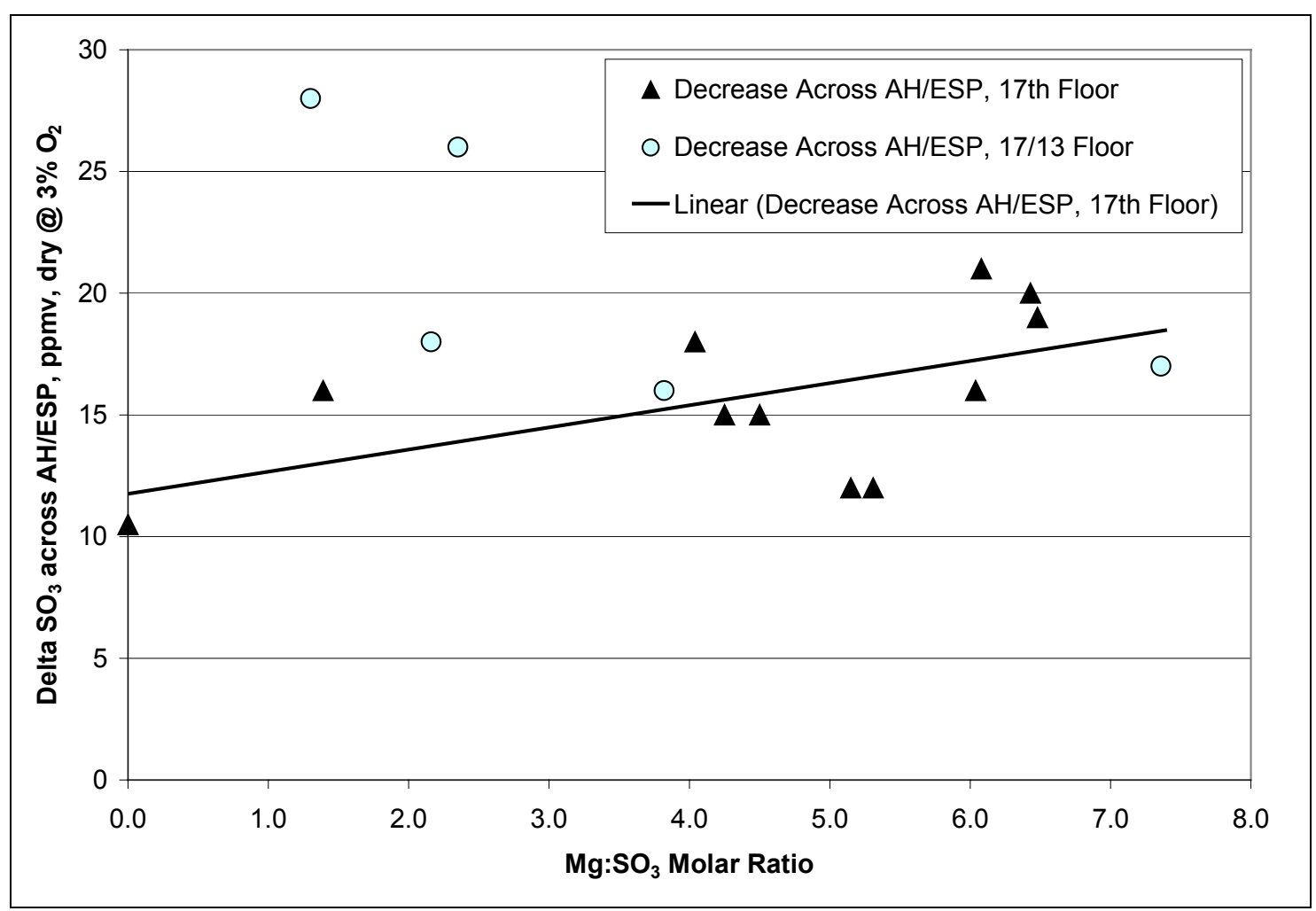

Figure 3-14. $\mathrm{SO}_{3}$ Concentration Changes across the Gavin Unit 1 Air Heaters and ESPs (byproduct Mg injection)

The removal of $\mathrm{SO}_{3}$ formed in the furnace appears to be more effective when injecting at two levels than when injecting all of the slurry at the $17^{\text {th }}$ floor. It is not clear whether this is a furnace gas residence time effect, a slurry droplet spatial distribution effect, or a droplet size effect (finer atomization with more nozzles in service and higher air/slurry mass ratios at each nozzle). Much of the data for the $17^{\text {th }}$ floor injection are from early in the test period, during any initial boiler "conditioning" and during a period where the slurry distribution into the furnace was being optimized. Initially, too much $\mathrm{SO}_{3}$ removal was occurring in the center gas path from the furnace and less from the outer gas paths.

Even taking the best performance for injection at the $17^{\text {th }}$ floor only, it appears that $90 \%$ removal of the $\mathrm{SO}_{3}$ formed in the furnace was removed at a $\mathrm{Mg}: \mathrm{SO}_{3}$ mole ratio of about $5: 1$, whereas with injection at both levels only $3.5: 1$ to $4: 1$ was required. Remember that these mole ratios are based on $\mathrm{SO}_{3}$ concentrations measured at the SCR outlet. To put these mole ratios on a furnace basis only, as were the BMP results, they should be multiplied by 1.77 . When put on the basis of furnace-formed $\mathrm{SO}_{3}$ only, the better of the Gavin results show a $\mathrm{Mg}: \mathrm{SO}_{3}$ mole ratio of approximately $6.2: 1$ to $7.1: 1$ being required to achieve $90 \%$ removal. This result agrees very well with the BMP Unit 3 results presented earlier in this section.

Figure 3-11 compares the results for the byproduct $\mathrm{Mg}$ and commercial $\mathrm{Mg}$ for injection split between the $13^{\text {th }}$ and $17^{\text {th }}$ floor levels, again as measured at the economizer outlet. Ignoring outlier data points (most likely caused by unrepresentative $\mathrm{wt} \%$ solids levels in commercial $\mathrm{Mg}$ slurry samples analyzed), it appears that with the commercial $\mathrm{Mg}$ sorbent, $90 \%$ removal of 
furnace-formed $\mathrm{SO}_{3}$ can be achieved at a $\mathrm{Mg}: \mathrm{SO}_{3}$ molar ratio of about 3.5:1 to 4:1 when injecting on both the $13^{\text {th }}$ and $17^{\text {th }}$ floors. This is equal to the performance with byproduct $\mathrm{Mg}$.

Figure 3-12 shows sulfuric acid removal percentages measured at the ESP outlet location for both the byproduct $\mathrm{Mg}$ and commercial $\mathrm{Mg}$ test periods, for injection at the $17^{\text {th }}$ floor versus injection at both floors. When measured at the ESP outlet, which takes into account the $\mathrm{SO}_{3}$ produced across the SCR reactors, additional residence time for sorbent reactions, and $\mathrm{SO}_{3} /$ sulfuric acid removed across the air heater and ESP, there was little difference in performance between the two sorbents or the two injection location modes. Discounting a few data points that are apparently outliers, both sets of data show about $60 \%$ overall $\mathrm{SO}_{3} /$ sulfuric acid removal at a $\mathrm{Mg}: \mathrm{SO}_{3}$ ratio of 5:1, with overall removal percentages between $65 \%$ and $70 \%$ possible at higher ratios. These highest removal percentages correspond with ESP outlet sulfuric acid concentrations of approximately 18 to $22 \mathrm{ppmv}$.

The percent removal plots shown in Figures 3-10 through 3-12 do not illustrate the effectiveness of the sorbent, which is added in the furnace, in controlling the $\mathrm{SO}_{3}$ formed across the SCR reactors. Figure 3-13 is an attempt to illustrate its effectiveness. In the figure, the $\mathrm{SO}_{3}$ concentration increase measured across the SCR is plotted versus $\mathrm{Mg}: \mathrm{SO}_{3}$ ratio for the byproduct $\mathrm{Mg}$ test period, both for injection at the $17^{\text {th }}$ floor and for injection split between the $13^{\text {th }}$ and $17^{\text {th }}$ floors. The data do not show a clear effect of sorbent injection on this increase. For injection at the $17^{\text {th }}$ floor, the increase across the SCR varies from 17 ppmv to $35 \mathrm{ppmv}$ (versus a baseline average of $28 \mathrm{ppmv}$ ) with no clear trend for a reduced increase as the $\mathrm{Mg}: \mathrm{SO}_{3}$ ratio increases.

For injection split between the $13^{\text {th }}$ and $17^{\text {th }}$ floor with byproduct $\mathrm{Mg}$, the results plotted in Figure 3-13 do show a reduced $\mathrm{SO}_{3}$ concentration increase as the $\mathrm{Mg}: \mathrm{SO}_{3}$ molar ratio increases from $1: 1$ to $7: 1$. However, the values at a $1: 1$ ratio (39 to $47 \mathrm{ppmv}$ ) are significantly higher than the baseline increase ( $28 \mathrm{ppmv})$; even the reduced values at a 7:1 ratio (30 to $33 \mathrm{ppmv}$ ) are higher than the baseline increase $(28 \mathrm{ppmv})$. The commercial $\mathrm{Mg}$ data are not plotted, but they also show no clear trends.

The data plotted in Figure 3-13 show that sorbent injection in the furnace did not measurably affect the conversion of $\mathrm{SO}_{2}$ in the flue gas to $\mathrm{SO}_{3}$ across the SCR reactors. However, scatter in the data made it difficult to note any trends.

Another possible effect of sorbent injected in the furnace on $\mathrm{SO}_{3}$ formed in the SCR reactors could be increased removal of $\mathrm{SO}_{3}$ as the flue gas passes through the air heaters and ESPs. Figure 3-14 is a plot of data that illustrate this effect. The plot shows the drop in $\mathrm{SO}_{3} /$ sulfuric acid concentration from the SCR outlet to the ESP outlet, for the byproduct Mg test period. The results in the figure shows that for sorbent injection at the $17^{\text {th }}$ floor, this drop in concentration becomes more significant as the $\mathrm{Mg}: \mathrm{SO}_{3}$ ratio increases. The line in the figure represents a linear least squares fit of the $17^{\text {th }}$ floor injection data. The drop in $\mathrm{SO}_{3} /$ sulfuric acid concentration increases from about $11 \mathrm{ppmv}$ at baseline conditions to about $20 \mathrm{ppmv}$ at a $\mathrm{Mg}: \mathrm{SO}_{3}$ molar ratio of $6: 1$, although there is considerable scatter in the data. The data plotted in the figure for injection split between the $13^{\text {th }}$ and $17^{\text {th }}$ floor do not show a similar trend, though. The commercial $\mathrm{Mg}$ data are not plotted, but also show considerable scatter and no clear trends. 
Based on a review of the $\mathrm{SO}_{3}$ /sulfuric acid concentration data in Figures 3-10 through 3-14, it can be concluded that byproduct $\mathrm{Mg}$ or commercial $\mathrm{Mg}$ sorbents injected into the furnace can remove a high percentage of the $\mathrm{SO}_{3}$ formed in the furnace. However, the furnace-injected sorbents have at most a modest effect on $\mathrm{SO}_{3}$ formed across the SCR reactors. The data show no clear trend for any impact of the injected sorbent on the conversion of $\mathrm{SO}_{2}$ to $\mathrm{SO}_{3}$ across the $\mathrm{SCR}$ reactors. There may be a weak trend for increased removal of $\mathrm{SO}_{3}$ formed in the $\mathrm{SCR}$ across the air heater and ESP at higher sorbent injection rates, though.

\section{Balance-of-plant Impacts}

The balance-of-plant effects tracked during the long-term $\mathrm{Mg}$ sorbent injection tests at Gavin Plant were, for the most part, minor. ESP secondary currents may have been lowered for the first three electrical sections of the center ESPs, but the downstream fields in these ESPs and all fields of the outer ESPs were unaffected. ESP outlet opacity readings were decreased somewhat by sorbent injection, which is a desirable effect. This is apparently because sorbent injection eliminated the formation of condensed sulfuric acid mist at the ESP outlet that occurred due to the elevated sulfuric acid concentrations in the flue gas with the SCR in service. There was no clear effect of sorbent injection on ESP outlet mass loading. This observation may have been influenced by the fact that an outer ESP rather than a center ESP was measured for performance. Also, the ESPs at Gavin Plant are relatively large, with design SCA values of $546 \mathrm{ft}^{2} / \mathrm{kacfm}$.

A review of temperature data show that the center economizer outlet duct temperatures increased by approximately $10^{\circ} \mathrm{F}\left(6^{\circ} \mathrm{C}\right)$ over the course of the test, possibly indicating minor fouling of back pass surface area in the center of the furnace. Air heater pressure drop data indicate an increase of approximately 0.5 inches $\mathrm{H}_{2} \mathrm{O}(0.1 \mathrm{kPa})$ over three weeks of test duration, at full-load operation, on all three air heaters. It is not known how this increase with time compares with normal operation. No effect of sorbent injection was seen on air heater outlet temperatures.

There was no apparent effect of sorbent injection or injection location on slagging tendencies or slag properties on the leading edge of the secondary superheater pendants. Gas sampling results showed no effect of sorbent injection on flue gas $\mathrm{HCl}$ or $\mathrm{HF}$ concentrations at the ESP outlet, and no effect on vapor-phase arsenic concentrations at the SCR inlet.

The stack gas opacity was measured by an AEP employee certified for EPA Method 9 (visual opacity), when possible. However, on many test days the ability to make opacity readings was limited by atmospheric conditions that were not conducive to visual determinations. In particular, the close proximity of the Unit 2 stack, with untreated flue gas, to the Unit 1 stack resulted in the two plumes mixing before the water vapor plume dissipated. This often made it impossible to read the visual opacity for Unit 1 alone. The results of the Method 9 reading were not reported by AEP due to regulatory issues related to the Unit 1 plume opacity. Qualitatively, the plume opacity appeared to be reduced during both the byproduct $\mathrm{Mg}$ and commercial $\mathrm{Mg}$ test periods. 


\section{Conclusions - Long-term Tests}

The long-term test results from BMP generally supported the short-term test $\mathrm{SO}_{3}$ removal results for byproduct $\mathrm{Mg}$ injection, showing that high removal percentages of furnce-formed $\mathrm{SO}_{3}$ could be achieved. The performance of the relatively small ESPs on BMP Unit 3 limited the overall $\mathrm{SO}_{3}$ removal achieved during this test, though. No other significant balance-of-plant impacts were observed, so the long-term test at BMP established byproduct Mg injection as a technically feasible $\mathrm{SO}_{3}$ control technology.

The long-term test at Gavin Plant resulted in two important new conclusions. One was that, as suspected after the short-term tests at $\mathrm{BMP}$ were completed, the $\mathrm{SO}_{3}$ control performance with byproduct $\mathrm{Mg}$ and commercial $\mathrm{Mg}$ are similar when the two slurries are injected at the same $\mathrm{Mg}: \mathrm{SO}_{3}$ molar ratios and in the same location in the boiler. The other conclusion was that, while it can be very effective at removing furnace-formed $\mathrm{SO}_{3}$, furnace injected $\mathrm{Mg}$ is relatively ineffective at removing SCR-formed $\mathrm{SO}_{3}$. This means that furnace $\mathrm{Mg}$ injection alone would not likely be able to achieve high overall $\mathrm{SO}_{3}$ /sulfuric acid control efficiencies for plants that have SCR systems in service. Two other significant observations from the long-term test at Gavin Plant were that, over the 23-day duration of this test, the furnace-injected Mg slurries did not adversely affect the SCR catalysts, nor this they effect the operation of the relatively large coldside ESPs installed on Unit 1.

\section{References}

1. Sulfuric Acid Removal Process Evaluation: Long-Term Results, EPRI, Palo Alto, CA, the U.S. Department of Energy, National Energy Technology Laboratory, Pittsburgh, PA, TVA, Chattanooga, TN, American Electric Power, Columbus, OH, and FirstEnergy, Shippingport, PA: 2002. EPRI 1004165

2. Flue Gas Sulfuric Acid Measurement Method Improvements, EPRI, Palo Alto, CA:2001. EPRI 1004027 


\section{4 \\ ECONOMIC COMPARISON OF FLUE GAS SULFURIC ACID REMOVAL TECHNOLOGIES}

A number of $\mathrm{SO}_{3}$ or sulfuric acid controls have been tested and/or applied for coal-fired units, including low-sulfur-coal switches, injecting alkaline sorbents at various locations in the furnace or flue gas path, and installing wet ESPs between the wet scrubber and stack. The costs of applying these technologies can vary over a wide range, and each has positive and negative attributes that could make that technology more or less favorable for application at a given power plant. This section describes a number of $\mathrm{SO}_{3} /$ sulfuric acid control technologies that could be applied as alternatives to furnace injection of magnesium hydroxide slurries, and presents estimates of the costs for applying these technologies at an example power plant.

\section{Introduction - Sulfuric Acid Control Alternatives}

Figure 4-1 shows the flue gas path of a typical coal-fired power plant, and illustrates where a number of potential $\mathrm{SO}_{3}$ /sulfuric acid control technologies might typically be applied. The technologies illustrated include:

- Fuel switching or blending to fire a lower-sulfur coal;

- Furnace injection of magnesium-based or dolomitic alkalis (the subject of this report);

- Injection of magnesium- or sodium-based alkalis into the economizer outlet or SCR outlet duct;

- Injection of sodium-, magnesium- or calcium-based alkalis, or ammonia, into the air heater outlet duct;

- Flue gas humidification upstream of an ESP or upstream of a wet scrubber, with or without alkali injection; and

- Wet ESP retrofit.

The following provides a brief discussion of each of these potential control technologies.

\section{Fuel Blending/Switching}

Fuel blending or switching lowers the amount of $\mathrm{SO}_{3}$ and sulfuric acid in the flue gas by lowering the $\mathrm{SO}_{2}$ content of the flue gas. This reduces the amount of $\mathrm{SO}_{3}$ produced in the furnace and across the SCR catalyst. If the fuel blended is a Western coal with an alkaline ash, there may be additional benefits from reactions between the fly ash and $\mathrm{SO}_{3}$ formed in the furnace. 


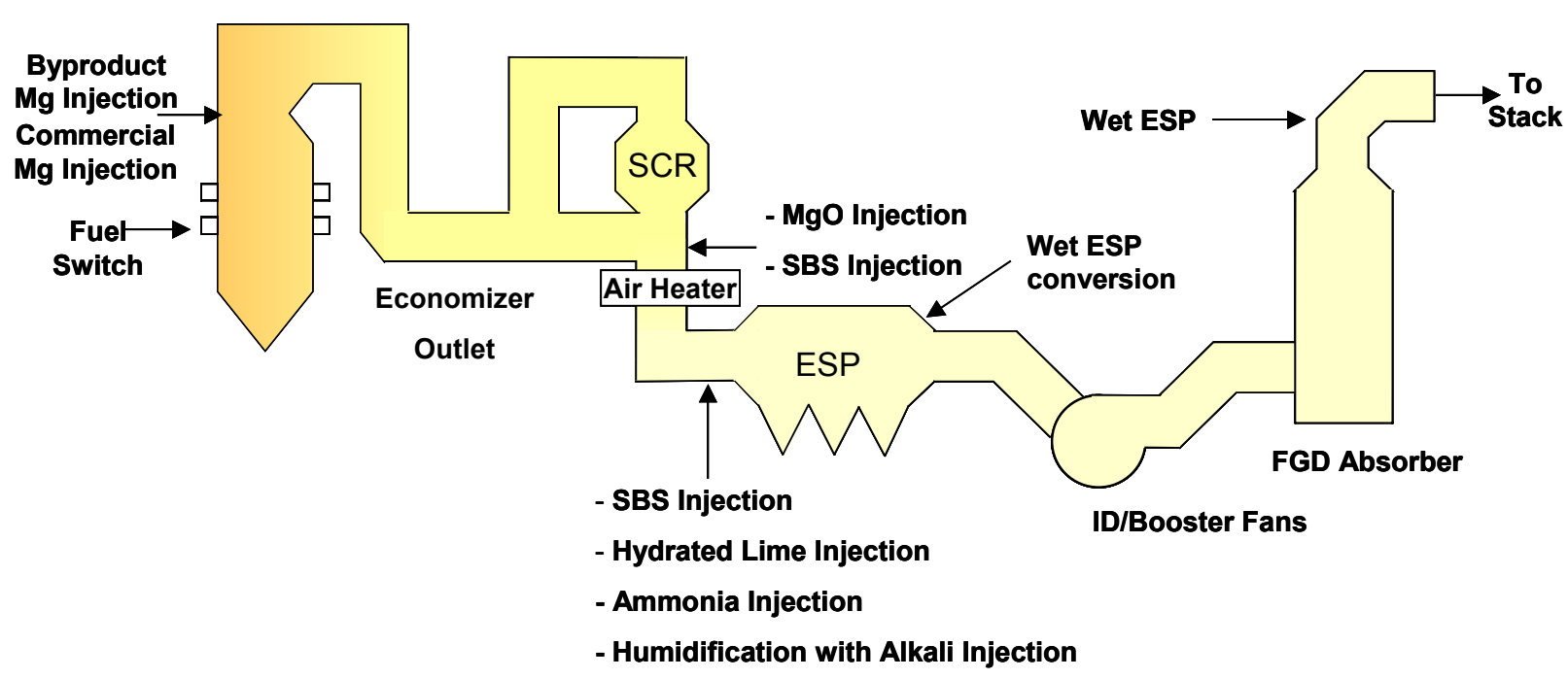

Figure 4-1

Illustration of Potential $\mathrm{SO}_{3} /$ Sulfuric Acid Control Options

The ability to implement this technology, and its cost effectiveness, can be very site specific. The ability to blend and switch to lower sulfur coal can be limited by issues such as existing coal contracts, coal mill capacity, furnace heat release rates, furnace slagging and fouling tendencies, ESP performance, and gypsum byproduct supply contracts. Blending also requires room to maintain multiple coal piles, and the ability to prepare coal blends in the coal yard, on conveyors, and/or in bunkers. However, if low-sulfur coal firing is feasible as a sulfuric acid control strategy, it can result in other benefits such as making more $\mathrm{SO}_{2}$ allowance tons available from the affected plant, and allowing lower air heater outlet temperatures to result in heat rate improvements. The latter effect is further described in the following subsection.

Notwithstanding capital expenditures for any required plant modifications, the economics of coal switching are driven almost entirely by the delivered fuel cost differential between the current coal and the low-sulfur coal. Changes in the delivered fuel price of a few cents per million Btu can change the economics of this potential control option by hundreds of thousands of dollars annually.

\section{Furnace Injection of Magnesium-based or Dolomitic Alkalis}

This technology has been discussed extensively in this report. For the purposes of this economic comparison, both byproduct $\mathrm{Mg}$ and commercial $\mathrm{Mg}$ have been considered. Based on the shortterm test results from this project (Section 2), dolomitic reagents have not been considered.

Furnace injection can have an advantage over downstream injection technologies for plants that cycle in load and that have operating SCR systems. Furnace injection can be implemented to lower flue gas $\mathrm{SO}_{3}$ concentrations at the SCR inlet. This, in turn, can allow the SCR to operate at 
lower unit loads, which lower SCR inlet flue gas temperatures, without condensing ammonium bisulfate in catalyst pores. Furnace injection for $\mathrm{SO}_{3}$ control might allow cycling plants to avoid having to install economizer bypass ducts or remove economizer surface area to raise SCR inlet flue gas temperatures during low-load operation. A disadvantage for plants with SCR, though, is that furnace injection appears to be less effective at controlling SCR-formed $\mathrm{SO}_{3}$ in the flue gas, as discussed in Section 3 for Gavin Plant. For plants without SCR, the furnace injection technology appears to be capable of high $\mathrm{SO}_{3}$ removal performance, but the performance of cold-side ESP particulate collectors may be adversely affected as described in Sections 2 and 3.

For either case (with or without SCR), furnace injection should lower the flue gas acid dew point, which may allow the plant to operate at lower air heater outlet flue gas temperatures and could result in plant heat rate improvements, as explained in the following paragraph. The plant may also experience reduced corrosion in downstream equipment, and correspondingly reduced maintenance costs.

The potential benefits of $\mathrm{SO}_{3}$ removal upstream of the air heater on plant heat rate are mentioned several places in this report, and warrant further explanation. Most coal-fired power plants have steam or glycol heaters to preheat the ambient combustion air going to the air heaters. The amount of preheat is adjusted to control the air heater outlet air and flue gas temperatures. On bituminous coal plants, the air heater outlet flue gas temperature is typically controlled to minimize adverse effects of sulfuric acid condensation, such as plugging and/or corrosion in the air heater or downstream corrosion. Lowering the flue gas $\mathrm{SO}_{3}$ concentration upstream of the air heater, such as by furnace $\mathrm{Mg}$ injection, may allow the plant to lower the air heater outlet temperature. This is typically implemented by reducing the amount of steam used to preheat the combustion air to the air heater (or to heat the glycol solution). Reduced steam consumption for combustion air preheat can improve the overall plant heat rate.

Conversely, in the event of an SCR retrofit, the air heater inlet flue gas $\mathrm{SO}_{3}$ concentration is increased, which could require more steam preheat to increase the air heater outlet flue gas temperature to compensate for the sulfuric acid dew point elevation. Technologies that remove $\mathrm{SO}_{3}$ upstream of the air heater may allow a plant to avoid such an increase after an SCR retrofit, and avoid a heat rate penalty. For this economic evaluation, only benefit of avoided air heater outlet flue gas temperature increase was considered as part of the economics for technologies that remove $\mathrm{SO}_{3}$ upstream of the air heater. In actual practice, further benefits may be possible.

\section{Alkali Injection into the Economizer Outlet or SCR Outlet Duct}

Performance data are available for two different technologies: injection of a reactive $\mathrm{MgO}$ powder, and injection of sodium bisulfite (SBS) solution into the $700^{\circ} \mathrm{F}\left(370^{\circ} \mathrm{C}\right)$ flue gas downstream of the economizer or SCR, upstream of the plant air heater. ${ }^{1,2}$ These processes form magnesium-based or sodium-based salts, respectively, that are removed with the fly ash in the ESP or other particulate control device. The reactive $\mathrm{MgO}$ powder is available from one supplier of magnesium-based alkalis, Martin Marietta, but other vendors may provide similar products. The SBS Injection ${ }^{\mathrm{TM}}$ process is patented by Codan Development LLC, and is available by license. The SBS solution can be provided as a byproduct from sodium-based or dual alkali FGD 
Economic Comparison of Flue Gas Sulfuric Acid Removal Technologies

systems, or commercially available sodium sulfite or sodium bisulfite can reportedly be used as a feed material. SBS process performance data are available from full-scale testing at Vectren Corporation's A.B. Brown Station. ${ }^{2}$ Two commercial installations of the SBS injection process went into service in April 2003, at FirstEnergy's BMP and TVA's Widows Creek Fossil Plant, and have operated during the "ozone season" of 2003. These two installations represent approximately $2300-\mathrm{MW}$ of installed capacity.

Since either of these technologies could be applied upstream of the plant air heater, they offer a potential for operating at lower flue gas exit temperatures from the air heater, allowing improvements to the plant heat rate. They may also reduce corrosion in the air heater and downstream equipment.

Relatively few performance data are available for the $\mathrm{MgO}$ powder injection process. Martin Marietta literature cites examples of high $\mathrm{SO}_{3}$ removal efficiency $(>80 \%)$ with near stoichiometric amounts of $\mathrm{MgO}$ being injected. ${ }^{1}$ However, recent discussions with the vendor indicates that more typical $\mathrm{SO}_{3}$ removal performance would be 60 to $70 \%$ removal when the sorbent is injected between the SCR and air heater at Mg:SO3 mole ratios of 1:1 to 2:1. ${ }^{3}$

Balance-of-plant impacts have not been reported for the $\mathrm{MgO}$ powder injection process. However, it is likely that high resistivity could become an issue for cold-side ESP performance if $\mathrm{MgO}$ powder injection is employed for high $\mathrm{SO}_{3}$ /sulfuric acid removal upstream of the ESP, as was seen in the BMP Unit 3 results reported in Sections 2 and 3.

Performance data and balance-of-plant impacts for the SBS injection process were documented in the EPRI report cited previously. High sulfuric acid removal levels are possible (down to less than 2 ppmv at the ESP outlet) when injecting SBS at $\mathrm{Na}: \mathrm{SO}_{3}$ mole ratios in the range of 1.5:1 to $2: 1$. The SBS injection process has not been observed to adversely affect ESP performance even when removing sulfuric acid down to less than 2 ppmv at the ESP outlet. This is apparently because the sodium salts formed by this process condition fly ash resistivity in a manner similar to conditioning by sulfuric acid. The biggest balance-of-plant impact from the SBS injection process seen in the A.B. Brown testing was a tendency for deposition of damp fly ash and sodium salts in the air heater inlet duct during injection nozzle/lance upsets. The process developers have reportedly made modifications to avoid such upsets, and to reduce or eliminate tendencies for solids deposition.

The two commercial installations of the SBS injection process have reportedly seen tendencies for solids deposition on air heater surfaces when injecting upstream of the air heater but at low $\mathrm{Na}: \mathrm{SO}_{3}$ mole ratios and/or limited flue gas residence time before the air heater. These deposits apparently result because of reactions between the SBS byproduct solids and sulfuric acid that condenses within the air heater. Because of this, the SBS injection process would likely only be installed upstream of the air heater for high removal efficiency ( $\sim 90 \%$ or greater) $\mathrm{SO}_{3}$ removal applications. For lower removal percentages, the process would more likely be installed between the air heater and ESP. 


\section{Alkali Injection into the Air Heater Outlet Duct}

EPRI evaluated duct injection of alkali powders at the pilot scale at their Environmental Control Technology Center (ECTC) in the early 1990s. ${ }^{4}$ The alkaline powders react with flue gas sulfuric acid to form sulfate salts that are collected with the fly ash in the ESP or other primary particulate control device. EPRI found that it was possible to achieve high sulfuric acid removal percentages when injecting hydrated lime, sodium bicarbonate, or other dry alkaline powders into the ductwork between the air heater and downstream particulate control device (primarily using a cold-side ESP). There were two disadvantages to this technology: high sorbent injection rates were required to achieve high $\mathrm{SO}_{3}$ removal efficiencies (many times the stoichiometric amount), and high ash resistivity conditions resulted when calcium-based alkalis such as hydrated lime were employed. High resistivity was not an issue with sodium bicarbonate injection, but the reagent cost and impacts on fly ash waste disposal or sales when injecting a large excess of sodium bicarbonate were seen as an issue. A blend of $80 \%$ lime and $20 \%$ sodium bicarbonate was also tested, and appeared to minimize ESP performance impacts at a lower overall sorbent cost than sodium bicarbonate alone.

Ammonia injection has been tested by many as a sulfuric acid control technology. Ammonia can be injected between the air heater and cold-side ESP at $\mathrm{NH}_{3}: \mathrm{SO}_{3}$ ratios in the range of 1.5:1 to 2:1 to achieve high sulfuric acid removal levels (90 to $95 \%$ ). Ammonia injection to achieve high sulfuric acid removal efficiency typically does not adversely affect ESP performance. In fact, ammonia injection is often employed at lower injection rates to enhance cold-side ESP performance, due to the cohesive properties of the ammonium sulfate/bisulfate salts that form. Furthermore, plants that have retrofitted SCR systems already have a supply of ammonia on site.

The biggest issue for ammonia injection is its effect on fly ash disposal and/or reuse/sales. While ammonia slip from SCR systems can result in small quantities of ammonia in the fly ash, the use of ammonia injection for sulfuric acid removal from the flue gas can increase the amount of ammonia in the fly ash by greater than an order of magnitude. Ammonia gas is known to desorb from alkaline solutions containing the ammonium ion. If the fly ash is mixed with an FGD byproduct stream to stabilize the sludge for disposal, and the resulting mixture is alkaline, the ammonia in the fly ash can strip out. This desorption can cause significant worker exposure and nuisance odor issues. If the fly ash is sold for cement admixture or road base use, worker exposure and nuisance odors can become an issue for the same reasons. Airborne release of nuisance ammonia odors can also result if the ash is sluiced to an open pond, or if dry-handled fly ash is not quickly covered.

Even if airborne releases of ammonia and nuisance odors are not concerns, the ammonia in the fly ash can cause water quality issues. As an example, if the fly ash is handled dry and disposed of in a dry landfill, there is typically a leachate and runoff collection and disposal system to handle rainfall on the disposal area. With the presence of significant quantities of water-soluble ammonia salts in the fly ash, ammonia content can limit the ability to discharge this leachate without resorting to water treatment. For plants that sluice their fly ash to a pond and reuse or discharge the pond water, the ammonium ion concentration of the water would also likely require some form of water treatment. 
Economic Comparison of Flue Gas Sulfuric Acid Removal Technologies

As with any technology that would be applied downstream of the air heater, these alkali injection technologies offer no benefits to SCR turn down or plant heat rate improvements resulting from lowered flue gas temperatures at the air heater exit.

\section{Flue Gas Humidification, With or Without Alkali Injection}

In this technology, also tested by EPRI at the ECTC, the flue gas is partially humidified and cooled to below its acid dew point. The sulfuric acid appears to be removed by condensing large acid droplets that can be collected in a cold-side ESP or wet scrubber. In contrast, the rapid quenching of flue gas at the wet-dry interface of a wet scrubber is known to form sub-microndiameter sulfuric acid droplets that are not effectively scrubbed.

Lime or limestone alkalis can also be injected, and serve several apparent purposes. One is to neutralize the sulfuric acid droplets formed, so they are less corrosive to ductwork, ESP collecting plates, etc. Although humidification is used for fly ash conditioning upstream of ESPs, this is typically under low-sulfur-coal conditions. For high-sulfur-coal conditions, corrosion due to condensed acid in ducts would be a concern. Another reason for alkali injection is to control the fly ash resistivity. When injecting upstream of a cold-side ESP, EPRI found that humidification can result in low fly ash resistivity and a tendency for increased ash reentrainment emissions, which could be avoided by also injecting a calcium-based alkali.

A number of options are possible for flue gas humidification downstream of the air heater. One is for humidification and alkali injection upstream of an ESP. The flue gas can be humidified and dry hydrated lime powder injected separately, or lime slurry can be injected in one step. EPRI tested both configurations. Alternately, the flue gas can be humidified between the ESP and wet FGD, with water alone or with lime slurry, relying on the FGD absorber to remove the sulfuric acid and/or calcium sulfate droplets formed. The Chemical Lime Company has reportedly conducted full-scale tests of humidification with lime slurry injected upstream of a wet FGD absorber for sulfuric acid control, but results from those tests are not publicly available. A potential concern with lime slurry injection at that location is whether the lime particles are scrubbed at high enough efficiency to avoid particulate emission increases.

PreussenElektra (now E.ON) reported the use of humidification (water only) just upstream of a wet FGD absorber as a means of reducing outlet $\mathrm{SO}_{3}$ concentrations, but reported performance data only for low inlet sulfuric acid concentration conditions. ${ }^{5}$ It is not known whether this technology would also be effective under high-sulfur-coal, SCR conditions.

Of the various possible configurations, humidification with separate hydrated lime powder injection upstream of the ESP was selected for evaluation in this report. Injection upstream of the ESP was selected because ECTC data for this configuration are readily available, while few data are available for injection upstream of the FGD system. Separate humidification and hydrated lime powder injection was selected over slurry injection because flue gas humidification with water and dry hydrated lime powder injection have each been demonstrated to some extent at full scale. The ability to successfully inject lime or limestone slurries in flue gas ducts is less demonstrated. Hydrated lime was selected over limestone reagent for this evaluation because it is 
more readily available in the Midwest as a dry, fine powder suitable for duct injection than is dry-ground limestone.

\section{Wet ESP}

Wet ESP technology has been in existence for nearly a century, but sulfuric acid control on coalfired power plants represents a relatively new application. In this control technique, sulfuric acid mist is collected by electrostatic forces in a wetted-plate ESP. The collected mist is washed from the plates either periodically or continuously, and the blow down can go to an FGD system or to a separate treatment system. To achieve high sulfuric acid removal efficiencies $(>80 \%)$, the wet ESP could be installed downstream of the wet FGD absorber or could be installed inside the absorber vessel as a replacement for the chevron-style mist eliminator. For lower efficiencies (60 to $80 \%$ ) it may be possible to convert the last field of a conventional dry ESP to wet operation. Wet ESPs can be installed in two configurations: a conventional plate and wire configuration for horizontal gas flow situations, or as a bundle of tubes with a wire running down the center of each tube for vertical gas flow situations.

Wet ESP technology solves the limitation on $\mathrm{SO}_{3}$ control by conventional dry ESPs, where most of the sulfuric acid remains in the gas phase and thus is not collected by electrostatic forces. In a wet ESP downstream of an FGD absorber, the sulfuric acid is all present as a sub-micron mist that is collectable by this mechanism. In a last-field dry ESP conversion, the humidification of the flue gas in the wet field condenses sulfuric acid so it can be removed by electrostatic forces. The wet environment lowers particle resistivity and allows high power input levels to enhance the removal of sub-micron-diameter mist. Also, wet ESPs can remove other flue gas components that contribute to plume opacity, including fine fly ash particles, unburned carbon or soot, and when installed downstream of wet FGD, scrubber carryover. Removal of the latter can be a benefit in controlling droplet rainout from wet stacks.

Based on discussions with vendors, wet ESP retrofits can have capital costs in the range of $\$ 30$ to $\$ 40$ per $\mathrm{kW}$ for last-field dry ESP conversions, and $\$ 40$ to over $\$ 90$ per $\mathrm{kW}$ for retrofits downstream of existing wet FGD absorbers. Downstream of an existing wet FGD, high capital costs can result because of the lack of available real estate, making for a difficult retrofit in an existing vessel or at an elevated location. Corrosion resistant materials are typically required for the discharge electrodes and collecting plates or tubes, ranging from 316 stainless steel to "C" class alloys. Some wet ESP vendors are testing plastic collecting plates as a way of lowering implementation costs.

By being installed at or near the end of the flue gas path, wet ESPs typically address only plume opacity and particulate emissions, and provide no upstream benefits for air heater exit temperatures or duct corrosion. A wet ESP generates an aqueous waste that must either be treated separately or added to the FGD system. Adding this stream to the FGD system would consume a small amount of FGD reagent to neutralize the acid, and would add sulfates and trace metals that could adversely affect FGD chemistry in low sulfite oxidation systems. On scrubbed units, because the wet ESP would remove both sulfuric acid and calcium-based scrubber carryover, careful control of the water chemistry is needed to avoid gypsum scale formation on 
Economic Comparison of Flue Gas Sulfuric Acid Removal Technologies

collector plates and/or blow down piping. The same is true if calcium-based reagents are used to neutralize the collected acid in the recirculating water used to wet the plates. A wet ESP sized to achieve $90 \%$ control of sulfuric acid mist at the scrubber outlet would consume approximately 0.1 to $0.2 \%$ of the station's gross output.

\section{Experimental - Sulfuric Acid Control Technology Cost Estimates}

As part of this project, cost estimates were prepared for applying a number of sulfuric acid control technologies to a hypothetical or model power plant. The plant consists of a single, 500MW unit. It is located in the Midwest on the Ohio River, and fires a 3.5\% sulfur bituminous coal. The plant is retrofitting an SCR system for $\mathrm{NO}_{\mathrm{X}}$ control, and currently has a cold-side ESP for particulate control and a wet FGD system for $\mathrm{SO}_{2}$ control. The FGD system uses limestone reagent and produces wallboard grade gypsum, which is sold as a byproduct. The fly ash is handled dry, and either sold as a byproduct or disposed of in a landfill. During warm weather months (coinciding with the "ozone season"), all of the fly ash is typically sold.

The plant has a wall-fired, pulverized coal boiler that typically converts $1 \%$ of the coal sulfur to $\mathrm{SO}_{3}$. The SCR catalyst guarantee is for no more than $0.75 \%$ conversion of $\mathrm{SO}_{2}$ to $\mathrm{SO}_{3}$ across the installed catalyst layers. Figure 4-2 summarizes the assumed baseline $\mathrm{SO}_{3} /$ sulfuric acid concentrations at various locations in the flue gas path, both with and without the SCR in line.

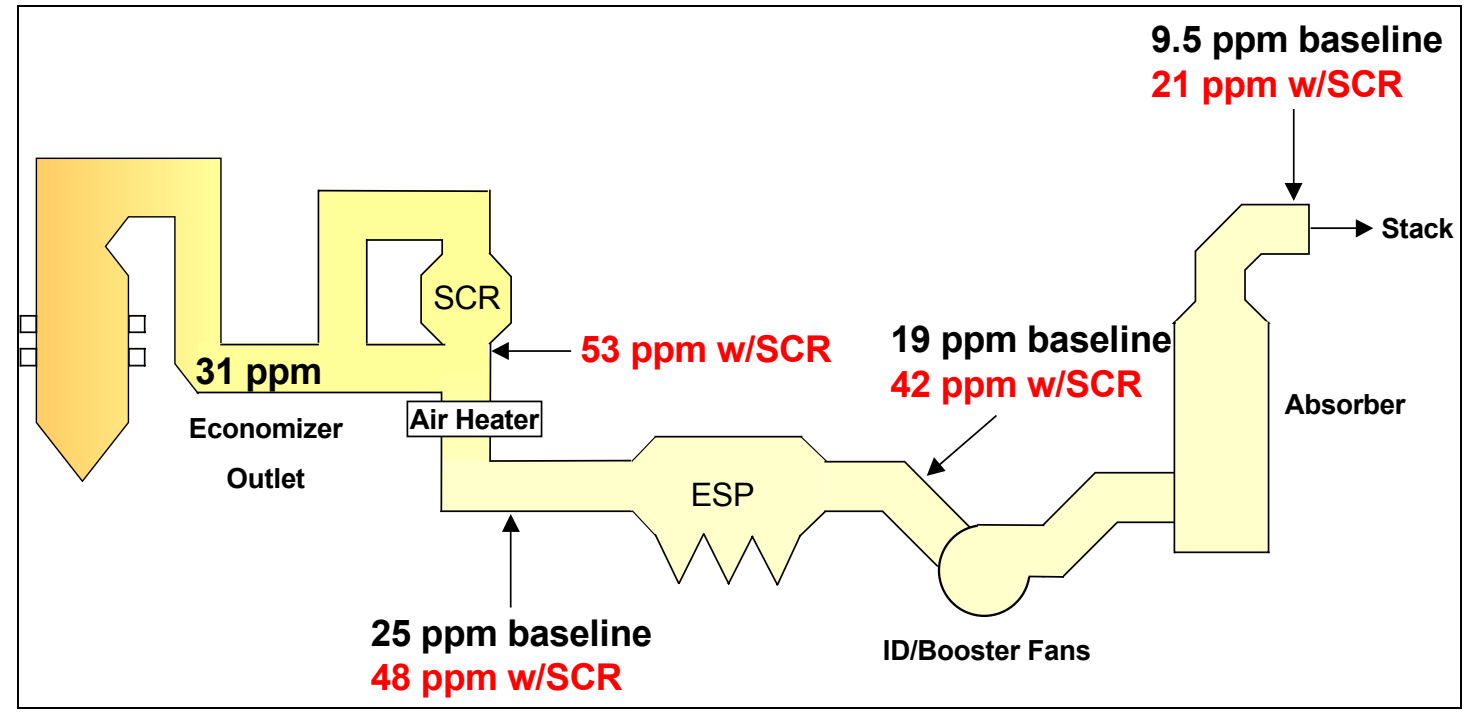

Figure 4-2

Baseline and Post-SCR $\mathrm{SO}_{3} /$ Sulfuric Acid Concentrations for Hypothetical Plant

The concentrations in the figure assume approximately 6 ppmv of $\mathrm{SO}_{3} /$ sulfuric acid removal each across both the air heater and ESP and 50\% removal of sulfuric acid mist across the FGD absorber, for both cases. The 6-ppmv removals across the air heater and ESP correspond with about 20\% removal across each device under baseline (pre-SCR) operation. It was assumed that the removal mechanism across these devices is adsorption on fly ash, and that a similar quantity would be adsorbed whether the SCR is in service or not. The removal across the FGD absorber is 
assumed to be by physical collection, so the percentage removal was assumed to be independent of sulfuric acid mist concentration.

The objective of applying sulfuric acid controls is to restore the stack sulfuric acid concentration to the pre-SCR value of $9.5 \mathrm{ppmv}$ (dry basis), from the projected value of $21 \mathrm{ppmv}$ with the SCR in service. A sensitivity case also looks at costs for achieving a higher level of $\mathrm{SO}_{3}$ control, down to 3 ppmv (dry basis) or less at the stack. This lower concentration should be adequate to result in a clear stack, or low stack plume opacity (at least due to the sulfuric acid mist contribution to plume opacity) under most conditions. The SCR operates only during the "ozone season," from May 1 through September 30, and for either removal level it was assumed the sulfuric acid controls will only be required to operate during that time period as well.

A number of potential sulfuric acid controls were considered for this hypothetical plant. The technologies include:

- Fuel switching;

- Furnace injection of byproduct Mg;

- Furnace injection of commercial $\mathrm{Mg}$;

- $\mathrm{MgO}$ powder injection between the SCR and air heater;

- SBS solution injection between the SCR and air heater or between the air heater and ESP, depending on the required $\mathrm{SO}_{3}$ /sulfuric acid removal percentage;

- Ammonia injection between the air heater and ESP;

- Dry hydrated lime powder injection between the air heater and ESP;

- Flue gas humidification with hydrated lime powder injection between the air heater and ESP; and

- Wet ESP retrofit, either as a last field conversion of the existing dry ESP or between the FGD absorber outlet and stack.

Figure 4-1, presented previously in this section, illustrates the gas path for the plant and indicates where in the gas path these candidate $\mathrm{SO}_{3}$ /sulfuric acid control technologies were assumed to be installed. Note that for the lower removal percentage target, the SBS injection process was assumed to be installed between the air heater and ESP, and the wet ESP was assumed to be implemented as a last field conversion of the existing ESP. For the higher removal percentage target, the SBS injection process was assumed to be installed between the SCR and air heater, and the wet ESP was to be implemented as a retrofit between the FGD absorber and stack.

As a first step in developing cost estimates for the various potential sulfuric acid controls, heat (enthalpy) and material balance calculations were conducted to estimate the expected $\mathrm{SO}_{3} /$ sulfuric acid control performance of each technology, and to estimate reagent and utility consumption rates. Table 4-1 summarizes the sources of performance information for each technology and operating cost considerations for each. 
Economic Comparison of Flue Gas Sulfuric Acid Removal Technologies

Table 4-1

Summary of $\mathrm{SO}_{3}$ Control Technology Performance Data Sources, and Reagents and Utilities Required

\begin{tabular}{|c|c|c|c|c|c|c|c|c|c|}
\hline & $\begin{array}{l}\text { Fuel } \\
\text { Switch/Blend }\end{array}$ & $\begin{array}{l}\text { Furnace } \\
\text { Injection of } \\
\text { Byproduct Mg }\end{array}$ & $\begin{array}{l}\text { Furnace } \\
\text { Injection of } \\
\text { Commercial } \\
\text { Mg }\end{array}$ & $\begin{array}{l}\text { MgO Injection } \\
\text { Downstream } \\
\text { of SCR }\end{array}$ & SBS Injection & $\begin{array}{l}\text { Ammonia } \\
\text { Injection } \\
\text { Between Air } \\
\text { Heater and } \\
\text { ESP }\end{array}$ & $\begin{array}{l}\text { Humidification } \\
\text { and Lime } \\
\text { Injection } \\
\text { Between Air } \\
\text { Heater and ESP }\end{array}$ & $\begin{array}{l}\text { Hydrated Lime } \\
\text { Injection } \\
\text { Between Air } \\
\text { Heater and } \\
\text { ESP }\end{array}$ & Wet ESP \\
\hline $\begin{array}{l}\text { Performance } \\
\text { Data Source }\end{array}$ & $\begin{array}{l}\text { Material balance } \\
\text { calculations }\end{array}$ & This report & This report & Vendor data & $\begin{array}{l}\text { Vendor/EPRI } \\
\text { data }\end{array}$ & $\begin{array}{l}\text { Vendor/EPRI } \\
\text { data }\end{array}$ & EPRI ECTC data & $\begin{array}{l}\text { EPRI ECTC } \\
\text { data (Chemstar } \\
\text { Lime) }\end{array}$ & $\begin{array}{l}\text { EPRI } \\
\text { data/vendor } \\
\text { contacts }\end{array}$ \\
\hline $\begin{array}{l}\text { Reagent } \\
\text { Used }\end{array}$ & $\begin{array}{l}\text { Reduced FGD } \\
\text { limestone } \\
\text { consumption }\end{array}$ & $\begin{array}{l}\text { Byproduct Mg } \\
\text { slurry }\end{array}$ & $\begin{array}{l}\text { Commercial Mg } \\
\text { slurry }\end{array}$ & MgO powder & $\begin{array}{l}\text { Sodium } \\
\text { sulfite/bisulfite } \\
\text { solution, FGD } \\
\text { limestone }^{1}\end{array}$ & $\begin{array}{l}\text { Ammonia } \\
\text { from SCR } \\
\text { system }\end{array}$ & $\begin{array}{l}\text { Hydrated lime } \\
\text { powder }\end{array}$ & $\begin{array}{l}\text { Hydrated lime } \\
\text { powder }\end{array}$ & $\begin{array}{l}\text { FGD } \\
\text { limestone }^{2}\end{array}$ \\
\hline $\begin{array}{l}\text { Plant Water } \\
\text { Use }\end{array}$ & None & None & $\begin{array}{l}\text { Dilution of } \\
\text { commercial } \\
\text { slurry }\end{array}$ & None & $\begin{array}{l}\text { Diluting } \\
\text { concentrated } \\
\text { solution } \\
\text { (softened water) }\end{array}$ & None & $\begin{array}{l}\text { Flue gas } \\
\text { humidification }\end{array}$ & None & $\begin{array}{l}\text { Washing } \\
\text { ESP } \\
\text { plates/tubes }\end{array}$ \\
\hline $\begin{array}{l}\text { Compressed } \\
\text { Air Use }\end{array}$ & None & Atomization air & Atomization air & $\begin{array}{l}\text { Pneumatic } \\
\text { conveying air }\end{array}$ & Atomization air & $\begin{array}{l}\text { Pneumatic } \\
\text { conveying air }\end{array}$ & $\begin{array}{l}\text { Atomization air, } \\
\text { pneumatic } \\
\text { conveying air }\end{array}$ & $\begin{array}{l}\text { Pneumatic } \\
\text { conveying air }\end{array}$ & None \\
\hline $\begin{array}{l}\text { Major Power } \\
\text { Consumers }\end{array}$ & None & $\begin{array}{l}\text { Air } \\
\text { compressors, } \\
\text { pumps }\end{array}$ & $\begin{array}{l}\text { Air } \\
\text { compressors, } \\
\text { pumps }\end{array}$ & Air blower & $\begin{array}{l}\text { Air } \\
\text { compressors, } \\
\text { pumps }\end{array}$ & $\begin{array}{l}\text { Air blower, } \\
\text { heater }\end{array}$ & $\begin{array}{l}\text { Air compressors, } \\
\text { pumps, air } \\
\text { blower }\end{array}$ & Air blower & $\begin{array}{l}\text { T/R set } \\
\text { input power }\end{array}$ \\
\hline $\begin{array}{l}\text { Waste } \\
\text { Disposal/ } \\
\text { Byproduct } \\
\text { Stream }\end{array}$ & $\begin{array}{l}\text { Potentially } \\
\text { reduced fly ash } \\
\text { production; } \\
\text { reduced FGD } \\
\text { gypsum } \\
\text { production }\end{array}$ & $\begin{array}{l}\mathrm{MgSO}_{4} \text {, mixed } \\
\text { with fly ash }\end{array}$ & $\begin{array}{l}\mathrm{MgSO}_{4} \text {, mixed } \\
\text { with fly ash }\end{array}$ & $\begin{array}{l}\mathrm{MgSO}_{4} \text {, mixed } \\
\text { with fly ash }\end{array}$ & $\begin{array}{l}\mathrm{Na}_{2} \mathrm{SO}_{4}, \text { mixed } \\
\text { with fly ash, } \\
\mathrm{CaSO}_{4} ; \\
\text { increased FGD } \\
\text { gypsum } \\
\text { production }{ }^{1}\end{array}$ & $\begin{array}{l}\left(\mathrm{NH}_{4}\right)_{2} \mathrm{SO}_{4} \text {, } \\
\mathrm{NH}_{4} \mathrm{HSO}_{4} \text {, } \\
\text { mixed with fly } \\
\text { ash }\end{array}$ & $\begin{array}{l}\mathrm{CaSO}_{4} \text {, excess } \\
\text { lime mixed with } \\
\text { fly ash }\end{array}$ & $\begin{array}{l}\mathrm{CaSO}_{4} \text {, excess } \\
\text { lime mixed with } \\
\text { fly ash }\end{array}$ & $\begin{array}{l}\mathrm{CaSO}_{4}, \\
\text { increased } \\
\text { FGD } \\
\text { gypsum } \\
\text { production }^{2}\end{array}$ \\
\hline
\end{tabular}


Table 4-1 (continued)

\begin{tabular}{|c|c|c|c|c|c|c|c|c|c|}
\hline & $\begin{array}{l}\text { Fuel } \\
\text { Switch/Blend }\end{array}$ & $\begin{array}{l}\text { Furnace } \\
\text { Injection of } \\
\text { Byproduct Mg }\end{array}$ & $\begin{array}{l}\text { Furnace } \\
\text { Injection of } \\
\text { Commercial } \\
\text { Mg }\end{array}$ & $\begin{array}{l}\text { MgO Injection } \\
\text { Downstream } \\
\text { of SCR }\end{array}$ & SBS Injection & $\begin{array}{l}\text { Ammonia } \\
\text { Injection } \\
\text { Between Air } \\
\text { Heater and } \\
\text { ESP }\end{array}$ & $\begin{array}{l}\text { Humidification } \\
\text { and Lime } \\
\text { Injection } \\
\text { Between Air } \\
\text { Heater and ESP }\end{array}$ & $\begin{array}{l}\text { Hydrated Lime } \\
\text { Injection } \\
\text { Between Air } \\
\text { Heater and } \\
\text { ESP }\end{array}$ & Wet ESP \\
\hline $\begin{array}{l}\text { Boiler } \\
\text { Efficiency } \\
\text { Impacts }\end{array}$ & $\begin{array}{l}\text { Increase due to } \\
\text { lowered } \mathrm{SO}_{3} \\
\text { concentration } \\
\text { upstream of air } \\
\text { heater }\end{array}$ & $\begin{array}{l}\text { Decrease due } \\
\text { to water } \\
\text { evaporated in } \\
\text { furnace, } \\
\text { increase due to } \\
\mathrm{SO}_{3} \text { removal } \\
\text { upstream of air } \\
\text { heater }\end{array}$ & $\begin{array}{l}\text { Decrease due } \\
\text { to water } \\
\text { evaporated in } \\
\text { furnace, } \\
\text { increase due to } \\
\mathrm{SO}_{3} \text { removal } \\
\text { upstream of air } \\
\text { heater }\end{array}$ & $\begin{array}{l}\text { Increase due } \\
\text { to } \mathrm{SO}_{3} \text { removal } \\
\text { upstream of air } \\
\text { heater }\end{array}$ & $\begin{array}{l}\text { Decrease due to } \\
\text { water } \\
\text { evaporated } \\
\text { upstream of air } \\
\text { heater, increase } \\
\text { due to } \mathrm{SO}_{3} \\
\text { removal } \\
\text { upstream of air } \\
\text { heater (only } \\
\text { when injecting } \\
\text { upstream of air } \\
\text { heater) }\end{array}$ & None & None & None & None \\
\hline $\begin{array}{l}\mathrm{SO}_{2} \\
\text { Allowance } \\
\text { Impacts }\end{array}$ & $\begin{array}{l}\text { Reduced } \mathrm{SO}_{2} \\
\text { emissions due to } \\
\text { lower coal sulfur }\end{array}$ & None & None & None & None & None & None & None & None \\
\hline $\begin{array}{l}\mathrm{NO}_{x} \\
\text { Removal } \\
\text { Impacts }\end{array}$ & $\begin{array}{l}\text { None were } \\
\text { evaluated }\end{array}$ & $\begin{array}{l}\text { None were } \\
\text { evaluated }\end{array}$ & $\begin{array}{l}\text { None were } \\
\text { evaluated }\end{array}$ & None & None & None & None & None & None \\
\hline
\end{tabular}

${ }^{1}$ The reaction of $\mathrm{SBS}$ or sodium sulfite to remove $\mathrm{SO}_{3}$ and form sodium sulfate releases an equal molar amount of $\mathrm{SO}_{2}$ into the flue gas, that must be scrubbed in the $\mathrm{FGD}$ absorber.

${ }^{2}$ Sulfuric acid collected will end up in the FGD liquor, requiring additional FGD limestone for neutralization. 
Economic Comparison of Flue Gas Sulfuric Acid Removal Technologies

To be able to conduct heat and material balance calculations, a number of assumptions had to be made about existing plant conditions such as unit capacity factor and coal composition. These assumptions are summarized in Table 4-2.

Table 4-2

Assumptions Made for Heat and Material Balances for Model Plant

\begin{tabular}{|c|c|}
\hline Parameter & Value \\
\hline Unit Load (gross MW) & 500 \\
\hline Gross Plant Heat Rate (Btu/hr/KW ) [kcal/hr/KW] & $9200[2320]$ \\
\hline Capacity Factor (\%) & 85 \\
\hline $\begin{array}{l}\text { Flue Gas Flow Rate (acfm at economizer outlet) } \\
\text { [actual } \mathrm{m}^{3} / \mathrm{hr} \text { ] }\end{array}$ & $2.07 \times 10^{6}\left[3.52 \times 10^{6}\right]$ \\
\hline Coal Sulfur Content (\%) & 3.5 \\
\hline $\begin{array}{l}\text { Flue Gas } \mathrm{SO}_{2} \text { Content (ppmv wet at economizer } \\
\text { outlet) }\end{array}$ & 2790 \\
\hline Furnace Conversion of $\mathrm{SO}_{2}$ to $\mathrm{SO}_{3}($ mole $\%)$ & 1.0 \\
\hline $\begin{array}{l}\text { Conversion of } \mathrm{SO}_{2} \text { to } \mathrm{SO}_{3} \text { Across SCR Catalyst } \\
\text { (mole \%) }\end{array}$ & 0.75 \\
\hline $\mathrm{NO}_{x}$ Season Duration (months/yr) & 5 \\
\hline \multicolumn{2}{|c|}{ Target Stack Sulfuric Acid Concentration (ppmv, dry basis): } \\
\hline For lower $\mathrm{SO}_{3}$ removal percentage target & 9.5 (return to pre-SCR conditions) \\
\hline For higher $\mathrm{SO}_{3}$ removal percentage target & 3.0 (assumed value corresponding to "clear" stack) \\
\hline
\end{tabular}

\section{Results and Discussion}

\section{Heat and Material Balance Estimate Results}

Table 4-3 summarizes the projected $\mathrm{SO}_{3}$ removal performance of each technology with the SCR operating, and Table 4-4 summarizes the bases used for estimating reagent and other consumables quantities for achieving these $\mathrm{SO}_{3}$ removal levels. Table 4-5 summarizes the corresponding heat and material balance results. Tables 4-3 and 4-5 represent predicted results only for the lower sulfuric acid removal percentage target, to restore the stack sulfuric acid concentration to the pre-SCR value. Table 4-4 shows performance estimate bases for both removal percentage targets. 
Economic Comparison of Flue Gas Sulfuric Acid Removal Technologies

Table 4-3

Summary of $\mathrm{SO}_{3}$ Control Performance Estimates for Lower Percentage Control Target (return to pre-SCR stack sulfuric acid concentrations)

\begin{tabular}{|c|c|c|c|c|c|c|c|c|c|}
\hline & $\begin{array}{l}\text { Fuel } \\
\text { Switch/ } \\
\text { Blend }\end{array}$ & $\begin{array}{l}\text { Furnace } \\
\text { Injection } \\
\text { of } \\
\text { Byproduct } \\
\text { Mg }\end{array}$ & $\begin{array}{l}\text { Furnace } \\
\text { Injection of } \\
\text { Commercial } \\
\text { Mg }\end{array}$ & $\begin{array}{l}\text { MgO } \\
\text { Injection } \\
\text { Downstream } \\
\text { of SCR }\end{array}$ & $\begin{array}{l}\text { SBS } \\
\text { Injection } \\
\text { Between Air } \\
\text { Heater \& } \\
\text { ESP }\end{array}$ & $\begin{array}{l}\text { Ammonia } \\
\text { Injection } \\
\text { Between } \\
\text { Air Heater } \\
\text { \& ESP }\end{array}$ & $\begin{array}{l}\text { Humidification } \\
\text { \& Lime } \\
\text { Injection } \\
\text { Between Air } \\
\text { Heater \& ESP }\end{array}$ & $\begin{array}{l}\text { Hydrated } \\
\text { Lime } \\
\text { Injection } \\
\text { Between } \\
\text { Air Heater } \\
\text { \& ESP }\end{array}$ & Wet ESP \\
\hline $\begin{array}{l}\text { Stack Sulfuric Acid } \\
\text { Concentration } \\
\text { (ppmv) }\end{array}$ & 9.5 & 9.5 & 9.5 & 9.5 & 9.5 & - & 9.5 & 9.5 & 9.5 \\
\hline $\begin{array}{l}\mathrm{SO}_{3} / \text { Sulfuric Acid } \\
\text { Removal at Point of } \\
\text { Implementation (\%) }\end{array}$ & - & 75 & 75 & 55 & 55 & - & 55 & 55 & 55 \\
\hline $\begin{array}{l}\text { Sulfuric Acid } \\
\text { Removal Rate, lb- } \\
\text { mole/hr }\end{array}$ & - & 3.2 & 3.2 & 4.0 & 3.6 & - & 3.6 & 3.6 & 1.6 \\
\hline
\end{tabular}

Note: $1 \mathrm{lb}-\mathrm{mole} / \mathrm{hr}=454 \mathrm{~g}-\mathrm{mole} / \mathrm{hr}$ 
Economic Comparison of Flue Gas Sulfuric Acid Removal Technologies

Table 4-4

Summary of Bases for Consumables Quantity Estimates for Candidate $\mathrm{SO}_{3} /$ Sulfuric Acid Control Technologies

\begin{tabular}{|c|c|c|}
\hline \multirow[b]{2}{*}{ Technology } & \multicolumn{2}{|l|}{ Bases for Consumables Quantity Estimates } \\
\hline & 9.5 ppmv at Stack & 3.0 ppmv at Stack \\
\hline Fuel Blending & $32 \%$ low-sulfur ( 0.5 wt $\%)$ coal & $87 \%$ low-sulfur (0.5 wt $\%$ ) coal \\
\hline Byproduct $\mathrm{Mg}(\mathrm{OH})_{2}$ Injection in Furnace & $\begin{array}{l}3.9: 1 \mathrm{Mg}: \mathrm{SO}_{3} \text { mole ratio (based on SCR } \\
\text { outlet) }\end{array}$ & $\begin{array}{l}\text { 8:1 Mg: } \mathrm{SO}_{3} \text { mole ratio (based on } \mathrm{SCR} \text { outlet) } \\
\text { plus hydrated lime injection at } 1.8 \mathrm{lb} / \mathrm{hr} / \mathrm{kacfm}\end{array}$ \\
\hline Commercial $\mathrm{Mg}(\mathrm{OH})_{2}$ Injection in Furnace & $\begin{array}{l}3.9: 1 \mathrm{Mg}: \mathrm{SO}_{3} \text { mole ratio (based on SCR } \\
\text { outlet) }\end{array}$ & $\begin{array}{l}\text { 8:1 Mg: } \mathrm{SO}_{3} \text { mole ratio (based on } \mathrm{SCR} \text { outlet) } \\
\text { plus hydrated lime injection at } 1.8 \mathrm{lb} / \mathrm{hr} / \mathrm{kacfm}\end{array}$ \\
\hline MgO Powder Injection Upstream of Air Heater & 2.0 moles $\mathrm{Mg}$ injected per mole $\mathrm{SO}_{3}$ removed & 2.5 moles $\mathrm{Mg}$ injected per mole $\mathrm{SO}_{3}$ removed \\
\hline SBS Injection ${ }^{\mathrm{TM}}$ Upstream of Air Heater & 1.0 moles $\mathrm{Na}$ injected per mole $\mathrm{SO}_{3}$ removed & 1.8 moles $\mathrm{Na}$ injected per mole $\mathrm{SO}_{3}$ removed \\
\hline $\mathrm{NH}_{3}$ Injection Upstream of ESP & Not estimated at lower removal percentage & $\begin{array}{l}2.0 \text { moles } \mathrm{NH}_{3} \text { injected per mole } \mathrm{SO}_{3} \\
\text { removed }\end{array}$ \\
\hline Humidification/Lime Injection Upstream of ESP & $\begin{array}{l}\text { Humidification to } 293^{\circ} \mathrm{F}\left(145^{\circ} \mathrm{C}\right) \text {, hydrated } \\
\text { lime injection at } 0.5 \mathrm{lb} / \mathrm{hr} \text { per kacfm }\end{array}$ & $\begin{array}{l}\text { Humidification to } 275^{\circ} \mathrm{F}\left(135^{\circ} \mathrm{C}\right) \text {, hydrated } \\
\text { lime injection at } 1 \mathrm{lb} / \mathrm{hr} \text { per kacfm }\end{array}$ \\
\hline Hydrated Lime Injection Upstream of ESP & Hydrated lime injection at $1.3 \mathrm{lb} / \mathrm{hr}$ per kacfm & Hydrated lime injection at $3.4 \mathrm{lb} / \mathrm{hr}$ per kacfm \\
\hline Wet ESP & $\begin{array}{l}\text { Electric power at } 320 \mathrm{~W} / \mathrm{kacfm} \text {, water at } 0.25 \\
\text { gal/kacf, last field conversion of dry ESP }\end{array}$ & $\begin{array}{l}\text { Electric power at } 320 \mathrm{~W} / \mathrm{kacfm} \text {, water at } 0.25 \\
\text { gal/kacf, new wet ESP between wet FGD and } \\
\text { stack }\end{array}$ \\
\hline
\end{tabular}


Economic Comparison of Flue Gas Sulfuric Acid Removal Technologies

Table 4-5

Summary of $\mathrm{SO}_{3}$ Control Technology Heat and Material Balances for Lower Control Percentage Target (return to pre-SCR stack sulfuric acid concentration, operating 5 months /year)

\begin{tabular}{|c|c|c|c|c|c|c|c|c|c|}
\hline & $\begin{array}{l}\text { Fuel } \\
\text { Switch/ } \\
\text { Blend }\end{array}$ & $\begin{array}{l}\text { Furnace } \\
\text { Injection } \\
\text { of } \\
\text { Byproduct } \\
\text { Mg }\end{array}$ & $\begin{array}{l}\text { Furnace } \\
\text { Injection of } \\
\text { Commercial } \\
\text { Mg }\end{array}$ & $\begin{array}{l}\text { MgO } \\
\text { Injection } \\
\text { Down- } \\
\text { stream } \\
\text { of SCR }\end{array}$ & $\begin{array}{l}\text { SBS } \\
\text { Injection } \\
\text { Between } \\
\text { Air Heater } \\
\text { \& ESP }\end{array}$ & $\begin{array}{l}\text { Ammonia } \\
\text { Injection } \\
\text { Between } \\
\text { Air } \\
\text { Heater \& } \\
\text { ESP }\end{array}$ & $\begin{array}{l}\text { Humidification } \\
\text { \& Lime } \\
\text { Injection } \\
\text { Between Air } \\
\text { Heater \& ESP }\end{array}$ & $\begin{array}{l}\text { Hydrated } \\
\text { Lime } \\
\text { Injection } \\
\text { Between } \\
\text { Air Heater } \\
\text { \& ESP }\end{array}$ & Wet ESP \\
\hline $\begin{array}{l}\text { Percent Low Sulfur Coal Fired } \\
\text { (heat input basis) }\end{array}$ & 32 & - & - & - & - & - & - & - & - \\
\hline Reagent Used (lbs/hr, [gpm]) & - & [15] & {$[5]$} & 330 & 230 & - & 820 & 2200 & 190 \\
\hline Reagent Used (tons/yr) ${ }^{1}$ & $-16,000$ & 13,000 & 2400 & 510 & 350 & - & 1300 & 3400 & 300 \\
\hline Plant Water Use (gpm) & 0 & 0 & 2 & 0 & 5 & - & 24 & 0 & 600 \\
\hline Compressed Air Use (scfm) & 0 & 240 & 90 & 0 & 110 & - & 520 & 0 & 0 \\
\hline Pneumatic Air Use (scfm) & 0 & 0 & 0 & 660 & 0 & - & 1600 & 4400 & 0 \\
\hline Waste Disposal Mass (tons/yr) & -3400 & 2600 & 1700 & 1100 & 490 & - & 1600 & 3700 & 0 \\
\hline $\begin{array}{l}\text { Additional Gypsum Produced } \\
\text { (tons/yr) }\end{array}$ & $-30,000$ & 0 & 0 & 0 & 960 & - & 0 & 0 & 460 \\
\hline $\begin{array}{l}\text { Additional } \mathrm{SO}_{2} \text { Allowances } \\
\text { (tons/yr) }\end{array}$ & 420 & - & - & - & - & - & - & - & - \\
\hline $\begin{array}{l}\text { Net Boiler Efficiency } \\
\text { Improvement }(\%)^{2}\end{array}$ & 0.3 & 0.1 & 0.2 & 0.3 & 0 & - & 0 & 0 & 0 \\
\hline $\begin{array}{l}\text { Increase in ESP Inlet Mass } \\
\text { Loading }(\%)\end{array}$ & -7.7 & 4.6 & 2.5 & 2.6 & 1.1 & - & 3.7 & 8.5 & - \\
\hline
\end{tabular}

${ }^{1}$ Includes weight of water and impurities shipped with slurry reagents.

${ }^{2}$ Boiler efficiency improvement is based on avoiding the need to raise the air heater outlet temperature with the SCR operating due to the elevation of the flue gas acid dew point at higher $\mathrm{SO}_{3}$ concentrations.

Note: $1 \mathrm{gpm}=3.8 \mathrm{l} / \mathrm{min}, 1 \mathrm{lb} / \mathrm{hr}=0.45 \mathrm{~kg} / \mathrm{hr}, 1 \mathrm{ton} / \mathrm{yr}=0.91$ metric ton $/ \mathrm{yr}, 1 \mathrm{scfm}=1.6 \mathrm{Nm} / \mathrm{hr}$. 


\section{Economic Comparison of Flue Gas Sulfuric Acid Removal Technologies}

The results in Table 4-5 include rates for reagent consumption, usage of plant water, compressed air for dual-fluid nozzle atomization and for pneumatic transport, and increased waste disposal quantities. For the fuel switch case, the table shows the percentage of the boiler heat input that would have to be supplied by low-sulfur coal (assumed to be Powder River Basin coal) to achieve the stack sulfuric acid concentration target. Also for this case, the table indicates the additional $\mathrm{SO}_{2}$ allowances that would result (assuming constant percent $\mathrm{SO}_{2}$ removal across the FGD system but a lower inlet $\mathrm{SO}_{2}$ ), and the corresponding decrease in the amount of gypsum byproduct. This could be a factor if a plant is under contract to supply gypsum to a wallboard plant and has a minimum contract amount to supply annually.

Two other rows of information are included in the table. One is an estimated net boiler efficiency improvement for technologies that remove $\mathrm{SO}_{3}$ upstream of the air heater. Flue gas acid dew point elevation due to the higher $\mathrm{SO}_{3}$ concentrations downstream of an SCR system would likely require the air heater exit flue gas temperature to be increased to avoid corresponding increases in acid deposition and/or cold-end corrosion. Technologies that remove $\mathrm{SO}_{3}$ upstream of the air heater could allow this air heater outlet temperature elevation to be avoided, with an associated benefit to the plant heat rate. A factor of $1 \%$ improvement in plant efficiency per $40^{\circ} \mathrm{F}\left(22^{\circ} \mathrm{C}\right)$ of avoided increase in air heater outlet temperature was used to quantify this benefit. In calculating the benefit, it was assumed that the plant air heater outlet flue gas temperature would not be lowered below the current (pre-SCR) value due to heat transfer area limitations. Consequently, no additional benefit was included for technologies that might be able to lower the air heater inlet $\mathrm{SO}_{3}$ concentration below pre-SCR values.

When figuring the cost benefits of avoiding this potential boiler efficiency loss later in this section, the net benefit had to also consider heat rate penalties associated with technologies that inject watercontaining slurries or solutions upstream of the air heater. The injected water enters the furnace or economizer outlet gas as a liquid at ambient temperature, and leaves after heat recovery in the air heater as vapor at approximately $300^{\circ} \mathrm{F}\left(150^{\circ} \mathrm{C}\right)$. The enthalpy increase for this water comes at the expense of increased coal firing. The efficiency improvement values shown in Table 4-5 are net after penalties associated with this water addition, and such penalties are included in operating cost estimates presented later in this section.

The last row of the table shows the estimated increase in particulate loading to the ESP, for the technologies that involve $\mathrm{SO}_{3}$ or sulfuric acid removal upstream of the ESP. This provides an indicator of the potential impacts of the technology on ESP operation and particulate emissions compliance.

As can be seen in Table 4-5, one technology was not estimated for the lower $\mathrm{SO}_{3}$ removal percentage. Ammonia injection can cause operating problems if controlled to lower removal percentages. If ammonia is added at sub-stoichiometric rates, so as to achieve only the $55 \%$ sulfuric acid removal required to meet the lower removal percentage target, the byproduct would all be ammonium bisulfate $\left(\mathrm{NH}_{4} \mathrm{HSO}_{4}\right)$. Ammonium bisulfate is a sticky and corrosive solid that would likely cause ESP operating and maintenance problems. Instead, ammonia would typically be added at higher $\mathrm{NH}_{3}: \mathrm{H}_{2} \mathrm{SO}_{4}$ mole ratios, in the range of 1.5 to 2.0 , so as to form predominantly ammonium sulfate $\left[\left(\mathrm{NH}_{4}\right)_{2} \mathrm{SO}_{4}\right]$ which is less sticky and less corrosive. When injected at these mole ratios, 90 to $95 \%$ sulfuric acid removal would be expected. 
Similar heat and material balance calculations were made for the higher sulfuric acid control percentage target, down to 3 ppmv or less in the stack flue gas. Table 4-6 summarizes the $\mathrm{SO}_{3} /$ sulfuric acid removal performance of each technology for the higher sulfuric acid removal percentage target and Table 4-7 summarizes the corresponding heat and material balance results. The form of these tables is similar to Tables 4-3 and 4-5, respectively. Two technologies, byproduct $\mathrm{Mg}$ injection and commercial $\mathrm{Mg}$ injection in the furnace, were not estimated to be able to achieve the higher sulfuric acid removal percentage (down to 3 ppmv at the stack) independently. A second technology would have to be installed downstream to achieve the higher overall removal target. Two U.S. power plants have operated or are planning to operate with a combination of $\mathrm{Mg}$ injection in the furnace and hydrated lime injection between the air heater and ESP to achieve relatively high overall $\mathrm{SO}_{3}$ /sulfuric acid control efficiencies when operating an SCR. ${ }^{6}$ Consequently, this combination of control technologies was included for economic evaluation for the higher removal percentage case.

Based on the heat and material balance results shown in Table 4-7, three technologies may not be viable for some plants at the higher removal percentage target, because of the large sorbent quantities estimated for injection to achieve $3 \mathrm{ppmv}$ at the stack. These technologies include the two furnace $\mathrm{Mg}$ injection technologies combined with downstream injection of hydrated lime, and injection of hydrated lime alone. These technologies or technology combinations were estimated to increase the mass loading to the ESP by 17 to $21 \%$. At these injection rates, it is possible that a small or moderately size ESP would not be able to maintain particulate emissions compliance, not only because of inlet mass loading effects but because of increased particle resistivity effects as well.

Also, for reasons described previously in this section, the SBS injection, ammonia injection and wet ESP options were evaluated at 90 to $91 \%$ sulfuric acid removal even though material balances indicated a slightly lower percentage was needed to achieve the 3 ppmv sulfuric acid target. For these technologies the estimated stack sulfuric acid concentration was between 2 and 3 ppmv (dry basis).

\section{Capital Cost Estimates}

The performance estimates and heat and material balances discussed above formed the basis for capital cost estimates for seven of the nine technologies under consideration:

- Byproduct Mg injection in the furnace,

- Commercial $\mathrm{Mg}$ injection in the furnace,

- $\mathrm{MgO}$ powder injection downstream of the SCR,

- SBS solution injection downstream of the SCR, or between the air heater and ESP,

- Ammonia injection between the air heater and ESP,

- Flue gas humidification with hydrated lime injection between the air heater and ESP, and

- Hydrated lime powder injection between the air heater and ESP. 
Economic Comparison of Flue Gas Sulfuric Acid Removal Technologies

Table 4-6

Summary of $\mathrm{SO}_{3}$ Control Performance Estimates for Higher Percentage Control Target (3 ppmv at stack with SCR in Service)

\begin{tabular}{|c|c|c|c|c|c|c|c|c|c|}
\hline & $\begin{array}{l}\text { Fuel } \\
\text { Switch/ } \\
\text { Blend }\end{array}$ & $\begin{array}{l}\text { Furnace } \\
\text { Injection } \\
\text { of } \\
\text { Byproduct } \\
\text { Mg/ } \\
\text { Hydrated } \\
\text { Lime } \\
\text { Injection }\end{array}$ & $\begin{array}{l}\text { Furnace } \\
\text { Injection of } \\
\text { Commercial } \\
\text { Mg/ } \\
\text { Hydrated } \\
\text { Lime } \\
\text { Injection }\end{array}$ & $\begin{array}{l}\text { MgO } \\
\text { Injection } \\
\text { Downstream } \\
\text { of SCR }\end{array}$ & $\begin{array}{l}\text { SBS } \\
\text { Injection } \\
\text { Downstream } \\
\text { of SCR }\end{array}$ & $\begin{array}{l}\text { Ammonia } \\
\text { Injection } \\
\text { Between } \\
\text { Air Heater } \\
\text { \& ESP }\end{array}$ & $\begin{array}{l}\text { Humidification } \\
\text { \& Lime } \\
\text { Injection } \\
\text { Between Air } \\
\text { Heater \& ESP }\end{array}$ & $\begin{array}{l}\text { Hydrated } \\
\text { Lime } \\
\text { Injection } \\
\text { Between } \\
\text { Air Heater } \\
\text { \& ESP }\end{array}$ & Wet ESP \\
\hline $\begin{array}{l}\text { Stack Sulfuric Acid } \\
\text { Concentration } \\
\text { (ppmv) }\end{array}$ & 3.0 & $7.2 / 3.0^{1}$ & $7.2 / 3.0^{1}$ & 3.0 & 2.2 & 2.4 & 3.0 & 3.0 & 2.1 \\
\hline $\begin{array}{l}\mathrm{SO}_{3} / \text { Sulfuric Acid } \\
\text { Removal at Point of } \\
\text { Implementation (\%) }\end{array}$ & - & $90 / 63^{2}$ & $90 / 63^{2}$ & 86 & 91 & 90 & 86 & 86 & 90 \\
\hline $\begin{array}{l}\text { Sulfuric Acid } \\
\text { Removal Rate, lb- } \\
\text { mole/hr }\end{array}$ & - & 5.6 & 5.6 & 6.3 & 6.7 & 5.9 & 5.6 & 5.6 & 2.6 \\
\hline
\end{tabular}

${ }^{1}$ First number is the projected stack concentration with furnace Mg injection only, second number reflects hydrated lime injection between air heater and ESP in combination with furnace $\mathrm{Mg}$ injection.

${ }^{2}$ First number reflects percentage removal of furnace-formed $\mathrm{SO}_{3}$, second number reflects percentage removal of sulfuric acid in the air heater outlet flue gas.

Note: $1 \mathrm{lb}$-mole/hr $=454 \mathrm{~g}-\mathrm{mole} / \mathrm{hr}$ 
Economic Comparison of Flue Gas Sulfuric Acid Removal Technologies

Table 4-7

Summary of $\mathrm{SO}_{3}$ Control Technology Heat and Material Balances for Higher Percentage Control Target (3 ppmv at stack with SCR in service, operating 5 months /year)

\begin{tabular}{|c|c|c|c|c|c|c|c|c|c|}
\hline & $\begin{array}{l}\text { Fuel } \\
\text { Switch/ } \\
\text { Blend }\end{array}$ & $\begin{array}{l}\text { Furnace } \\
\text { Injection } \\
\text { of } \\
\text { Byproduct } \\
\text { Mg/ } \\
\text { Hydrated } \\
\text { Lime } \\
\text { Injection }\end{array}$ & $\begin{array}{l}\text { Furnace } \\
\text { Injection of } \\
\text { Commercial } \\
\text { Mg/ } \\
\text { Hydrated } \\
\text { Lime } \\
\text { Injection }\end{array}$ & $\begin{array}{l}\text { MgO } \\
\text { Injection } \\
\text { Down- } \\
\text { stream } \\
\text { of SCR }\end{array}$ & $\begin{array}{l}\text { SBS } \\
\text { Injection } \\
\text { Down- } \\
\text { stream } \\
\text { of SCR }\end{array}$ & $\begin{array}{l}\text { Ammonia } \\
\text { Injection } \\
\text { Between } \\
\text { Air Heater } \\
\text { \& ESP }\end{array}$ & $\begin{array}{l}\text { Humidifi- } \\
\text { cation \& } \\
\text { Lime } \\
\text { Injection } \\
\text { Between Air } \\
\text { Heater \& ESP }\end{array}$ & $\begin{array}{l}\text { Hydrated } \\
\text { Lime } \\
\text { Injection } \\
\text { Between } \\
\text { Air Heater } \\
\text { \& ESP }\end{array}$ & $\begin{array}{l}\text { Wet } \\
\text { ESP }\end{array}$ \\
\hline $\begin{array}{l}\text { Percent Low Sulfur Coal Fired (heat } \\
\text { input basis) }\end{array}$ & 87 & - & - & - & - & - & - & - & - \\
\hline Reagent Used (lbs/hr, [gpm]) & - & {$[30]+3000$} & {$[11]+3000$} & 640 & 750 & 180 & 1600 & 5700 & 310 \\
\hline Reagent Used (tons/yr) ${ }^{1}$ & $-51,000$ & $\begin{array}{l}26,000+ \\
4600\end{array}$ & $4900+4600$ & 990 & 1160 & 280 & 2500 & 8800 & 490 \\
\hline Plant Water Use (gpm) & - & 0 & 4 & - & 15 & - & 62 & - & 330 \\
\hline Compressed Air Use (scfm) & - & 490 & 190 & - & 370 & - & 1400 & - & - \\
\hline Pneumatic Air Use (scfm) & - & 5900 & 5900 & 1300 & - & 1300 & 3300 & 11,000 & - \\
\hline Waste Disposal Mass (tons/yr) & $-11,000$ & 9800 & 8000 & 2000 & 1500 & $45,000^{3}$ & 3100 & 9400 & - \\
\hline Additional Gypsum Produced (tons/yr) & $-99,000$ & - & - & - & 1800 & 0 & 0 & 0 & 750 \\
\hline Additional $\mathrm{SO}_{2}$ Allowances (tons/yr) & 1400 & 0 & 0 & 0 & 0 & 0 & 0 & 0 & - \\
\hline Net Boiler Efficiency Improvement $(\%)^{2}$ & 0.3 & 0.3 & 0.3 & 0.3 & 0.1 & 0 & 0 & 0 & - \\
\hline Increase in ESP Inlet Mass Loading (\%) & -26 & 21 & 17 & 4.7 & 3.4 & 2.7 & 7.1 & 21 & - \\
\hline
\end{tabular}

${ }^{1}$ Includes weight of water and impurities shipped with slurry reagents.

${ }^{2}$ Efficiency improvement based on avoiding need to raise air heater outlet temperature with the SCR operating due to elevated flue gas acid dew point.

${ }^{3}$ Represents loss of fly ash sales of $100 \%$ of fly ash production.

Note: $1 \mathrm{gpm}=3.8 \mathrm{l} / \mathrm{min}, 1 \mathrm{lb} / \mathrm{hr}=0.45 \mathrm{~kg} / \mathrm{hr}, 1 \mathrm{ton} / \mathrm{yr}=0.91 \mathrm{metric}$ ton $/ \mathrm{yr}, 1 \mathrm{scfm}=1.6 \mathrm{Nm} / \mathrm{hr}$. 
Capital cost estimates were also developed for the wet ESP case, but based solely on general budgetary cost factors. A cost factor of $\$ 35 / \mathrm{kW}$ was used for a last-field dry ESP conversion for the lower $\mathrm{SO}_{3}$ removal target, and a factor of $\$ 55 / \mathrm{kW}$ for standalone wet ESP retrofits downstream of the wet FGD absorbers. The capital costs for a wet ESP retrofit can be very site specific, depending on the difficulty of the retrofit and materials of construction selection, and could vary by $\pm 50 \%$ from these estimates for a specific circumstance.

No capital costs were estimated for fuel switching. Again, the capital cost requirements for this technology can be very site specific. Some plants may be able to blend low sulfur coals with little or no capital requirements, while other plants may require extensive revisions such as new coal blending conveyors, increased mill capacity, soot blower upgrades, etc., and/or unit derating.

For the seven technologies listed above, the heat and material balance results were used to develop budgetary capital cost estimates. The approach taken was to identify major equipment such as silos, tanks, pumps, and air compressors, and estimate their size based on the material balance calculation results. Storage silos or tanks were generally sized for 15-day storage at full load, and at the corresponding $\mathrm{SO}_{3}$ /sulfuric acid removal target. Most technologies were also assumed to have a day tank or silo near the unit, sized for 24 hours of capacity at full load for the $\mathrm{SO}_{3} /$ sulfuric acid removal target being evaluated. Pumps, blowers, and air compressors were also sized based on the material balance results for full load operation. Once sized, the major equipment purchase costs were estimated based on recent data for purchases, or quotations from URS project and proposal files.

Spreadsheets were then used to develop an overall project cost estimate. Piping costs were based on estimated piping run lengths and standardized per-foot cost estimates for each pipe size and material (carbon steel or 300-series stainless steel). Instrumentation requirements were based on typical process flow diagrams for each technology. Other items such as motor controls and valves were estimated from the number of major equipment items and piping requirements.

Standard factors were used for developing estimates for process design, detailed design and procurement, installation labor, construction management, commissioning startup and training, etc. Labor rates were based on union labor in the Midwest.

An estimate of this type is typically regarded as having an accuracy of $\pm 25 \%$. However, for these particular estimates, the accuracy is more likely in the range of \pm 30 to $50 \%$ for a variety of reasons, including:

- Major equipment item costs were interpolated based on previous cost data rather than soliciting vendor quotes for each specific equipment item;

- Assumptions were made regarding redundancy, instrumentation requirements and control approach that might change during a detailed design effort; and

- The exact placement of and the retrofit difficulty for each equipment item could not be determined given that the plant represents a hypothetical case. 
This level of accuracy should be adequate for comparing the cost-effectiveness of candidate control technologies, though, particularly considering that the uncertainties listed above should apply to each of the technology options.

Table 4-8 summarizes the capital cost estimates for the six technologies for which estimates were developed for the lower $\mathrm{SO}_{3}$ /sulfuric acid removal percentage target of returning the stack sulfuric acid concentration to pre-SCR levels. Table 4-9 summarizes the capital cost estimates for achieving the higher $\mathrm{SO}_{3}$ /sulfuric acid removal percentage target. The following paragraphs describe salient features of each of the estimates.

Byproduct or Commercial Mg Injection in the Furnace. Byproduct Mg slurry would be received in truckload quantities and stored in a 320,000-gallon $\left(1200-\mathrm{m}^{3}\right)$ storage tank. Due to the large size of this tank and the assumed proximity of the model plant to the byproduct $\mathrm{Mg}$ source, the same tank size was assumed for both removal percentage cases. This lowers the effective days of storage to 7 for the higher removal case compared to 15 for the lower removal. For either case, a day tank closer to the unit would be sized for 24 hours' usage of the byproduct slurry.

For commercial $\mathrm{Mg}$, the storage tank would be much smaller, at 50,000 gallons $\left(160 \mathrm{~m}^{3}\right)$ for the lower removal percentage target and 100,000 gallons $\left(320 \mathrm{~m}^{3}\right)$ for the higher removal target. Provisions were included to dilute the concentrated slurry from $58 \mathrm{wt} \%$ in the storage tank to about $30 \mathrm{wt} \%$ for injection, just prior to pumping makeup slurry to the day tank.

For both technologies, it was assumed that the injection lances would be installed through existing view port openings in the furnace walls; no waterwall modifications were included. It is possible that the removal efficiency and/or reagent utilization for the two furnace injection technologies could be improved by computational fluid dynamics (CFD) modeling to optimize injection locations. However, such improvements would come with additional costs to conduct the CFD model study and the costs (and potentially increased boiler outage time) associated with adding new waterwall penetrations.

Neither of the furnace $\mathrm{Mg}$ injection technologies were estimated to be able to achieve the $3 \mathrm{ppmv}$ sulfuric acid target with the SCR in service. Consequently, the capital costs shown for these technologies in Table 4-9 include costs for a downstream hydrated lime powder injection system.

$\mathrm{MgO}$ Injection. The estimate is based on truck unloading of $\mathrm{MgO}$ powder into a storage silo. Adjacent to the unit would be a 24-hr day silo and pneumatic injection equipment for each of two duct runs. 
Economic Comparison of Flue Gas Sulfuric Acid Removal Technologies

Table 4-8

Summary of $\mathrm{SO}_{3}$ Control Technology Capital Cost Estimates for the Lower Sulfuric Acid Removal Percentage Target - All Values in $\$ 1000$

\begin{tabular}{|c|c|c|c|c|c|c|c|c|c|}
\hline & $\begin{array}{l}\text { Fuel } \\
\text { Switch/ } \\
\text { Blend }\end{array}$ & $\begin{array}{l}\text { Furnace } \\
\text { Injection of } \\
\text { Byproduct } \\
\text { Mg }\end{array}$ & $\begin{array}{l}\text { Furnace } \\
\text { Injection of } \\
\text { Commercial } \\
\text { Mg }\end{array}$ & $\begin{array}{l}\text { MgO } \\
\text { Injection } \\
\text { Downstream } \\
\text { of SCR }\end{array}$ & $\begin{array}{l}\text { SBS } \\
\text { Injection } \\
\text { Between Air } \\
\text { Heater \& } \\
\text { ESP }\end{array}$ & $\begin{array}{l}\text { Ammonia } \\
\text { Injection } \\
\text { Between Air } \\
\text { Heater \& } \\
\text { ESP }\end{array}$ & $\begin{array}{l}\text { Humidifica- } \\
\text { tion \& Lime } \\
\text { Injection } \\
\text { Between Air } \\
\text { Heater \& } \\
\text { ESP }\end{array}$ & $\begin{array}{l}\text { Hydrated } \\
\text { Lime } \\
\text { Injection } \\
\text { Between Air } \\
\text { Heater \& } \\
\text { ESP }\end{array}$ & $\begin{array}{l}\text { Last Field } \\
\text { Conversion } \\
\text { to Wet ESP }\end{array}$ \\
\hline \multicolumn{10}{|c|}{ Procurement and Construction: } \\
\hline Material & - & 1,120 & 770 & 1,130 & 800 & - & 1,540 & 1,820 & - \\
\hline Labor & - & 570 & 560 & 760 & 710 & - & 1,140 & 1,000 & - \\
\hline $\begin{array}{l}\text { Total Material } \\
\text { and Labor }\end{array}$ & - & 1,690 & 1,330 & 1,890 & 1,510 & - & 2,680 & 2,820 & - \\
\hline $\begin{array}{l}\text { Process Design } \\
\text { and Project } \\
\text { Management }\end{array}$ & - & 100 & 80 & 110 & 90 & - & 160 & 170 & - \\
\hline $\begin{array}{l}\text { Detailed Design } \\
\text { \& Procurement }\end{array}$ & - & 270 & 210 & 300 & 240 & - & 430 & 450 & - \\
\hline $\begin{array}{l}\text { Construction } \\
\text { Management }\end{array}$ & - & 100 & 100 & 100 & 100 & - & 100 & 100 & - \\
\hline $\begin{array}{l}\text { Commissioning, } \\
\text { Startup, and } \\
\text { Operator } \\
\text { Training }\end{array}$ & - & 20 & 20 & 20 & 20 & - & 20 & 20 & - \\
\hline Subtotal & - & 2,180 & 1,740 & 2,420 & 1,960 & - & 3,390 & 3,560 & - \\
\hline
\end{tabular}


Table 4-8 (continued)

\begin{tabular}{|c|c|c|c|c|c|c|c|c|c|}
\hline & $\begin{array}{l}\text { Fuel } \\
\text { Switch/ } \\
\text { Blend }\end{array}$ & $\begin{array}{l}\text { Furnace } \\
\text { Injection of } \\
\text { Byproduct } \\
\text { Mg }\end{array}$ & $\begin{array}{l}\text { Furnace } \\
\text { Injection of } \\
\text { Commercial } \\
\text { Mg }\end{array}$ & $\begin{array}{l}\text { MgO } \\
\text { Injection } \\
\text { Downstream } \\
\text { of SCR }\end{array}$ & $\begin{array}{l}\text { SBS } \\
\text { Injection } \\
\text { Between Air } \\
\text { Heater \& } \\
\text { ESP }\end{array}$ & $\begin{array}{l}\text { Ammonia } \\
\text { Injection } \\
\text { Between Air } \\
\text { Heater \& } \\
\text { ESP }\end{array}$ & $\begin{array}{l}\text { Humidifica- } \\
\text { tion \& Lime } \\
\text { Injection } \\
\text { Between Air } \\
\text { Heater \& } \\
\text { ESP }\end{array}$ & $\begin{array}{l}\text { Hydrated } \\
\text { Lime } \\
\text { Injection } \\
\text { Between Air } \\
\text { Heater \& } \\
\text { ESP }\end{array}$ & $\begin{array}{l}\text { Last Field } \\
\text { Conversion } \\
\text { to Wet ESP }\end{array}$ \\
\hline Project Fee & - & 340 & 270 & 370 & 690 & - & 510 & 530 & - \\
\hline $\begin{array}{l}\text { Project Cost with } \\
\text { Fee }\end{array}$ & - & 2,520 & 2,010 & 2,790 & 2,650 & - & 3,900 & 4,090 & - \\
\hline Contingency & - & 250 & 200 & 280 & 270 & - & 390 & 410 & - \\
\hline $\begin{array}{l}\text { Total Estimated } \\
\text { Project Cost }\end{array}$ & - & 2,770 & 2,210 & 3,070 & 2,920 & - & 4,290 & 4,500 & 17,500 \\
\hline
\end{tabular}


Economic Comparison of Flue Gas Sulfuric Acid Removal Technologies

Table 4-9

Summary of $\mathrm{SO}_{3}$ Control Technology Capital Cost Estimates for the Higher Sulfuric Acid Removal Percentage Target - All Values in $\$ 1000$

\begin{tabular}{|c|c|c|c|c|c|c|c|c|c|}
\hline & $\begin{array}{l}\text { Fuel } \\
\text { Switch/ } \\
\text { Blend }\end{array}$ & $\begin{array}{l}\text { Furnace } \\
\text { Injection } \\
\text { of } \\
\text { Byproduct } \\
\text { Mg + } \\
\text { Hydrated } \\
\text { Lime } \\
\text { Injection }\end{array}$ & $\begin{array}{l}\text { Furnace } \\
\text { Injection of } \\
\text { Commercial } \\
\text { Mg + } \\
\text { Hydrated } \\
\text { Lime } \\
\text { Injection }\end{array}$ & $\begin{array}{l}\text { MgO } \\
\text { Injection } \\
\text { Downstream } \\
\text { of SCR }\end{array}$ & $\begin{array}{l}\text { SBS Injection } \\
\text { Downstream } \\
\text { of SCR }\end{array}$ & $\begin{array}{l}\text { Ammonia } \\
\text { Injection } \\
\text { Between Air } \\
\text { Heater \& } \\
\text { ESP }\end{array}$ & $\begin{array}{l}\text { Humidifica- } \\
\text { tion \& Lime } \\
\text { Injection } \\
\text { Between Air } \\
\text { Heater \& } \\
\text { ESP }\end{array}$ & $\begin{array}{l}\text { Hydrated } \\
\text { Lime } \\
\text { Injection } \\
\text { Between Air } \\
\text { Heater \& } \\
\text { ESP }\end{array}$ & $\begin{array}{l}\text { Wet ESP } \\
\text { Between } \\
\text { FGD } \\
\text { Absorber \& } \\
\text { Stack }\end{array}$ \\
\hline \multicolumn{10}{|c|}{ Procurement and Construction: } \\
\hline Material & - & 3,090 & 2,760 & 1,190 & 1020 & 520 & 1,770 & 2,110 & - \\
\hline Labor & - & 1,580 & 1,560 & 770 & 730 & 380 & 1,140 & 1,010 & - \\
\hline $\begin{array}{l}\text { Total Material } \\
\text { and Labor }\end{array}$ & - & 4,670 & 4,320 & 1,960 & 1,750 & 900 & 2,920 & 3,120 & - \\
\hline $\begin{array}{l}\text { Process Design } \\
\text { and Project } \\
\text { Management }\end{array}$ & - & 290 & 270 & 120 & 100 & 50 & 180 & 190 & - \\
\hline $\begin{array}{l}\text { Detailed Design } \\
\text { \& Procurement }\end{array}$ & - & 740 & 690 & 310 & 280 & 150 & 470 & 490 & - \\
\hline $\begin{array}{l}\text { Construction } \\
\text { Management }\end{array}$ & - & 100 & 100 & 100 & 100 & 100 & 100 & 100 & - \\
\hline $\begin{array}{l}\text { Commissioning, } \\
\text { Startup, and } \\
\text { Operator } \\
\text { Training }\end{array}$ & - & 20 & 20 & 20 & 20 & 20 & 20 & 20 & - \\
\hline Subtotal & - & 5,820 & 5,400 & 2,510 & 2,250 & 1,220 & 3,680 & 3,920 & - \\
\hline
\end{tabular}


Table 4-9 (continued)

\begin{tabular}{|c|c|c|c|c|c|c|c|c|c|}
\hline & $\begin{array}{l}\text { Fuel } \\
\text { Switch/ } \\
\text { Blend }\end{array}$ & $\begin{array}{l}\text { Furnace } \\
\text { Injection } \\
\text { of } \\
\text { Byproduct } \\
\text { Mg + } \\
\text { Hydrated } \\
\text { Lime } \\
\text { Injection }\end{array}$ & $\begin{array}{l}\text { Furnace } \\
\text { Injection of } \\
\text { Commercial } \\
\text { Mg + } \\
\text { Hydrated } \\
\text { Lime } \\
\text { Injection }\end{array}$ & $\begin{array}{l}\text { MgO } \\
\text { Injection } \\
\text { Downstream } \\
\text { of SCR }\end{array}$ & $\begin{array}{l}\text { SBS Injection } \\
\text { Downstream } \\
\text { of SCR }\end{array}$ & $\begin{array}{l}\text { Ammonia } \\
\text { Injection } \\
\text { Between Air } \\
\text { Heater \& } \\
\text { ESP }\end{array}$ & $\begin{array}{l}\text { Humidifica- } \\
\text { tion \& Lime } \\
\text { Injection } \\
\text { Between Air } \\
\text { Heater \& } \\
\text { ESP }\end{array}$ & $\begin{array}{l}\text { Hydrated } \\
\text { Lime } \\
\text { Injection } \\
\text { Between Air } \\
\text { Heater \& } \\
\text { ESP }\end{array}$ & $\begin{array}{l}\text { Wet ESP } \\
\text { Between } \\
\text { FGD } \\
\text { Absorber \& } \\
\text { Stack }\end{array}$ \\
\hline Project Fee & - & 870 & 810 & 380 & 790 & 180 & 550 & 590 & - \\
\hline $\begin{array}{l}\text { Project Cost with } \\
\text { Fee }\end{array}$ & - & 6,690 & 6,210 & 2,890 & 3,040 & 1,400 & 4,230 & 4,510 & - \\
\hline Contingency & - & 670 & 620 & 290 & 300 & 140 & 420 & 450 & - \\
\hline $\begin{array}{l}\text { Total Estimated } \\
\text { Project Cost }\end{array}$ & - & 7,360 & 6,830 & 3,180 & 3,340 & 1,540 & 4,650 & 4,960 & 27,500 \\
\hline
\end{tabular}


SBS Injection. The estimate is based on truck unloading of sodium sulfite powder, wetting it to form a solution, and pumping the concentrated solution to a storage tank. From the storage tank the concentrated solution would be diluted with water and pumped to nozzle arrays on each of two duct runs on the unit. A dedicated compressor, with spare, would provide atomizing air to the nozzles.

Ammonia Injection. Ammonia would be supplied by the existing ammonia feed system for the SCR, which assumes that system has adequate capacity. Anhydrous ammonia would be mixed with pre-heated air, then pneumatically conveyed into the two duct runs via injection grids.

Humidification with Lime Injection. The humidification water would be plant water, fed through a booster pump and fine particle filter. Atomizing air would be provided by a dedicated compressor and spare. Hydrated lime would be received by truck or rail and stored in a large silo. A day silo near the unit would be equipped with a weigh belt to meter the solids to each air heater outlet duct and a pneumatic air blower, with spare, to inject the powder.

Hydrated Lime Powder Injection. Hydrated lime would be received by truck or rail and stored in a large silo. A day silo near the unit would be equipped with a weigh belt to meter the solids to each air heater outlet duct and a pneumatic air blower, with spare, to inject the powder.

Wet ESP. The capital cost factor of $\$ 35 / \mathrm{kW}$ for the lower removal percentage case is based on a last-field conversion of the existing dry ESP, and using 316 alloy. The factor of $\$ 55 / \mathrm{kW}$ for the higher removal percentage assumes the addition of a new wet ESP downstream of the wet FGD absorber, and the use of duplex stainless steel alloy. A conservative estimate based on the use of the higher alloy was employed because the wet ESP would be situated downstream of the wet scrubber and chloride-containing FGD liquor could be carried up into the acidic environment.

\section{Summary of Operating and Capital Cost Estimates for Control Technologies}

The reagent and utility consumption estimates from Tables 4-5 and 4-7, and the amortized capital cost estimates from Tables 4-8 and 4-9 were combined to generate annual cost estimates for each of the technologies. These estimates were not "levelized" to reflect escalation and discount rates, but instead represent first-year costs. Nor do they include operating labor, or maintenance labor and materials. For most of the technologies, there is not a good experience basis for estimating these values, so such an estimate would be based on a percentage of capital, reagent, and/or utility costs, and would not help differentiate the projected costs of technologies.

Table 4-10 summarizes the operating and capital costs for each technology for returning the stack sulfuric acid concentration to pre-SCR values. Table 4-11 shows the operating and capital costs for each technology for the higher sulfuric acid removal percentage target of 3 ppmv or less at the stack. The reagent and utility consumption values in the two tables are based on operating the technologies at the target $\mathrm{SO}_{3}$ control level from May 1 to September 30 each year (the ozone season). 
Economic Comparison of Flue Gas Sulfuric Acid Removal Technologies

Table 4-10

Summary of $\mathrm{SO}_{3}$ Control Technology First-year Reagent and Utility Cost Estimates for the Lower Target Sulfuric Acid Removal Percentage (return to pre-SCR stack concentrations, operation 5 months per year) - All Values in $\$ 1000$

\begin{tabular}{|c|c|c|c|c|c|c|c|c|c|}
\hline & $\begin{array}{l}\text { Fuel } \\
\text { Switch/ } \\
\text { Blend }\end{array}$ & $\begin{array}{l}\text { Furnace } \\
\text { Injection of } \\
\text { Byproduct } \\
\text { Mg }\end{array}$ & $\begin{array}{l}\text { Furnace } \\
\text { Injection of } \\
\text { Commercial } \\
\text { Mg }\end{array}$ & $\begin{array}{l}\text { MgO } \\
\text { Injection } \\
\text { Downstream } \\
\text { of SCR }\end{array}$ & $\begin{array}{l}\text { SBS } \\
\text { Injection } \\
\text { Between Air } \\
\text { Heater and } \\
\text { ESP }\end{array}$ & $\begin{array}{l}\text { Ammonia } \\
\text { Injection } \\
\text { Between } \\
\text { Air Heater } \\
\text { and ESP }\end{array}$ & $\begin{array}{l}\text { Humidifica- } \\
\text { tion and Lime } \\
\text { Injection } \\
\text { Between Air } \\
\text { Heater and } \\
\text { ESP }\end{array}$ & $\begin{array}{l}\text { Hydrated } \\
\text { Lime } \\
\text { Injection } \\
\text { Between } \\
\text { Air Heater } \\
\text { and ESP }\end{array}$ & $\begin{array}{l}\text { Wet ESP } \\
\text { Conversion }\end{array}$ \\
\hline $\begin{array}{l}\text { Reagent Cost } \\
\text { (Savings) }\end{array}$ & $(122)$ & 137 & 288 & 203 & 110 & - & 102 & 271 & 15 \\
\hline Reagent Shipping & (included) & 76 & 172 & 37 & (included) & - & (included) & (included) & (included) \\
\hline $\begin{array}{l}\text { Technology License } \\
\text { Fee }\end{array}$ & - & - & - & - & 100 & - & - & - & - \\
\hline Plant Water & - & - & - & - & 2 & - & 2 & - & 44 \\
\hline Auxiliary Power & - & 6 & 2 & 4 & 3 & - & 23 & 27 & 76 \\
\hline Fuel Cost (Savings) & 847 & $(12)$ & (31) & (41) & - & - & - & - & - \\
\hline $\begin{array}{l}\mathrm{SO}_{2} \text { Allowance } \\
\text { Credit }\end{array}$ & 62 & - & - & - & - & - & - & & - \\
\hline $\begin{array}{l}\text { Waste Disposal } \\
\text { Cost (Gypsum } \\
\text { Value) }\end{array}$ & 136 & 10 & 4 & 4 & (3) & - & 6 & 15 & (2) \\
\hline $\begin{array}{l}\text { Total Net Non-labor } \\
\text { Operating Cost }\end{array}$ & 798 & 217 & 437 & 207 & 212 & - & 133 & 313 & 133 \\
\hline $\begin{array}{l}\text { Capital Recovery } \\
\text { Cost }\end{array}$ & - & 415 & 332 & 460 & 438 & - & 644 & 675 & 2625 \\
\hline $\begin{array}{l}\text { Total Annual } \\
\text { Operating and } \\
\text { Capital Cost }\end{array}$ & $\begin{array}{l}798 \\
\text { (operating } \\
\text { cost only) }\end{array}$ & 632 & 769 & 667 & 650 & - & 777 & 988 & 2,758 \\
\hline
\end{tabular}


Economic Comparison of Flue Gas Sulfuric Acid Removal Technologies

Table 4-11

Summary of $\mathrm{SO}_{3}$ Control Technology First-year Reagent and Utility Cost Estimates for the Higher Target Sulfuric Acid Removal Percentage (3 ppmv at stack with SCR in service, operation 5 months per year) - All Values in $\$ 1000$

\begin{tabular}{|c|c|c|c|c|c|c|c|c|c|}
\hline & $\begin{array}{l}\text { Fuel } \\
\text { Switch/ } \\
\text { Blend }\end{array}$ & $\begin{array}{l}\text { Furnace } \\
\text { Injection } \\
\text { of } \\
\text { Byproduct } \\
\text { Mg }\end{array}$ & $\begin{array}{l}\text { Furnace } \\
\text { Injection of } \\
\text { Commercial } \\
\text { Mg }\end{array}$ & $\begin{array}{l}\text { MgO } \\
\text { Injection } \\
\text { Downstream } \\
\text { of SCR }\end{array}$ & $\begin{array}{l}\text { SBS } \\
\text { Injection } \\
\text { Downstream } \\
\text { of SCR }\end{array}$ & $\begin{array}{l}\text { Ammonia } \\
\text { Injection } \\
\text { Between } \\
\text { Air Heater } \\
\text { and ESP }\end{array}$ & $\begin{array}{l}\text { Humidifica- } \\
\text { tion and Lime } \\
\text { Injection } \\
\text { Between Air } \\
\text { Heater and } \\
\text { ESP }\end{array}$ & $\begin{array}{l}\text { Hydrated } \\
\text { Lime } \\
\text { Injection } \\
\text { Between } \\
\text { Air Heater } \\
\text { and ESP }\end{array}$ & $\begin{array}{l}\text { Wet ESP } \\
\text { Between } \\
\text { FGD } \\
\text { Absorber } \\
\text { and } \\
\text { Stack }\end{array}$ \\
\hline $\begin{array}{l}\text { Reagent Cost } \\
\text { Savings) }\end{array}$ & $(407)$ & 626 & 937 & 397 & 357 & 84 & 203 & 704 & 24 \\
\hline Reagent Shipping & (included) & 157 & 354 & 72 & (included) & (included) & (included) & (included) & (included) \\
\hline $\begin{array}{l}\text { Technology License } \\
\text { Fee }\end{array}$ & - & - & - & - & 100 & - & - & - & - \\
\hline Plant Water & - & - & - & - & 7 & - & 5 & - & 24 \\
\hline Auxiliary Power & - & 48 & 41 & 8 & 9 & 13 & 53 & 70 & 42 \\
\hline Fuel Cost (Savings) & 2,434 & (14) & (23) & (41) & (11) & - & - & - & - \\
\hline $\begin{array}{l}\mathrm{SO}_{2} \text { Allowance } \\
\text { Credit }\end{array}$ & 208 & - & - & - & - & - & - & - & - \\
\hline $\begin{array}{l}\text { Waste Disposal } \\
\text { Cost (Gypsum } \\
\text { Value) }\end{array}$ & 452 & 39 & 32 & 8 & (3) & 310 & 12 & 37 & (4) \\
\hline $\begin{array}{l}\text { Total Net Non-labor } \\
\text { Operating Cost }\end{array}$ & 2,272 & 885 & 1341 & 444 & 459 & 407 & 273 & 811 & 87 \\
\hline $\begin{array}{l}\text { Capital Recovery } \\
\text { Cost }\end{array}$ & - & 1,104 & 1024 & 477 & 502 & 232 & 698 & 744 & 4,125 \\
\hline $\begin{array}{l}\text { Total Annual } \\
\text { Operating and } \\
\text { Capital Cost }\end{array}$ & $\begin{array}{l}2,272 \\
\text { (operating } \\
\text { cost only) }\end{array}$ & 1,989 & 2,365 & 921 & 961 & 639 & 971 & 1,555 & 4,212 \\
\hline
\end{tabular}


These cost estimates are also summarized in Figure 4-3 for the lower removal target and Figure 4-4 for the higher removal targets. The cost estimate for ammonia injection is included in Figure $4-3$, even though it was estimated for achieving the higher removal percentage target only.

The factors used to develop costs from the consumption rates summarized previously (in Tables 4-5 and 4-7) are shown in Table 4-12. In general, the reagent costs are based on f.o.b quotes from vendors, and an assumed shipping distance at an average shipping cost as shown in the table. Plant water, softened water, auxiliary power, and fuel costs are "typical" values taken from previous economic evaluations conducted by URS for power plants east of the Mississippi River. The values for gypsum byproducts, fly ash byproduct sales, and incremental landfill disposal costs represent the nominal averages (rounded to the nearest whole dollar) for power plants with medium- and high-sulfur-coal limestone forced oxidation FGD systems, as reported on their 2001 Form EIA-767. Capital cost recovery values are based on an annual recovery factor of 0.15 , which nominally represents an $8 \%$ discount rate and a 10 -year book life.

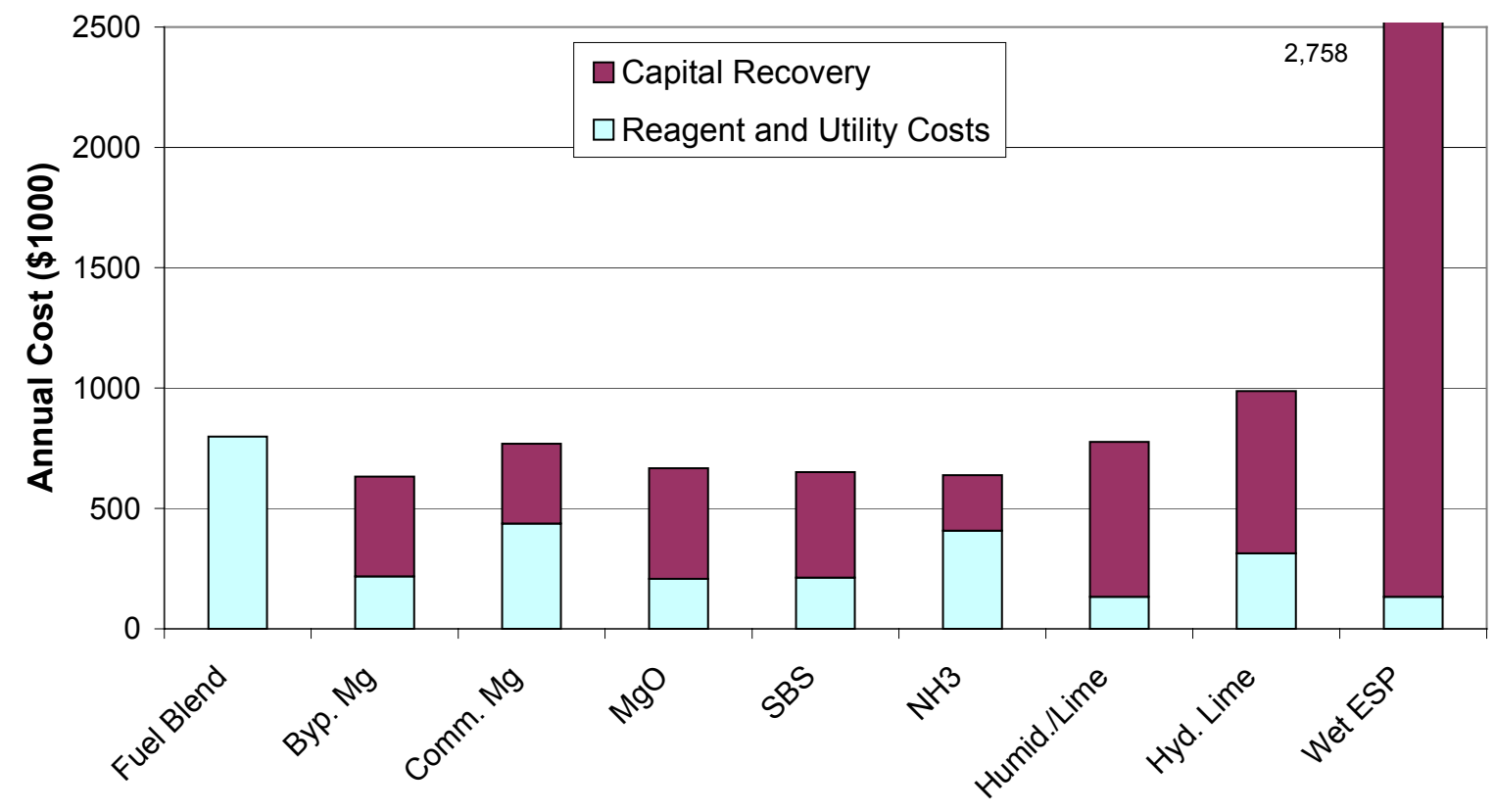

Figure 4-3

Summary of First-year Capital Recovery and Non-labor Operating Costs by $\mathrm{SO}_{3} / \mathrm{Sulfuric}$ Acid Control Technology for Achieving the Lower Removal Percentage Target 
Economic Comparison of Flue Gas Sulfuric Acid Removal Technologies

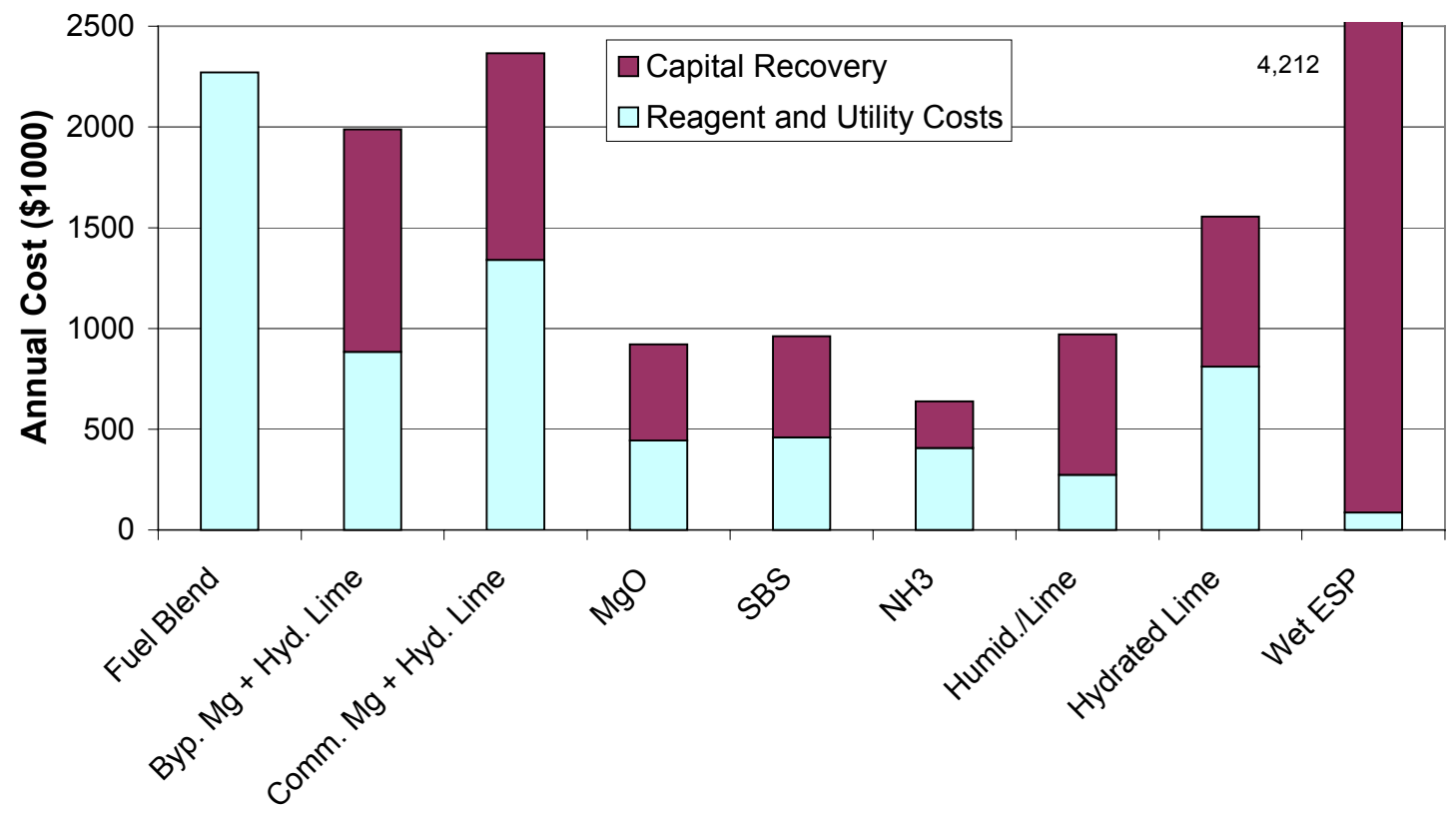

Figure 4-4

Summary of First-year Capital Recovery and Non-labor Operating Costs by $\mathrm{SO}_{3} / \mathrm{Sulfuric}$ Acid Control Technology for Achieving the Higher Removal Percentage Target

Table 4-12

Factors Used to Generate Annual Reagent and Utility Costs

\begin{tabular}{|c|c|}
\hline Factor & Value Used \\
\hline $\begin{array}{l}\text { Byproduct } \mathrm{Mg}(\mathrm{OH})_{2} \text { slurry, delivered from Midwest supplier }(\$ / \text { dry ton of } \\
\text { pure } \mathrm{Mg}(\mathrm{OH})_{2} \text {, shipped at } 18 \% \text { solids, } 65 \% \text { purity in solids, assumed } \\
50 \text {-mile delivery distance) [ } \$ \text { /metric ton] }\end{array}$ & $151[166]$ \\
\hline $\begin{array}{l}\text { Commercial } \mathrm{Mg}(\mathrm{OH})_{2} \text { slurry, delivered from Manistee, } \mathrm{Ml} \text { ( } \$ / \text { dry ton } \\
\mathrm{Mg}(\mathrm{OH})_{2} \text {, shipped at } 58 \mathrm{wt} \% \text { solids, } 100 \% \text { purity in solids, assumed } \\
600 \text {-mile delivery distance) [\$/metric ton] }\end{array}$ & 334 [367] \\
\hline $\begin{array}{l}\text { Utilimag } 40 \mathrm{MgO} \text { powder, delivered from Manistee, } \mathrm{Ml} \text { ( } \$ / \mathrm{dry} \text { ton } \mathrm{MgO} \text {, } \\
\text { assumed } 600 \text {-mile delivery distance) [\$/metric ton] }\end{array}$ & $472[464]$ \\
\hline $\begin{array}{l}\text { Sodium Sulfite, delivered from Green River, WY ( } \$ / \text { dry ton available Na } \\
\left.\text { as } \mathrm{Na}_{2} \mathrm{SO}_{3}\right) \text { [ } \$ \text { /metric ton] }\end{array}$ & $300[330]$ \\
\hline Ammonia, delivered from existing plant system (\$/ton) [\$/metric ton] & 300 [330] \\
\hline Hydrated Lime, delivered from Midwest location (\$/ton) [\$/metric ton] & $80[88]$ \\
\hline Truck Transit Costs (\$/ton-mile) [\$/metric-ton-km] & $0.12[0.08]$ \\
\hline Plant Water Cost $\left(\$ / 1000\right.$ gal) $\left[\$ / \mathrm{m}^{3}\right]$ & $0.40[1.52]$ \\
\hline
\end{tabular}


Table 4-12 (continued)

\begin{tabular}{|l|l|}
\hline Factor & Value Used \\
\hline Plant Softened Water Cost $(\$ / 1000 \mathrm{gal})\left[\$ / \mathrm{m}^{3}\right]$ & $2.30[8.72]$ \\
\hline Plant Auxiliary Power $(\$ / \mathrm{kwh})$ & 0.032 \\
\hline Plant Fuel Costs $\left(\$ / \mathrm{MM}\right.$ Btu) $\left[\$ / 10^{6} \mathrm{kcal}\right]$ & $1.04[0.26]$ \\
\hline Plant Low-sulfur Fuel Cost $\left(\$ / \mathrm{MM} \mathrm{Btu)}\left[\$ / 10^{6} \mathrm{kcal}\right]\right.$ & $1.24[0.31]$ \\
\hline Gypsum Byproduct Value $(\$ /$ wet ton, f.o.b. plant) $[\$ /$ metric ton] & $5.00[5.50]$ \\
\hline Fly Ash Sales Value $(\$ /$ ton, f.o.b. plant) $[\$ /$ metric ton] & $3.00[3.30]$ \\
\hline Incremental Landfill Disposal Costs $(\$ /$ ton) $[\$ /$ metric ton] & $4.00[4.40]$ \\
\hline Annual Capital Recovery Factor & 0.15 \\
\hline
\end{tabular}

For the lower sulfuric acid control percentage, six control options had projected reagent, utility, and capital recovery costs in the range of $\$ 640,000$ to $\$ 800,000$ annually per unit (seven including ammonia injection at the higher removal level). These six include fuel blending, furnace injection of either byproduct or commercial $\mathrm{Mg}, \mathrm{MgO}$ powder injection, SBS Injection $^{\mathrm{TM}}$, and humidification with hydrated lime injection between the air heater and ESP. The costs for fuel blending with low-sulfur coal disregard any potential capital modifications that may be required by the plant. Significant capital modification requirements could make this option less attractive.

The differences between the projected costs of these six control options are not great relative to the level of uncertainty for these estimates. For example, if these annual cost estimates are assumed to have an uncertainty of $\pm 25 \%$, the "error bars" (not shown in Figure 4-3) for these six (or seven including ammonia injection) lower cost options would substantially overlap. This suggests that a more detailed analysis would be required to determine the most cost effective control option for this application.

The remaining technologies for which costs were developed at the lower removal percentage include dry hydrated lime powder injection upstream of the ESP and a wet ESP retrofit to the last field of the existing dry ESP. These two options appear to be less cost effective, with annual costs projected at $\$ 990,000$ and $\$ 2.8$ million, respectively. However, the wet ESP comparison is skewed by the assumption that the control technologies will only operate five months out of the year, and the relatively high capital recovery factor (10-year recovery). Both of these assumptions favor low capital cost control options such as fuel blending or sorbent injection.

The estimated costs for the higher sulfuric acid removal percentage, as shown in Table 4-11 and Figure 4-4, show ammonia injection as a potentially low cost technology, with projected firstyear costs of less than $\$ 640,000$. Three other technologies, MgO powder injection, SBS injection and humidification with hydrated lime injection, show somewhat higher annual projected costs 
Economic Comparison of Flue Gas Sulfuric Acid Removal Technologies

between $\$ 920,000$ and $\$ 970,000$. Again, if these annual cost estimates have an uncertainty of $\pm 25 \%$, the error bars for these technologies would overlap.

Four other technologies show considerably higher first-year operating costs of $\$ 1.6$ to $\$ 2.4$ million. These include fuel switching; the two furnace injection technologies, which were combined with hydrated lime injection between the air heater and ESP for this estimate; and hydrated lime injection alone. Note that the latter three technologies might adversely affect the base plant ESP performance due to the addition of relatively large quantities (17 to $21 \%$ of the base fly ash loading) of high resistivity calcium or magnesium salts to the ESP inlet flue gas and reduced $\mathrm{SO}_{3}$ conditioning.

The wet ESP retrofit downstream of the wet FGD system shows the highest first-year cost of over \$4 million. However, as mentioned above, the wet ESP comparison is skewed by the assumption that the control technologies will only operate five months out of the year and the relatively high capital recovery factor (10-year recovery). Both assumptions favor low capital cost control options.

\section{Discussion of First-year Cost Estimate Results}

For the lower sulfuric acid removal percentage target, seven technologies were estimated to be able to achieve that target with first-year, non-labor costs in the range of approximately $\$ 640,000$ to $\$ 1$ million. An eighth technology, ammonia injection, was estimated to be able to achieve the higher removal percentage at a cost in the same range.

For the higher removal percentage, four technologies were estimated to achieve that level of performance with first-year, non-labor costs in the range of about $\$ 640,000$ to $\$ 1$ million.

However, the results of this economic comparison are highly dependent on assumptions made about performance, cost and technical issues regarding the potential control technologies. The following describes the factors that affect the ranking of each of the technologies in terms of cost effectiveness:

Fuel Blending/Fuel Switch. The cost effectiveness of this technology is very dependent on the cost differential between the normal plant fuel and low-sulfur coal. At the assumed differential of $\$ 0.20$ per million Btu $\left[\$ 0.050 / 10^{6} \mathrm{kcal}\right]$ used for this evaluation, fuel blending/switching was cost competitive with several of the injection technologies at the lower $\mathrm{SO}_{3}$ removal target, but less competitive at the higher target. But, some plants may be able to purchase low-sulfur coals at little or no cost premium relative to their current fuel. At a $\$ 0.10$ per million Btu $\left[\$ 0.025 / 10^{6}\right.$ kcal] or lower differential, fuel switching could be cost effective for achieving the higher sulfuric acid control percentage target as well. This assumes minimal capital cost requirements to be able to blend and fire the low-sulfur coal.

Furnace Injection of Byproduct Mg. The costs for this technology are driven by the delivered cost of the byproduct $\mathrm{Mg}$ reagent. Since this material is not currently produced for byproduct sales, there is not a well-established price. Also, the delivered cost is very dependent on the 
shipping method and distance, since the slurry tested in this project was produced at a relatively low purity and solids content. Rail or barge delivery, closer distances, or production on site will make this technology more cost effective, while greater distances with truck delivery will increase the estimated cost.

This technology alone was not estimated to achieve the higher sulfuric acid control percentage target for a plant with an SCR, based on the Gavin Plant data presented in Section 3. For this example, furnace injection was combined with downstream hydrated lime injection to achieve the higher control percentage target. However, for a plant that does not have an SCR but must control sulfuric acid concentrations in the stack flue gas, furnace Mg injection technology could potentially achieve high control efficiency. The BMP data in this report suggest that in a plant without an SCR, the control efficiency would only be limited by potential adverse impacts on the ESP, where a cold-side ESP is used as the plant's primary particulate control device.

Also, even for plants that have an SCR, there are other potential benefits from byproduct $\mathrm{Mg}$ injection to remove the $\mathrm{SO}_{3}$ formed in the furnace at high efficiency. In plants that cycle in load, SCR operation may be limited at low load by the potential for forming ammonium bisulfate salts on active catalyst sites, or economizer bypass ducts or economizer tube bundle removal may be required to maintain high SCR inlet flue gas temperatures at low load. Byproduct $\mathrm{Mg}$ injection to remove up to $90 \%$ of the furnace-formed $\mathrm{SO}_{3}$ might allow SCR operation at low unit load without having to resort to economizer bypass or surface area removal. These potential benefits were not considered in this economic evaluation, but could make furnace $\mathrm{Mg}$ injection a favorable control technology for some plants.

Furnace Injection of Commercial Mg. The comments about this technology are similar to those for byproduct $\mathrm{Mg}$ above. Since magnesium hydroxide slurry is produced in only a limited number of locations, the cost effectiveness of this technology will be highly dependent on the proximity of the candidate plant to a source of this material.

MgO Injection Downstream of the SCR. This technology appears to be cost effective based on the economics presented above. However, the performance of this technology was based on a very limited amount of vendor-supplied data. Furthermore, the performance required to achieve the higher removal percentage target $\left(86 \% \mathrm{SO}_{3}\right.$ removal) may be a "stretch" for this technology based on discussions with the vendor, who was more comfortable with removal percentages in the range of 60 to $70 \%$. More data are needed, particularly for higher uncontrolled $\mathrm{SO}_{3}$ concentrations, higher removal percentages, and preferably measured by a third party, to be able to use these performance and cost estimates with confidence.

As for the magnesium hydroxide slurry injection processes, the costs for this technology will be dependent on the distance from the source of this reagent to the candidate plant. Also, the ability to achieve high $\mathrm{SO}_{3}$ control efficiencies with this technology may be limited by adverse effects on ESP operation.

$\underline{\text { SBS Injection }}{ }^{\mathrm{TM}}$. The biggest issue for estimating the cost of this technology is the delivered cost of the reagent, which will be a function of f.o.b. price, distance and delivery method (truck, rail or barge). Also, this is the only proprietary technology evaluated in this section, so the cost 
Economic Comparison of Flue Gas Sulfuric Acid Removal Technologies

estimate includes an annual technology license fee ( $\$ 0.20$ per $\mathrm{kW}$ of generator capacity) not included for the other processes.

Ammonia Injection. This process may not be applicable to many plants because of impacts of the ammonium salts on byproduct reuse or disposal. The economics presented in Table 4-11 consider the loss of fly ash sales revenue and costs for landfill disposing of the ammoniacontaining fly ash. However, neither potential costs associated with treating ammonia-containing landfill runoff or leachate nor costs associated with avoiding nuisance odors during fly ash handling were considered. These potential costs could make the application of ammonia injection for sulfuric acid control more expensive to implement than is estimated in Table 4-11.

Also, other plant configurations would not likely be compatible with ammonia injection for sulfuric acid control. Plants with FGD systems that produce a calcium sulfite byproduct and that mix ash with the byproduct for stabilization, would not likely be able to employ ammonia injection for sulfuric acid control due to the potential for ammonia off-gassing from the mixture, particularly if lime is also added. Similarly, plants that use wet scrubbers for particulate control, or that sluice and/or pond dispose of fly ash would likely find ammonia injection incompatible with their plant configuration.

Humidification and Lime Injection. The costs for this technology are based on pilot-scale test results from nearly a decade ago. No full-scale results were available on which to base performance or cost estimates.

Notwithstanding the lack of full-scale data, the costs for applying this technology will vary significantly depending on the configuration in which it is implemented. If the humidification and lime injection could be implemented by injecting slaked lime or ground limestone slurry into the duct, reagent costs could be reduced by avoiding having to procure and ship hydrated lime powder. Capital costs would be reduced by eliminating the need for a separate humidification system and a powder handling and injection system. Also, if this technology were implemented between an ESP and wet scrubber, the excess reagent would be carried into the FGD system and should reduce FGD reagent consumption. However, slurry injection is seen as posing a greater risk for the deposition of wet solids in the duct than is dry powder injection, and injecting upstream of the wet scrubber requires that the lime or limestone particles be removed in the FGD system at high efficiency.

Hydrated Lime Powder Injection. The performance and cost estimates for this technology are also based on decade-old pilot-scale results. There is anecdotal information that others have tested hydrated lime powder injection at full scale, and have seen lower lime injection rates to achieve a given level of sulfuric acid removal than are predicted from the average pilot-scale results. However, the full-scale results are not well documented and/or were not available to serve as the basis for performance estimates for this technology. To address this issue, these economics used the EPRI ECTC data for the highest performance hydrated lime tested there (Chemstar) rather than average performance as the basis for lime injection performance estimates. 
These cost estimates were based on using commercially available hydrated lime as the sorbent. It might be possible to lower the reagent costs by hydrating less expensive quicklime on site, although capital costs would increase to add the hydrator and associated equipment. Benson, et $\mathrm{al}^{6}$ state that on-site hydration could allow the production of a higher specific surface area hydrate that might also reduce the amount of hydrate required to achieve a given sulfuric acid removal level. These two effects could lower the cost of hydrated lime injection technology from what was estimated here.

The ability to achieve the higher sulfuric acid control percentage target remains in question for plants that would inject hydrated lime powder upstream of ESP particulate collectors. Removal of sulfuric acid from the flue gas and the injection of high-resistivity, calcium-based solids could significantly degrade ESP performance. Dry injection of a blend of calcium and sodium-based sorbents, as was tested by EPRI, could be employed to overcome adverse effects on ash resistivity, although at a higher overall sorbent cost. ${ }^{4}$

Wet ESP. Wet ESP retrofit costs will be very site specific, depending on the retrofit difficulty, the required level of sulfuric acid mist control, and the materials of construction. Wet ESP capital costs should be considerably lower for a new installation than for a retrofit. Regardless of this potential variation, the wet ESP option is the most capital-intensive control technology considered in this evaluation. However, the cost effectiveness of a wet ESP would be much more attractive in a situation where sulfuric acid mist control is needed year-round, rather than just during the ozone season, and in a new plant were lower capital costs and longer capital recovery periods would be expected.

Wet ESP technology offers an advantage over the other technologies because it can also control fine fly ash or carbon particulate that may contribute to elevated plume opacity. However, since a wet ESP would be installed at or near the end of the flue gas path, it would not address upstream impacts of elevated $\mathrm{SO}_{3}$ /sulfuric acid concentrations such as air heater plugging or corrosion.

Wet ESP technology is the most mature of the control options considered, but is not well demonstrated for the situation at the example plant. Only one full-scale, last-field dry ESP conversion has been demonstrated in the U.S., at the Mirant Dickerson station, which fires medium-sulfur coal. For the higher sulfuric acid control percentage, no existing full-scale wet ESP demonstrates all of the example plant criteria: high-sulfur coal firing, SCR in service, installation downstream of a wet lime or limestone FGD system, and high required sulfuric acid control percentage. Only one existing U.S. installation comes close to demonstrating these criteria, at AES' Deepwater plant.

There is little doubt that a multi-stage wet ESP could be designed and installed to achieve high sulfuric acid control efficiency, with coincident removal of other fine particulates that contribute to plume opacity. However, as for all of the candidate technologies, the reliability of a wet ESP in a situation such as at the model plant needs to be better demonstrated. 
Economic Comparison of Flue Gas Sulfuric Acid Removal Technologies

\section{Conclusions - Example Economics}

The example economics presented in this section show that byproduct $\mathrm{Mg}$ injection in the furnace can be a cost-effective technology for restoring stack sulfuric acid mist concentrations to pre-SCR levels when an SCR is retrofitted. For the model plant, commercial Mg injection in the furnace was slightly less cost effective.

Neither furnace injection technology was estimated to be capable of achieving the higher sulfuric acid removal percentage target. Although it would be possible to combine furnace injection with another technology downstream to achieve less than 3 ppmv of sulfuric acid mist at the stack, the economics of installing two control technologies in series did not appear to be attractive for the set of assumptions made in this study.

Ammonia injection was projected to be a low cost technology, but balance-of-plant impacts may preclude its use. $\mathrm{MgO}$ injection and SBS injection appear to be cost competitive technologies at either control level, although more data are needed to support the performance estimates used for $\mathrm{MgO}$ powder injection at high control efficiencies. Humidification combined with lime injection may also be a cost-competitive control approach, particularly if the two steps can be combined by injecting lime or limestone slurry.

Fuel switching or blending with low-sulfur coal could be cost effective depending on the cost differential between the current and low-sulfur coal, and assuming only minimal capital cost implications. Finally, although wet ESP technology was evaluated at the highest cost in this comparison, its economics would look better if $\mathrm{SO}_{3}$ control was required year-round rather than just during the ozone season. A longer capital recovery period would also make the economics for the wet ESP cases more competitive with the other, low capital cost alternatives.

The example economics presented here underline two important observations about $\mathrm{SO}_{3} / \mathrm{sulfuric}$ acid controls. One is that there is no one "best" control option available. The cost effectiveness of the various options depend on site specifics such as the location of the plant relative to reagent sources, coal combustion byproduct reuse and disposal practices, the sulfuric acid mist control level required, and the extent to which other particulate matter contributes to plume opacity. Depending on these specifics, one technology may be favored over the others for a particular plant situation.

The second observation is that there are several candidate $\mathrm{SO}_{3} /$ sulfuric acid control technologies for which there is not adequate full-scale demonstration and test data to serve as a basis for power generators to evaluate control technologies with confidence. For example, MgO powder injection and humidification/lime injection technologies (combined or separately) show promise as being cost effective for some situations, but it is the authors' opinion that neither has been adequately demonstrated and characterized at full scale.

Finally, it should be noted that the candidate $\mathrm{SO}_{3}$ /sulfuric acid control technologies evaluated in this section should not be considered an all-inclusive list; the technologies evaluated here were limited to those for which the authors had performance and cost data available. The retrofit of 
$\mathrm{SCR}$ to plants that fire high-sulfur coal has created a need for retrofit $\mathrm{SO}_{3}$ /sulfuric acid controls, and has spawned the development of several new processes that were not include in this evaluation.

\section{References}

1. Martin Marietta Magnesia Specialties, Inc. " $\mathrm{SO}_{3}$ Reduction Using Highly-Reactive Magnesium Oxide,” Case Studies: Coal-Fired Units and Case Studies: Oil-Fired Units, Baltimore, MD, August, 2001.

2. Results of Full-scale Testing of Sodium Bisulfite Injection for Flue Gas Sulfuric Acid Control, EPRI, Palo Alto, CA: 2002. 1004167.

3. E-mail correspondence from Paul Schmidtchen of Martin Marietta to Katherine Dombrowski of URS Corporation, Austin, TX, October 31, 2003.

4. $\mathrm{SO}_{3}$ Mitigation Guide, EPRI, Palo Alto, CA: 1994. EPRI TR-104424s.

5. Gutberlet, Dr. Heinz, Hans-Ulrich Hartenstein, and Anthony Licata, " $\mathrm{SO}_{2}$ Conversion Rate of DeNO $\mathrm{X}_{\mathrm{X}}$ Catalysts - Effects on Downstream Plant Components and Remedial Measures," paper presented at the EPRI-DOE-EPA Combined Utility Air Control Symposium: The Mega Symposium, Atlanta, GA, August 16-20, 1999.

6. Benson, Lewis B., Kevin J. Smith and Robert A. Roden, "Control of Sulfur Dioxide and Sulfur Trioxide Using By-Product of a Magnesium-Enhanced Lime FGD System,” paper presented at the Institute of Clean Air Companies' Forum '03, Multi-Pollutant Emission Controls \& Strategies, Nashville, TN, October 14-15, 2003. 


\section{5 \\ SUMMARY AND CONCLUSIONS}

This project conducted full-scale sorbent injection tests at two different sites to determine the effects of calcium- and/or magnesium-based alkalis injected into the furnace of coal-fired boilers for removing $\mathrm{SO}_{3}$ /sulfuric acid from the flue gas. A summary of the results and conclusions from this effort are discussed below.

\section{Project Summary}

\section{Short-term Test Results}

Short-term (one- to two-week duration) tests were conducted at FirstEnergy's BMP, with the first being conducted on Unit 2 and the other three conducted on Unit 3. Four potential furnace injection sorbents were tested: dolomite powder injected through out-of-service burners (Unit 2), pressure-hydrated dolomitic lime slurry injected into the upper furnace, byproduct Mg slurry injected into the upper furnace, and commercial $\mathrm{Mg}$ slurry injected into the upper furnace. These short-term tests identified byproduct $\mathrm{Mg}$ as the most favorable furnace injection sorbent for longer-term testing.

Dolomite injection through out-of-service burners was found to be capable of achieving the project objective of $90 \%$ removal of furnace-formed $\mathrm{SO}_{3}$. However, the injection rates required were relatively high (molar ratios of about 40:1 for calcium plus magnesium alkali compared to baseline $\mathrm{SO}_{3}$ at the economizer outlet). There were concerns that injecting large quantities of high-resistivity, calcium-based powders would adversely affect ESP performance in a plant equipped with a cold-side ESP as the primary particulate control device. BMP Unit 2 uses a venturi scrubber as the primary particulate control device and thus did not experience such issues. Also, there was evidence of increased slagging and fouling of the furnace during the short-term test that may have been a result of the dolomite injection.

Of the three calcium- and/or magnesium- based slurries tested on Unit 3, both the commercial $\mathrm{Mg}$ and byproduct $\mathrm{Mg}$ sorbents were observed to achieve the project objective of $90 \%$ removal of furnace-formed $\mathrm{SO}_{3}$. The commercial $\mathrm{Mg}$ sorbent required molar ratios of about 12:1 (magnesium alkali to baseline $\mathrm{SO}_{3}$ at the economizer outlet) to achieve $90 \%$ removal of flue gas sulfuric acid as measured at the ESP outlet. The byproduct $\mathrm{Mg}$ achieved $90 \%$ removal at a lower molar ratio of 7:1. However, this success was achieved after moving the injection location higher on the front wall of the furnace, from across from the nose of the boiler to across from the pendant superheat tubes. The other two slurries were tested only at the lower injection level, across from the nose, and might have performed better had they been re-tested with injection at the higher level. The byproduct Mg slurry was of greatest interest for testing by FirstEnergy, 
though, since it could potentially be made on site, so it was selected for the subsequent long-term test at BMP.

\section{Long-term Test Results}

The first test was conducted at FirstEnergy's BMP Unit 3 using byproduct Mg slurry. During the 23-day injection period, the molar ratio of injected sorbent to $\mathrm{SO}_{3}$ in the economizer outlet gas (as measured under baseline conditions) was varied from about 2:1 to 5:1. The corresponding sulfuric acid removal efficiencies, as measured at the ESP B outlet, varied from about 40 to $75 \%$. The amounts of sorbent injected and sulfuric acid removal were generally limited by ESP performance. As the sulfuric acid removal increased, the power to the ESP electrical fields generally decreased, and ESP outlet opacity increased, presumably due to increases in fly ash resistivity resulting from the upstream sulfuric acid removal. However, at the beginning of the test, two of the four ESPs on Unit 3 were not performing well with respect to electrical conditions. Higher injection rates and higher sulfuric acid removal levels may have been possible with four well-performing ESPs.

Within these limitations, the long-term test showed that byproduct $\mathrm{Mg}$ injection through the front wall, across from the pendant superheat tubes, could be implemented to achieve 60 to $70 \%$ sulfuric acid removal with only minor impacts on ESP performance. Higher sulfuric acid removal levels might have been possible if the ESP had been in better electrical condition at the start of the test. No significant balance-of-plant impacts were noted, and no multi-pollutant removal was measured (e.g., no $\mathrm{HCl}$ or HF removal). The stack plume opacity was not measured during the long-term test period, but qualitative observations noted greatly reduced plume opacity.

The second long-term test was conducted at the AEP Gavin Plant. Both byproduct Mg and commercial $\mathrm{Mg}$ injection were tested, with two different injection location schemes. This test was significantly different than the BMP test because the Gavin Plant has operating SCR reactors that convert about $1 \%$ of the flue gas $\mathrm{SO}_{2}$ to $\mathrm{SO}_{3}$. This, combined with the furnace conversion, resulted in approximately $2.3 \%$ overall conversion of the coal sulfur to the $\mathrm{SO}_{3}$ form, and relatively high flue gas $\mathrm{SO}_{3} /$ sulfuric acid concentrations.

There was no clear difference between the performance of the byproduct Mg slurry and the commercial Mg slurry purchased from the Dow Chemical Company when the two were compared at equal magnesium hydroxide injection rates. The test results did indicate that for this boiler, it was more effective to inject about $40 \%$ of the sorbent slurry at the $13^{\text {th }}$ floor of the boiler and the remainder at the $17^{\text {th }}$ floor, rather than inject all of the slurry at the $17^{\text {th }}$ floor. The $13^{\text {th }}$ floor is just above the nose of the boiler, and the $17^{\text {th }}$ floor is adjacent to the tops of the pendant superheat tubes.

When injecting either sorbent with $40 \%$ going to the $13^{\text {th }}$ floor and $60 \%$ going to the $17^{\text {th }}$ floor, $90 \%$ of the furnace-formed $\mathrm{SO}_{3}$ was removed at a $\mathrm{Mg}: \mathrm{SO}_{3}$ ratio of about 3.5:1. For injection all on the $17^{\text {th }}$ floor, a $\mathrm{Mg}: \mathrm{SO}_{3}$ ratio of about 5:1 was required. These molar ratios are based on the $\mathrm{SCR}$ outlet $\mathrm{SO}_{3}$ concentrations, as measured during baseline (no sorbent injection) Unit 1 
operation, and thus should not be compared directly to the ratios required at BMP, which were based on furnace outlet $\mathrm{SO}_{3}$ concentrations.

The furnace-injected sorbent was relatively ineffective at removing $\mathrm{SO}_{3}$ formed across the SCR catalyst. When measured at the ESP outlet, downstream of the SCR reactors and air heaters, the overall sulfuric acid removal was only $70 \%$ at a $\mathrm{Mg}: \mathrm{SO}_{3}$ molar ratio of 5:1, with the maximum removal observed being about $78 \%$ at a molar ratio between $6: 1$ and $7: 1$. The data show no clear reduction in the conversion of $\mathrm{SO}_{2}$ to $\mathrm{SO}_{3}$ across the $\mathrm{SCR}$ reactors during sorbent injection, and at best a minor increase in sulfuric acid removal across the air heaters and ESP compared to baseline removal.

Balance-of-plant effects tracked during the long-term $\mathrm{Mg}$ sorbent injection tests at Gavin Plant were, for the most part, minor. A positive effect of $\mathrm{Mg}$ sorbent injection into the furnace for $\mathrm{SO}_{3}$ control was an apparent reduction in visible plume opacity from Unit 1.

\section{Sulfuric Acid Control Process Economics}

Results from this project were used along with data from other sources to project capital and first-year operating costs for furnace injection of magnesium-based sorbents, and for other potential sulfuric acid control technologies, for a hypothetical plant. The plant was assumed to fire a high-sulfur coal, and be equipped with an SCR followed by an ESP and wet FGD system for air emissions controls. The results of these calculations showed that byproduct $\mathrm{Mg}$ injection or commercial $\mathrm{Mg}$ injection into the furnace can be cost competitive with other potential technologies for lowering stack sulfuric acid mist concentrations to pre-SCR levels.

If the objective is to lower stack sulfuric acid concentrations to the point where sulfuric acid mist does not contribute significantly to plume opacity, estimated at approximately 3 ppmv or less, furnace injection of byproduct $\mathrm{Mg}$ or commercial $\mathrm{Mg}$ would not likely achieve this removal efficiency on plants equipped with SCR. In this circumstance, a technology that removes $\mathrm{SO}_{3}$ /sulfuric acid from the flue gas downstream of the SCR at high efficiency would likely be more effective, or furnace $\mathrm{Mg}$ injection may have to be combined with a downstream technology.

The economics of sulfuric acid controls for coal-fired boilers can be very site specific, though. Specifics such as plant location, coal combustion byproduct disposal/reuse practices, low-sulfurcoal cost differentials, and required control levels can markedly change the relative economics of sulfuric acid control technologies.

\section{Project Conclusions}

Furnace injection of byproduct $\mathrm{Mg}$ or commercial $\mathrm{Mg}$ slurries were demonstrated to remove furnace-formed $\mathrm{SO}_{3}$ at high efficiency, but were relatively ineffective at reducing or removing $\mathrm{SO}_{3}$ formed across SCR catalysts. Other than potential adverse effects on ESP performance if ESP outlet sulfuric acid concentrations were reduced below approximately 5 ppmv (dry basis), the balance-of-plant impacts from these injection technologies were relatively minor. 
Qualitatively, the furnace injection of magnesium hydroxide slurries into the furnace was effective at reducing plume opacity due to sulfuric acid mist content.

The cost effectiveness of various $\mathrm{SO}_{3} /$ sulfuric acid control technologies was estimated to be very site specific. Any power generator that is considering applying $\mathrm{SO}_{3} /$ sulfuric acid controls should carefully evaluate the economics of all candidate technologies for the specifics of that plant.

The results from this project should serve as a good basis for estimating the effectiveness and costs associated with applying furnace injection of magnesium hydroxide slurry reagents to coalfired plants. Under some plant scenarios, furnace injection of byproduct $\mathrm{Mg}$ or commercial $\mathrm{Mg}$ may be the most economical control alternative available. In particular, a nearby supply of byproduct $\mathrm{Mg}$ reagent would enhance the cost effectiveness of this technology. Also, plant upgrades to produce the byproduct $\mathrm{Mg}$ slurry at higher purity and/or higher wt $\%$ solids concentrations would lower delivery costs for this sorbent. Finally, the potential benefits of reducing flue gas $\mathrm{SO}_{3}$ concentrations upstream of the $\mathrm{SCR}$ catalyst could make furnace $\mathrm{Mg}$ injection a favorable $\mathrm{SO}_{3}$ control technology for plants that cycle in load. 